University of Louisville

ThinkIR: The University of Louisville's Institutional Repository

$12-2014$

\title{
Cultural capital and the family-school mesosystem : a multiple groups analysis of school-based parent involvement types and their relations with early student achievement.
}

Emily R. Dickinson 1974-

University of Louisville

Follow this and additional works at: https://ir.library.louisville.edu/etd

Part of the Educational Psychology Commons, and the Social and Philosophical Foundations of Education Commons

\section{Recommended Citation}

Dickinson, Emily R. 1974-, "Cultural capital and the family-school mesosystem : a multiple groups analysis of school-based parent involvement types and their relations with early student achievement." (2014). Electronic Theses and Dissertations. Paper 1717.

https://doi.org/10.18297/etd/1717

This Doctoral Dissertation is brought to you for free and open access by ThinkIR: The University of Louisville's Institutional Repository. It has been accepted for inclusion in Electronic Theses and Dissertations by an authorized administrator of ThinkIR: The University of Louisville's Institutional Repository. This title appears here courtesy of the author, who has retained all other copyrights. For more information, please contact thinkir@louisville.edu. 
CULTURAL CAPITAL AND THE FAMILY-SCHOOL MESOSYSTEM: A MULTIPLE GROUPS ANALYSIS OF SCHOOL-BASED PARENT INVOLVEMENT TYPES AND THEIR RELATIONS WITH EARLY STUDENT ACHIEVEMENT

\title{
By
}

\author{
Emily R. Dickinson
}

A

Dissertation

Submitted to the Faculty of the

College of Education and Human Development of the University of Louisville in Partial Fulfillment of the Requirements for the Degree of

\section{Doctor of Philosophy}

Department of Educational \& Counseling Psychology, Counseling, and College Student

Personnel

University of Louisville

Louisville, Kentucky

December 2014 

CULTURAL CAPITAL AND THE FAMILY-SCHOOL MESOSYSTEM: A MULTIPLE GROUPS ANALYSIS OF SCHOOL-BASED PARENT INVOLVEMENT TYPES AND THEIR RELATIONS WITH EARLY STUDENT ACHIEVEMENT

\section{By}

Emily R. Dickinson

A Dissertation Approved on

November 24, 2014

by the following Dissertation Committee:

Dr. Jill L. Adelson

Dr. Jacob P. K. Gross

Dr. Kate E. Snyder

Dr. Jeffrey C. Valentine 


\section{ACKNOWLEDGEMENTS}

This dissertation and the culmination of work that it reflects could not have been completed without the support of a great many smart people.

I first thank my advisor, Dr. Jill Adelson, who helped me recognize my strengths and interests, showed me the path where they could lead, and then provided me support and guidance along the way. She truly is a Super-Woman.

Next, I thank the other members of my committee, Dr. Jacob Gross, Dr. Kate Snyder, and Dr. Jeffrey Valentine, for sharing their expertise and providing thoughtprovoking feedback that was essential for converting the ideas in my head into the words and pictures contained herein.

Next, I thank my colleagues at HumRRO, especially Dr. Gene Hoffman and Dr. Arthur Thacker. I've had many jobs in my life, but when Gene hired me my career truly began, and thanks to Art I continue to be not only employed but enriched by challenging and fun work.

Next, I thank Dr. Melissa Evans-Andris, who has connected me with many opportunities over the years, and whose mentorship I value so much.

Finally, I thank my family, who truly provide the fuel to my engine. To my husband Keegan, I thank you for the pep talks, the shoulder to cry on, the co-parenting, and for constantly reminding me that it is possible to work hard and still find time to relax, laugh, and love. To my boys Cassian and Deacon, I thank you for your patience while mom is focused on work, and for providing me the best reason ever to stop 
working for a while. And to my mother, Lee Hendren, I thank you for your constant support and love. 


\begin{abstract}
CULTURAL CAPITAL AND THE FAMILY-SCHOOL MESOSYSTEM: A MULTIPLE GROUPS ANALYSIS OF SCHOOL-BASED PARENT INVOLVEMENT TYPES AND THEIR RELATIONS WITH EARLY STUDENT ACHIEVEMENT

Emily R. Dickinson
\end{abstract}

November 24, 2014

This dissertation study explored the relationship between school-based parent involvement and early reading outcomes by positing that different types of parent involvement activities reflect access to different forms of cultural capital and therefore should be analyzed as separate constructs. Exploratory factor analysis (EFA) and confirmatory factor analysis (CFA) techniques were used to establish the factor structure underlying measures of school-based parent involvement available in the Early Childhood Longitudinal Study-Kindergarten Cohort of 2011 (ECLS-K: 2011).

Also of interest were the variations in the amount of participation in different types of involvement between families from various sociocultural backgrounds, as well as the relationships between different types of parent involvement and early reading achievement outcomes among these groups. Before such comparisons were made, a series of multiple groups CFA models were run to establish measurement invariance among the parent involvement factors. Data were analyzed across racial/ethnic, parent education, parent occupational prestige, and primary language subgroups. Two achievement outcomes, reading IRT scores and teacher literacy ratings, were modeled 
separately, to determine if the observed relationships held across achievement outcomes. Finally, all analyses were conducted separately for two school types: public and nonpublic schools.

Results indicated three components of school-based parent involvement that aligned with differences in cultural capital requirements. Subgroup differences in average values of a subset of the parent involvement factors were observed, as well as differences in the relationships between the parent involvement types and student achievement outcomes. Differences in these relationships were also observed across school type. Several directions for future research based on these findings are discussed. 
TABLE OF CONTENTS

CHAPTER 1:_OVERVIEW OF DISSERTATION STUDY ........................................ 1

CHAPTER 2:_THEORETICAL FRAMEWORK AND LITERATURE REVIEW ........... 7

Theoretical Framework ................................................................................. 8

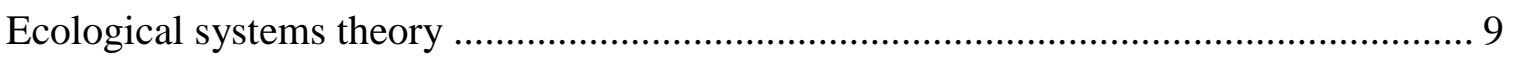

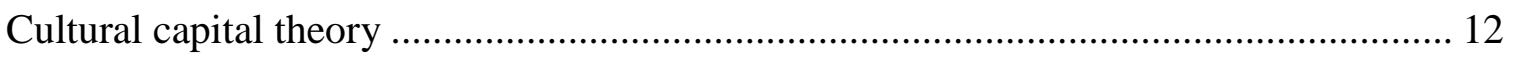

Integration of ecological systems and cultural capital theories .................................. 15

The Components of Parental Involvement and Their Measurement ............................. 17

School-Based Involvement and Cultural Capital..................................................... 20

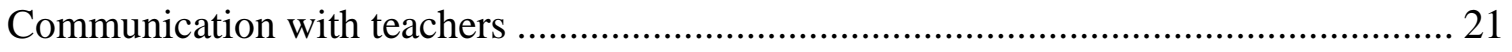

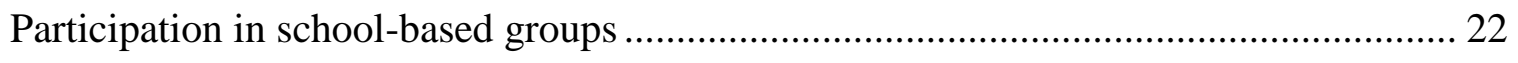

The Role of Parent Involvement in Achievement Outcomes ...................................... 23

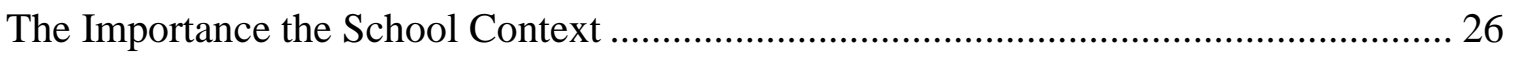

Developing a Model for Understanding the Relationship between Families' School-Based

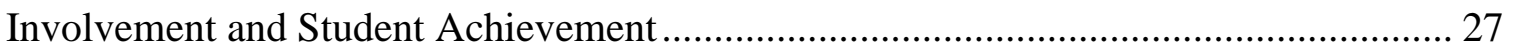

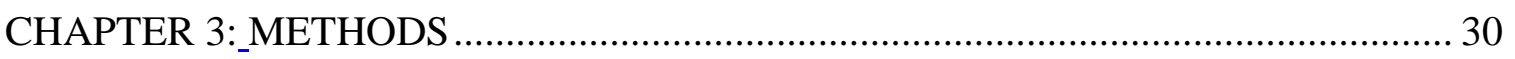

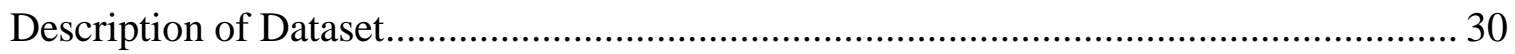

Description of Sample................................................... 30

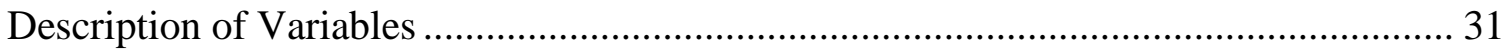




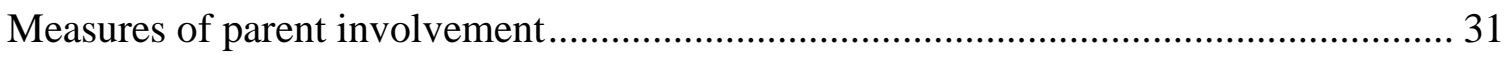

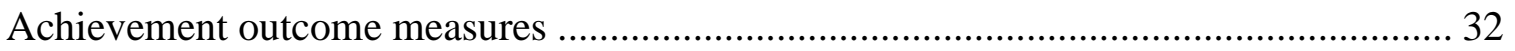

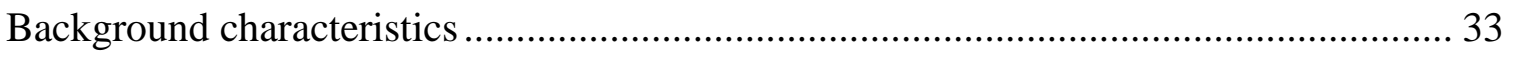

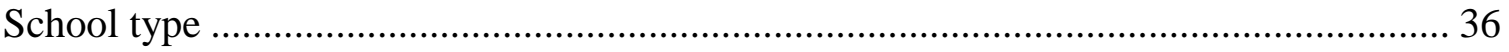

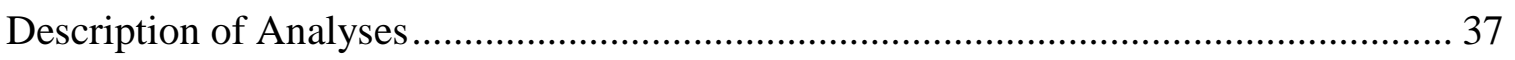

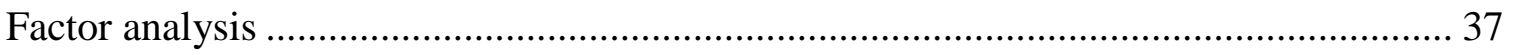

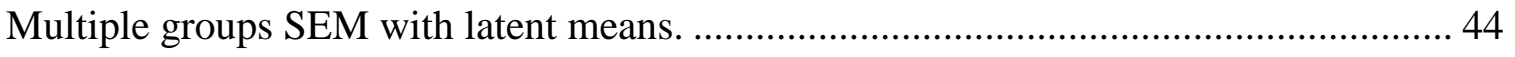

Using Multiple Groups SEM to Understand the Relationship between Parent Involvement

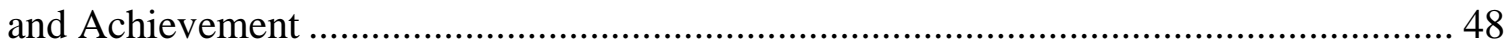

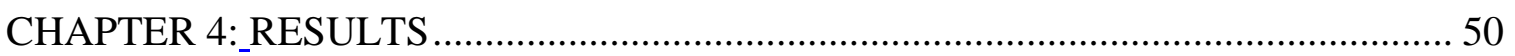

Confirmatory Factor Analysis Using the Full Sample............................................. 50

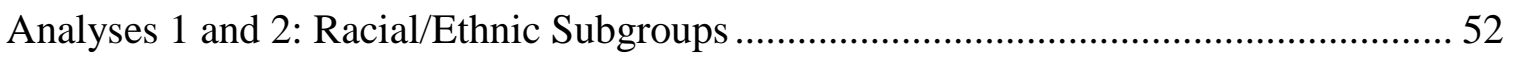

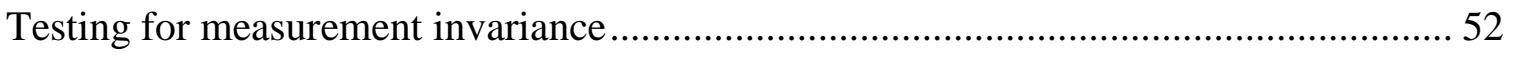

The relationship between parent involvement and achievement .................................. 54

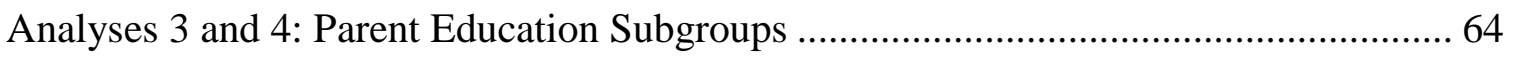

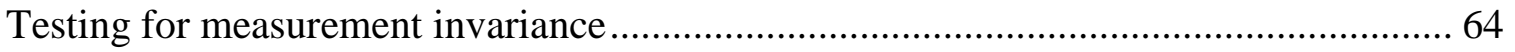

The relationship between parent involvement and achievement ............................... 66

Analyses 5 and 6: Parent Occupation Subgroups .................................................. 74

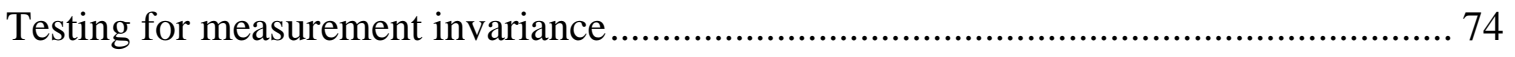

The relationship between parent involvement and achievement ................................. 76

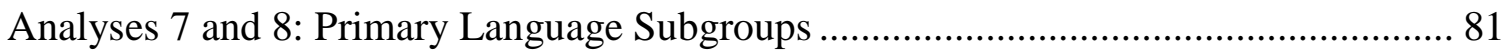

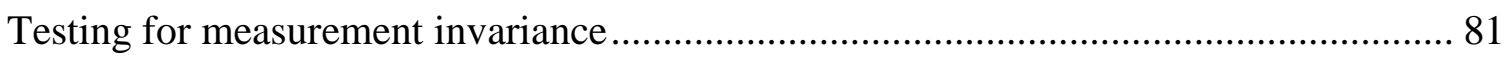

The relationship between parent involvement and achievement ................................. 83 
CHAPTER 5:_DISCUSSION AND DIRECTIONS FOR FUTURE RESEARCH......... 89

Parent Involvement Types and Cultural Capital.................................................... 90

Parent Involvement Factors and Early Reading Achievement .................................. 95

Directions for Future Research...............................................104

Subsequent releases of ECLS-K datasets ........................................................... 104

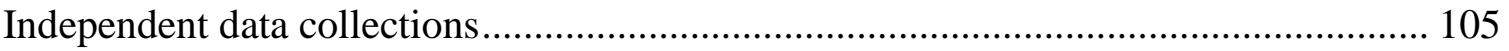

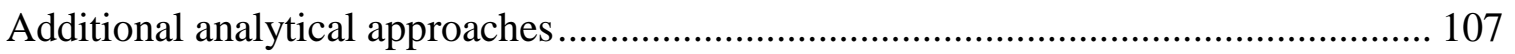

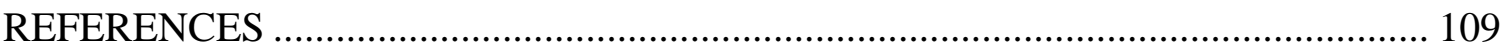

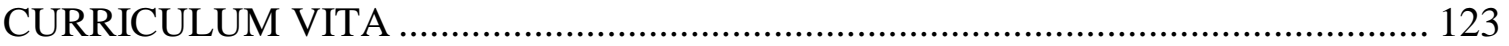




\section{LIST OF TABLES}

Table 1. Pattern Matrix of Factor Loadings for Selected Indicators .............................. 40

Table 2. Multiple Groups SEM Analyses Predicting each Achievement Type from Parent

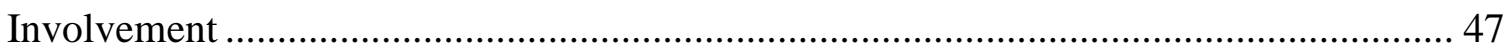

Table 3. Tests of Measurement Invariance across Racial/Ethnic Subgroups .................. 53

Table 4. Unstandardized Regression Results Predicting Reading IRT Scores among

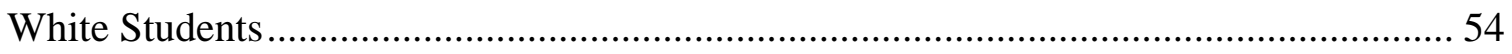

Table 5. Unstandardized Regression Results Predicting Reading IRT Scores among Black

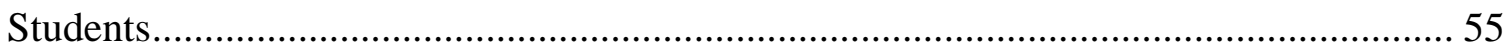

Table 6. Unstandardized Regression Results Predicting Reading IRT Scores among

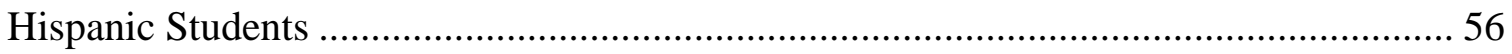

Table 7. Unstandardized Regression Results Predicting Reading IRT Scores among Asian

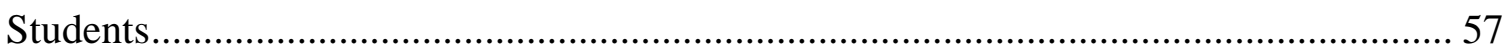

Table 8. Unstandardized Regression Results Predicting Reading IRT Scores among

Students of Other Racial/Ethnic Backgrounds ...................................................... 58

Table 9. Unstandardized Regression Results Predicting Teacher Literacy Ratings among

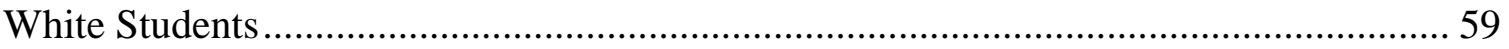

Table 10. Unstandardized Regression Results Predicting Teacher Literacy Ratings among

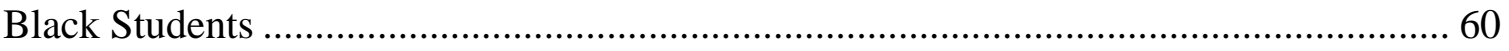

Table 11. Unstandardized Regression Results Predicting Teacher Literacy Ratings among

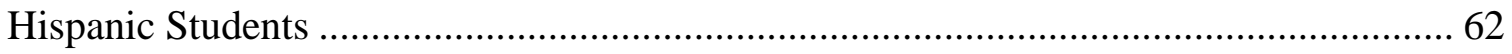


Table 12. Unstandardized Regression Results Predicting Teacher Literacy Ratings among Asian Students

Table 13. Unstandardized Regression Results Predicting Teacher Literacy Ratings among Students of Other Racial/Ethnic Backgrounds 63

Table 14. Tests of Measurement Invariance across Parent Education Subgroups 64

Table 15. Comparing Participating in Open School Events Factor Means among Parent Education Subgroups 66

Table 16. Comparing Unstandardized Regression Results Predicting Reading IRT Scores among Parent Education Subgroups 67

Table 17. Comparing Unstandardized Regression Results Predicting Reading IRT Scores among Parent Education Subgroups: Comparable Factors by School Type 68

Table 18. Unstandardized Regression Results Predicting Reading IRT Scores for Participating in School-Based Organizations by Parent Education Subgroup and by School Type 70

Table 19. Comparing Unstandardized Regression Results Predicting Reading Teacher Ratings among Parent Education Subgroups. 71

Table 20. Comparing Unstandardized Regression Results Predicting Teacher Literacy

Ratings among Parent Education Subgroups: Comparable Factors by School Type ....... 72 Table 21. Unstandardized Regression Results Predicting Teacher Literacy Ratings for the Participating in School-Based Organizations by Parent Education Subgroup and by School Type 74

Table 22. Tests of Measurement Invariance across Parent Occupation Subgroups ......... 75

Table 23. Comparing Factor Means among Parent Occupation Subgroups 76 
Table 24. Comparison of Unstandardized Regression Results Predicting Reading IRT

Scores among Parent Occupation Subgroups 77

Table 25. Comparison of Unstandardized Regression Results Predicting Reading IRT

Scores among Parent Occupation Subgroups by School Type 78

Table 26. Unstandardized Regression Results Predicting Teacher Literacy Ratings among

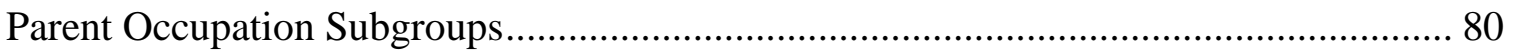

Table 27. Unstandardized Regression Results Predicting Teacher Literacy Ratings among

Parent Occupation Subgroups with School Type Added........................................... 80

Table 28. Tests of Measurement Invariance across Primary Language Subgroups ......... 81

Table 29. Comparing Factor Means among Primary Language Subgroups .................... 82

Table 30. Comparing Unstandardized Regression Results Predicting Reading IRT Scores

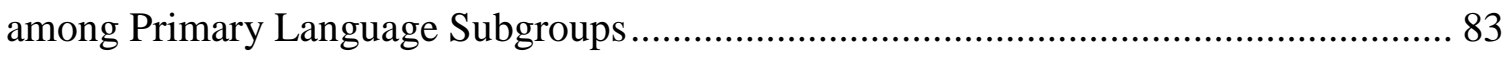

Table 31. Comparing Unstandardized Regression Results Predicting Reading IRT Scores from Participation in Open School Events among Primary Language Subgroup by School

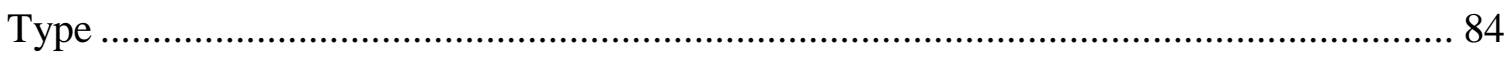

Table 32. Unstandardized Regression Results Predicting Reading IRT Scores from Teacher Communication and School-Based Organizations by Parent Primary Language

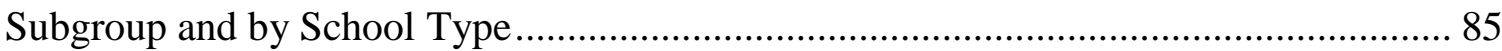

Table 33. Comparing Unstandardized Regression Results Predicting Reading Teacher

Ratings among Primary Language Subgroups.................................................... 86

Table 34. Comparing Unstandardized Regression Results Predicting Teacher Literacy

Ratings from Participation in Open School Events among Primary Language Subgroup

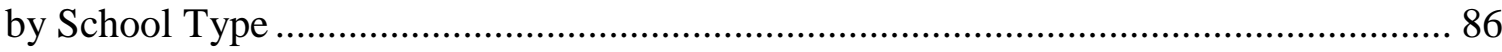


Table 35. Unstandardized Regression Results Predicting Reading IRT Scores from Teacher Communication and School-Based Organizations by Parent Primary Language

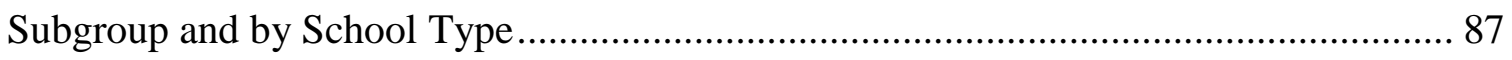

Table 36. Summary of Measurement Invariance Test Results ........................................... 93

Table 37. Summary of Comparisons of Factor Means ...................................................... 93

Table 38. Summary of Associations between Parent Involvement Factors and Measures

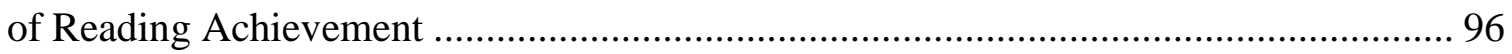

Table 39. Comparison of the Magnitude of Comparable Unstandardized Factor Loadings 100

Table 40. Summary of Associations between Parent Involvement Factors and Measures

of Reading Achievement by School Type 102 


\section{LIST OF FIGURES}

Figure 1. Model depicting Bronfenbrenner's ecological systems theory ........................ 16

Figure 2. Conceptual model integrating ecological systems and cultural capital theories.

Figure 3. Scree plot depicting number of factors extracted............................................ 38

Figure 4. Final model of school-based parent involvement factors................................. 48 


\section{CHAPTER 1}

\section{OVERVIEW OF DISSERTATION STUDY}

This dissertation study explored the relationship between school-based parent involvement and early reading outcomes by positing that different types of parent involvement activities reflect access to different forms of cultural capital and therefore should be analyzed as separate constructs. Furthermore, because larger social and cultural factors influence access to the forms of cultural capital that are required to successfully engage in school-based parent involvement activities, variations in the amount of participation in different types of involvement between families from various sociocultural backgrounds should be documented. Similarly, the relationship between parent involvement and student achievement should be analyzed to determine if schoolbased involvement relates to student achievement differently for students with these diverse family backgrounds. Finally, because parent involvement at the school constitutes an interaction between the family and school settings, characteristics of the school also should be considered as potentially moderating the relationship between school-based parent involvement and achievement.

Parents' level of involvement in their child's educational experiences has been the subject of a great deal of theoretical and empirical research (e.g., Epstein, 1987; Lee \& Bowen, 2006). Its importance has been further highlighted through its inclusion in current education legislation (The Elementary and Secondary Education Act, Section 9101(32)). Parent involvement is conceptualized and measured in myriad ways, yet a specific focus 
on school-based parent involvement, arguably a set of behaviors readily amenable to intervention and support by educational practitioners, is lacking in the literature.

Furthermore, studies that focus on the role that cultural capital plays in parent involvement is largely qualitative in nature (e.g., Lareau, 2011). The present study thus seeks to fill these gaps by using statistical modeling to explore multiple, culturallyinfluenced components of school-based parent involvement and their relationships with student achievement.

The goals of this study included the following:

- Identify the components of school-based parent involvement;

- Examine whether the different components of school-based parent involvement coincide with different forms of cultural capital as implied by prior research;

- Determine if the measurement of school-based parent involvement components is consistent across multiple sociocultural subgroups to allow for quantitative comparisons between groups; and

- Ascertain any moderating effects of sociocultural background characteristics and type of school attended.

To achieve these research goals, data from the Early Childhood Longitudinal StudyKindergarten Cohort of 2011 (ECLS-K: 2011) were used. The sample included approximately $18,170^{1}$ kindergarten students from the 2010-2011 school year. Data sources included student assessments and parent and teacher surveys.

Due to the exploratory nature of the study, the first step was to conduct exploratory factor analysis (EFA) using a random sample of 500 cases to establish that the indicators of school-based parent involvement did, in fact, represent multiple

\footnotetext{
${ }^{1}$ Sample size has been rounded due to use of restricted dataset.
} 
constructs, or factors. This implied factor structure was then tested on the full sample using confirmatory factor analysis (CFA) to determine the appropriateness of subsequent analyses. Once good fit between the implied model and the observed data was established, a series of tests for measurement invariance across four sets of sociocultural subgroups was conducted. These subgroups included student race/ethnicity, parent education, parent occupational prestige, and primary language. Because one of the goals of the study was to make quantitative comparisons between groups in terms of the amount of participation in each type of involvement and the relationships between involvement and achievement, establishing that the parent-involvement structures were measured on comparable scales was essential (Milfont \& Fischer, 2010). For those parent involvement factors for which measurement invariance could be established, factor mean values were compared to ascertain group differences in the amount of participation in the types of parent involvement. Next, a structural equation modeling (SEM) framework was applied to model the relationships between different types of school-based involvement and student achievement. Among the factors for which measurement invariance had been established it was possible to compare the magnitude of these relationships across the sociocultural groups. Where measurement invariance could not be established, the relations between the parent involvement factors and achievement were considered separately. Two different measures of achievement, reading IRT scores and teacher literacy ratings, were used in separate models to account for potential differences in the measurement of achievement (Dickinson \& Adelson, 2013). The final analytical step added school type to the model to determine if the type of school attended further moderated the relationship between the parent involvement factors and achievement measures. 
Results from the EFA yielded a three-factor structure that corresponded to the conceptual model implied in the literature. This factor structure was further confirmed using the full student sample and CFA. The three factors corresponded to three types of school-based parent involvement, each reflecting differences in the cultural capital tools required for participation. The three factors were labeled as participating in open events at the school, communicating with teachers, and participating in school-based organizations.

The three-factor structure also was found to demonstrate adequate to good modelto-data fit across all included subgroups (i.e., race/ethnicity, parent education, parent occupation, and primary language). This indicated that the three types of parent involvement were distinguishable across all sociocultural subgroups included in the study, thus laying the groundwork for making further comparisons. Tests for measurement invariance, however, indicated that quantitative comparisons across some of the subgroups were not appropriate. Specifically, comparisons could be made between the parent occupation subgroups on all three school-based parent involvement factors, between parent education subgroups on the participating in open events at the school and communicating with teachers factors, and between primary language subgroups on the participating in open events at the school factor. However, they could not be made between racial/ethnic subgroups on any of the three parent involvement factors, between parent education subgroups on the participating in school-based organizations factor, or between primary language subgroups on the communicating with teachers and participating in school-based organizations factors.

Comparisons of factor means between subgroups for which measurement invariance was established yielded several interesting findings. Families in which parents 
had higher levels of education tended to have higher levels of involvement in open school events, but parent education levels did not appear to play a role in the amount of communicating with teachers. Higher levels of parent occupational prestige were associated with higher amounts of all three school-based parent involvement factors, though the middle and high occupational subgroups had similar amounts of communicating with teachers that were markedly higher than that of the low occupational prestige group. Families for which English was not their primary language had lower levels of participating in open school events compared to primary English speakers.

Analyses of the relationships between the parent involvement types and achievement yielded several non-significant effects, though other patterns emerged. When significant relationships were detected, participation in open school events and communicating with teachers tended to be positively associated with achievement, while participation in school-based organizations tended to be negatively associated with student achievement. The positive association between participation in open school events and achievement was strongest for groups defined by low levels of parent education, low levels of parent occupational prestige, and primarily speaking a language other than English, particularly when achievement was measured by IRT score. Higher levels of communicating with teachers had a negative association with reading IRT scores among students whose parents' highest level of education was a high school diploma but had a positive association when a parent had some postsecondary experience. There was also a stronger negative association between participation in school-based organizations and reading IRT scores among students whose parents had low levels of occupational prestige. 
School type (i.e., public, non-charter schools vs. private or public charter schools) did not appear to have an additional moderating effect on the relationship between the school-based parent involvement types and student achievement, with one notable exception. When type of school attended was taken into consideration, the positive association between participating in open school events and reading IRT scores was no longer observed among students from primarily non-English speaking homes. This and other findings are discussed both in terms of the conceptual model and in terms of potential limitations of the research design and measures used.

Findings from the current study have both practical and theoretical implications. In terms of practical implications, the strong pattern of positive associations between participation in open school events and student achievement point to two rather simple ways that schools can positively impact students' educational experiences: ensuring that parents have multiple opportunities to engage with the school and identifying ways to ensure that parents whose students are struggling academically feel that they are a valued part of the school community.

This study also contributes to the existing theory by integrating the concept of cultural capital with ecological systems theory to enhance understanding of the factors that may influence if and how families become actively engaged at their child's school and how these various approaches to family involvement at school contribute to the context in which a child's academic achievement is realized. Future research in this vein could apply the measurement and structural models used in this study to cross-sectional models using student data from other grade levels or in longitudinal models that allow for the exploration of reciprocal effects between parent involvement and achievement. 


\section{CHAPTER 2}

\section{THEORETICAL FRAMEWORK AND LITERATURE REVIEW}

The Elementary and Secondary Education Act (ESEA) defines parent involvement as parents' participation "in regular, two-way, and meaningful communication involving student academic learning and other school activities," and Title I funding is tied to local educational agencies' ability to implement programs and procedures for increasing parent involvement (The Elementary and Secondary Education Act, Section 9101(32)). Current federal education policy thus reflects recognition of the importance of parent involvement for students' educational outcomes and the need to find ways to increase it.

The purpose of this study is to explore the relationship between school-based parent involvement and early achievement using multiple indicators of school-based involvement that are posited to reflect multiple factors reflecting different forms of cultural capital. This approach to measuring involvement was tested across multiple subgroups defined by racial/ethnic, socioeconomic, and primary language subgroups to verify that this measurement approach is appropriate for students and families from a variety of backgrounds. These tests of measurement invariance were conducted within a larger structural model that posited a relationship between school-based parent involvement factors and early reading achievement outcomes. Finally, the type of school was introduced into the models as a means of accounting for the school context in which involvement activities occur. 
One criticism of the predominant narrative on involvement is the use of parent involvement to describe the interactions between families and schools, as it carries with it connotations of traditional nuclear families that are not reflective of all students' family structures (Doucet, 2011). This study uses indicators of involvement that may be carried out by any adult in the child's household and thus explores parent involvement in a broad sense. Similarly, the terms parent involvement and family involvement are used interchangeably to recognize that involvement in school may include family members other than biological parents. The implications of this approach and directions for future research will be discussed in the concluding section.

A critical first step in this exploratory study is to establish a theoretical framework within which to analyze parent involvement. To that end, Bronfenbrenner's early work on ecological systems theory and cultural capital theory based on the work of Bourdieu are discussed and integrated.

\section{Theoretical Framework}

Ecological systems theory (Bronfenbrenner, 1976) provides a framework for understanding how students' educational experiences are embedded in a series of overlapping and interacting systems that include the interaction between family and school, while Bourdieu's (1986) work on cultural capital is useful for understanding how interactions between families and educators embody social and cultural differences that contribute to different levels of engagement in activities that are considered supportive of students' educational achievement. Together these perspectives support a study of parent involvement that recognizes that parent involvement may manifest differently across subgroups of individuals whose accumulated cultural capital influence the activities in which they choose to or are able to engage, that parent involvement may also relate 
differently to student achievement for these subgroups, and that the school context may further moderate these relationships.

Ecological systems theory. According to Bronfenbrenner's (1976) ecological systems theory, individual development is embedded in and is shaped by a larger system that can be divided into a series of subsystems, each shaping the context of development from increasing levels of distance. More distant and indirect levels of influence are represented by the exosystem and macrosystems, or the larger social structures (e.g., neighborhoods, governmental agencies) and cultural institutions (e.g., economic system, political system) that shape the more immediate settings in which individual lived experience takes place. Finally, the chronosystem represents the transitions that occur throughout an individual's development, including individual-level transitions (e.g., the transition through the K-12 educational system), as well as historical shifts (e.g., access to public education for all children, educational policy changes to focus on accountability). Although ecological systems theory provides a framework for understanding individual development that is conceptually robust, it has been noted that the multitude of relations that would result from the environmental layers posited by Bronfenbrenner have seldom been tested empirically (Darling, 2007).

Although some have argued that Bronfenbrenner's more recent work on proximal processes is a more mature theoretical perspective (e.g., Trudge, Mokrova, Hatfield, \& Karnik, 2009), his early ecological systems theory provides an appropriate framework for variable-centered analyses such as what is employed in the present study. Rather than focusing on individual-level interactions, this study looks at patterns of relationships between involvement and achievement outcomes across the kindergarten student population in the United States and how these relationships may be moderated by family 
and school characteristics. Inherent to this analytical approach in which patterns of relationships are tested across multiple subgroups and school settings is the notion that families and schools are shaped by larger societal and cultural forces. The present study focuses on the inner layers of Bronfenbrenner's early ecological systems model that are particularly relevant to the discussion of educational involvement. Moving from the inside out, microsystems represent the spheres that have the most direct influence on the individual; microsystems shape and are shaped by the characteristics of their members. Though individual children vary in the number of microsystems in which they are located, most experience their early development in some family context, and family is arguably the predominant microsystem of childhood. Children's early educational outcomes are frequently linked to their earliest experiences within the family (Dodici, Draper, \& Peterson, 2003; Schmitt, Simpson, \& Friend, 2011), and for simplicity's sake, entry into the K-12 school system is discussed as marking a child's introduction into new microsystems.

When children enter into the typical kindergarten setting, they are introduced into one or more new microsystems, most notably the classroom and the school, each representing a new sphere of influence. The child's development is now situated in multiple microsystems, and the interplay between these microsystems is known as the mesosystem. The mesosystem represents the next level of influence on the individual, as the interactions between family, classroom, and school take on characteristics that contribute to the environment in which that child's development is carried out. Interactions between microsystems do not necessarily require direct contact between members. A child's experience at home can influence their behavior at school, and their experience at school can influence their behavior at home (Bronfenbrenner, 1986). Thus, 
it is possible that the interaction between home and school could occur only indirectly through each sphere influencing the child's interaction with the other.

Epstein's (1987) identification of three major perspectives on the relationship between families and schools provides a useful illustration of indirect interactions between the family and school microsystem. According to Epstein, family and school are separate spheres, each with their own responsibilities and goals relative to child development. These responsibilities and goals may be viewed as at odds with one another. For example, family may be viewed as the domain of meeting physical or spiritual developmental needs but not educational needs, while school may be considered the domain in which educational needs are met while other developmental needs are not addressed. Alternatively, families may be viewed as responsible for educational development up to a child's entry into formal schooling, at which point education professionals may be viewed as assuming that responsibility exclusively. Finally, families and schools may be viewed as sharing in the responsibilities of the education and social development of children.

The family and school thus represent separate but mutually influencing settings that provide a great deal of the context in which school-age children's development is carried out. It is wholly possible that a lack of direct interaction between members of the family and school microsystems is a defining characteristic of a particular child's familyschool mesosystem. The term involvement suggests active participation. Interventions designed to increase levels of involvement have focused on strengthening the link between family and school, either through increased presence and participation in schoolbased activities (Buchanan, Hansen, \& Quilling, 1969; Gilmore, 1985) or changes in attitudes, beliefs, and behaviors about roles and abilities relative to supporting children's 
academic success (Brooks, Bruno, \& Burns, 1997; Hampton, Mumford, \& Bold, 1998). The present study focuses on direct interactions between families and schools in the form of activities that require an adult family member to either be present in the school or to have some form of direct contact with school staff.

Cultural capital theory. The concept of capital has been applied to the understanding of both human behavior and social inequality. Rooted in economic theory, capital generally describes the assets, both material and symbolic, that individuals can access and activate to achieve a particular goal (Lin, 2001). Capital has further been subdivided into subtypes, with human, cultural, and social capital being frequently applied in the field of educational research (Gottfredson, \& DiPietro, 2010; Jaeger, 2011; Wallenborn; 2010).

Human capital is typically discussed as the aggregate of the education and skills available within a particular economy that can be invested to produce economic growth (Ehrlich \& Murphy, 2007). Educational studies conducted within a human capital framework are often focused on identifying predictors of academic success, typically measured by scores on tests of achievement, as a means of informing how the available pool of human capital might be increased (e.g., Todd \& Wolpin, 2007). Also within this framework, reducing gaps in achievement scores is considered vital for reducing subsequent inequality in the job market (Todd \& Wolpin, 2003). Assumptions underlying this approach include that the most valuable knowledge, skills, and abilities can be identified and measured, that individuals can be ranked on a continuum that reflects this hierarchy of knowledge, skills, and abilities, and that increasing these knowledge, skills, and abilities is possible through educational intervention. Critics of a human capital approach to education have pointed out that measures of human capital such as 
educational ability or achievement may fail to adequately capture the multidimensionality of "economically relevant" skills (Bowles \& Gintis, 1975, p. 78) and that the approach "fails to recognize that families and schools teach different things to different peoplenot simply more or less" (Bowles \& Gintis, 1975, p. 78).

Theories of cultural capital emerged in response to what were viewed as inadequacies of human capital theory in explaining enduring inequalities in educational outcomes. Although Bourdieu's (1986) original work focused on how the concept of capital could be applied to explain the reproduction of social inequalities in $20^{\text {th }}$ century France, it continues to be used to explain social conditions and human behavior in American society (Putnam, 1995; Tondeur, Sinnaeve, van Houtte, \& van Braak, 2011; Winters, 2011). Bourdieu's own criticisms of the human capital approach included the argument that "ability or talent is itself the product of an investment of time and cultural capital" and that "...the scholastic yield from educational action depends on the cultural capital previously invested by the family," (p. 48). From this point of view, educational opportunities and interventions during formal schooling may not be enough to ameliorate differences in early family investments toward educational preparedness.

There is not, however, universal agreement as to how the concepts of capital should be operationalized. Cultural capital, for example, often has been treated as access to and participation in elite cultural experiences such as visiting museums and attending plays (e.g., DiMaggio, 1982) or has been measured by characteristics of a child's home such as the number of books in a household (Lauglo, 2000). Such treatment can be linked back to Bourdieu's original work, but sociologists have since argued that rather than elite cultural experiences, cultural capital is made up of "knowledge of the norms, values, 
beliefs, and ways of life of the groups to which people belong” (McNamee \& Miller, 2009, p. 79).

Farkas (1996) attempted to bridge the gap between human capital and cultural capital theories by arguing that culture affects behavior not only through its effects on values but more so through its effects on skills, or the tools that individuals are able to use as they act in particular social situations. Rather than cultural capital being solely a possession of elite groups, these perspectives suggest that all individuals amass cultural capital throughout their lives that reflects the individuals, groups, and institutions with which they regularly interact. This perspective recognizes that cultural capital as something accrued by all people but that certain forms of capital may be more highly valued among particular groups and in particular contexts.

If cultural capital that is invested by families on behalf of their children is conceptualized as knowledge about and tools for navigating the educational system, then parents with greater understanding of the expectations of the school could be viewed as having an advantage when they invest their resources to support their child's educational experience. Lareau (2011) has written extensively about class differences in cultural capital in the context of families' school involvement. According to Lareau, schools are institutions with particular standards that are reflective of the values of the middle class. She argues that all families want their children to succeed but that they may differ in beliefs about the role they play in ensuring academic success and about their ability to help their child and in the tools they have at their disposal for supporting their children's school experience. Family educational involvement is an overt investment of family cultural capital on behalf of students. It follows then that investment of different cultural tools, each with differing levels of correspondence to the expectations of schools, may 
yield differences in returns on this investment for their child's educational experience. The present study uses multiple indicators of parent involvement at the school to explore whether there may be factors underlying these indicators which reflect differences in cultural capital requirements and if the relations of these parent involvement factors relate to achievement outcomes similarly for families from different sociocultural backgrounds and in different school settings.

Integration of ecological systems and cultural capital theories. Taken together, ecological systems and cultural capital theories provide a logical framework for recognizing the relevance of interactions between families and schools for students' educational experiences and outcomes and for explaining how families may differ in their capacity for meeting schools' expectations for providing educational supports. Figure 1 depicts the child as embedded in the series of broader systems. Cultural capital permeates the systems, as historical shifts (the chronosystem), as well as laws and government policies (the macrosystem) shape which resources are valued by the larger society and how these resources are distributed. This distribution of resources further shapes community resources (the exosystem), which serves as the local context in which family cultural capital is accumulated. Finally, the family-school mesosystem serves as the "interactional context," the characteristics of which may "promote or hinder activation of cultural capital" (Rubtsova \& Dowd, 2004, p.120). Figure 2 focuses in on the familyschool mesosystem to which families bring their accumulated cultural capital and to which schools bring existing policies, practices, and institutional norms, also which are shaped by historical, legal, and community contexts. Parent involvement is one component of this interaction between families and schools, and how that involvement is 
manifest and its relation to student achievement is influenced by both families' access to cultural capital and schools' expectations of families.

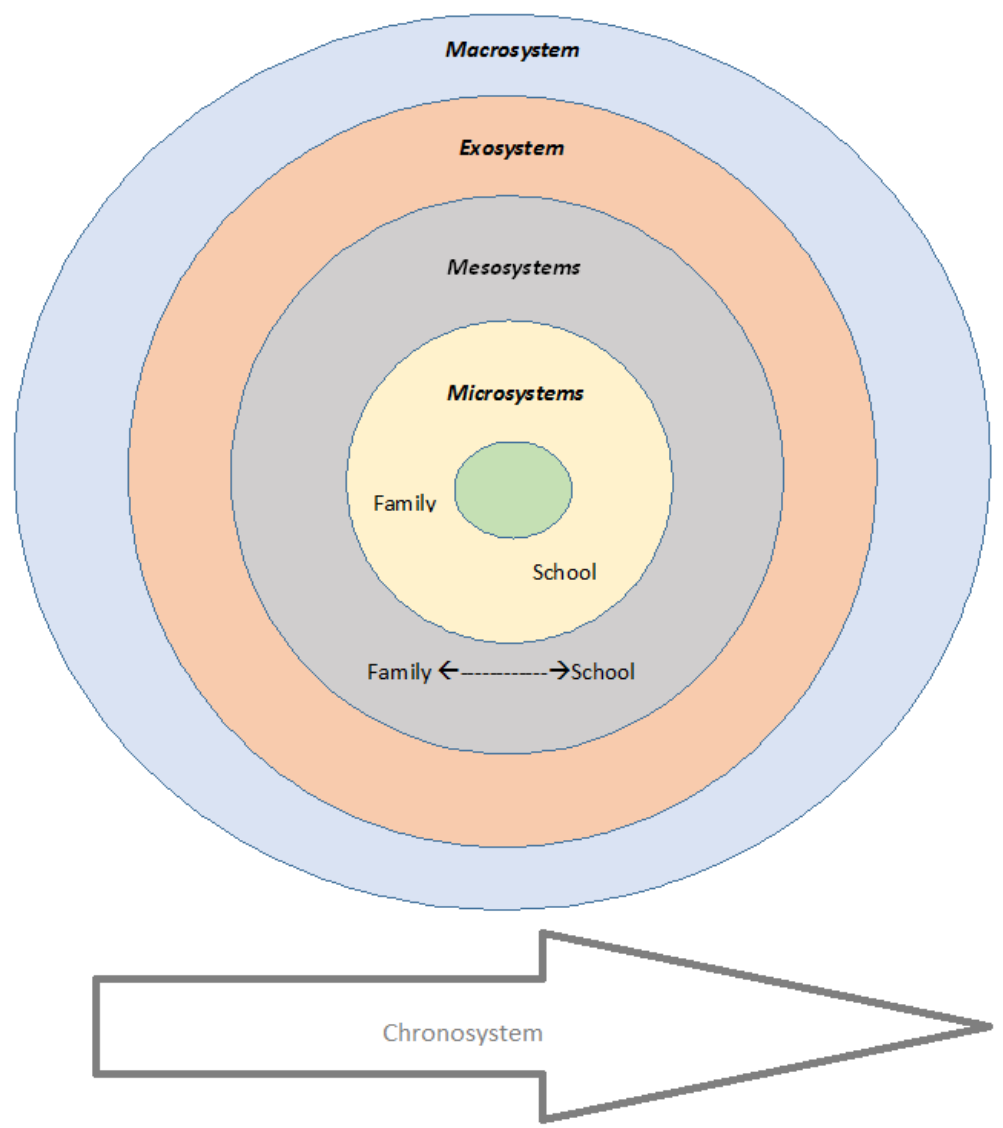

Figure 1. Model depicting Bronfenbrenner's ecological systems theory 


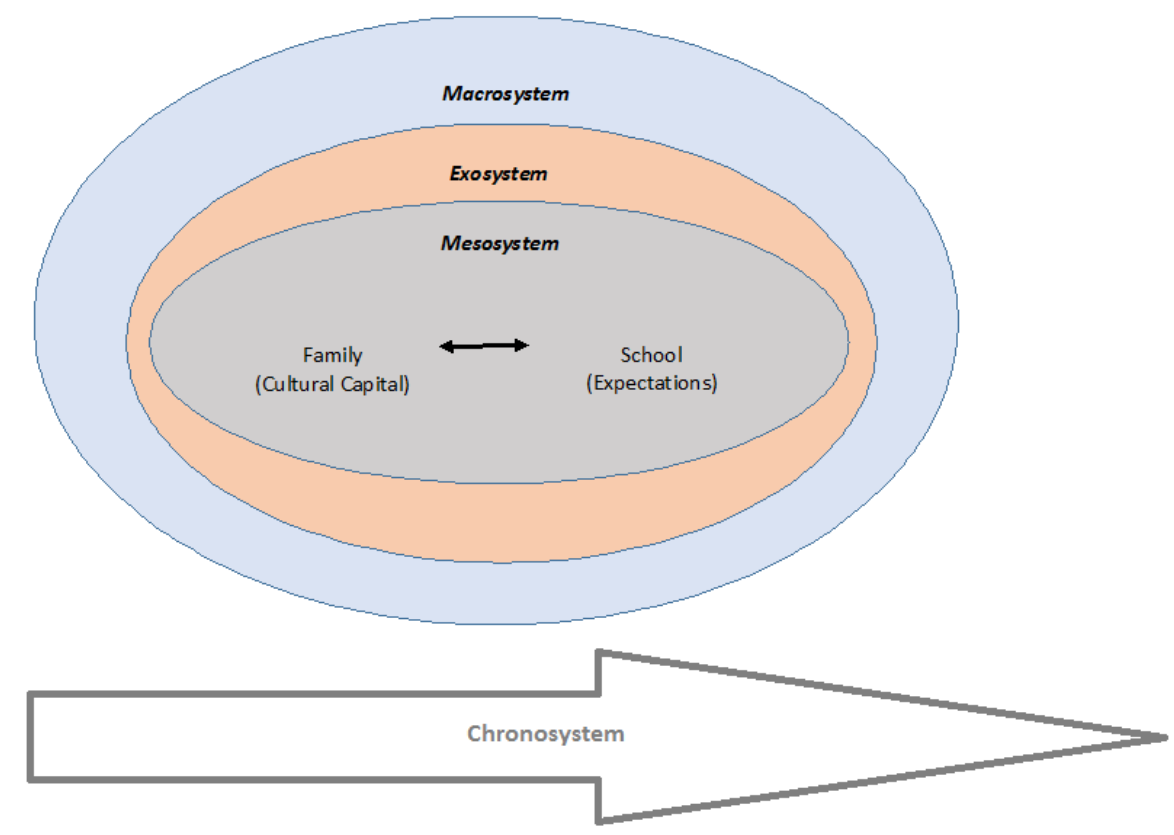

Figure 2. Conceptual model integrating ecological systems and cultural capital theories.

\section{The Components of Parental Involvement and Their Measurement}

Parent involvement has been measured in a variety of ways that include not only involvement in the school building but also activities at home, as well as parents' attitudes and beliefs. Lee and Bowen (2006) used such indicators as talking about education-related subjects, helping with homework, managing children's time, and holding expectations for children's educational success as measures of the level of parent educational involvement. One potential problem with defining involvement by parents' educational expectations is that what constitutes success may differ according to parents' own educational experiences and completion levels, and this is not necessarily a reflection of their level of support for their child's education. Parents may also hold expectations about their child's educational outcomes that are based on their beliefs about their child's ability level, regardless of their involvement. For example parents of a student with learning disabilities may recognize that their child will likely not complete 
high levels of education, but this will not necessarily translate into low levels of involvement.

More "subtle components of parent involvement" have also been identified (Jeynes, 2012, p. 734), including openly communicating with children and maintaining a loving home environment. What is concerning about such subtle indicators of involvement is that they cannot be easily extracted from values surrounding appropriate parenting practices. For example, cultural norms will likely influence the forms of parentchild communication that are considered appropriate and what constitutes a "loving" home environment. Although it may be appropriate to argue that caring home environments are beneficial for children, conflating such value-laden constructs with educational involvement only muddies the waters for practitioners seeking to identify parent involvement activities that are readily amenable to policies and practices at the school.

In other studies, parent involvement has been defined as parents' understanding of and compliance with school expectations (Smith \& Wohlstetter, 2009) or as parents' willingness to cooperate with the teacher/school and being responsive to teacher needs and expectations (Lawson, 2003). In both of instances, judgments about the quality of parent involvement are reliant on the perspectives of school staff and do not clearly define these expectations. Equating parent involvement with perceptions of parent compliance or responsiveness assumes that parents' understand the expectations of the school and/or have the necessary resources to respond to these expectations. These approaches to measuring involvement also fail to provide information about specific school involvement activities that are beneficial for student achievement. 
Measures of parent involvement may be built around ratings provided by school staff (Hilado, Kallemeyn, Leow, Lundy, \& Israel, 2011) or around teacher perceptions of not only parents' behavior but also of their attitudes and beliefs as well, such as asking teachers to rate the importance of education to a family (Topor, Keane, Shelton, \& Calkins, 2010). Relying on such ratings is problematic because of the potential for bias. Prior research has indicated that teachers' personal backgrounds may interact with student backgrounds in ways that can bias teachers' evaluations of students (Alexander, Entwisle, \& Thompson, 1987), and teacher ratings of family involvement may be impacted by prior student performance (Izzo, Weissberg, Kasprow, \& Fendrich, 1999). Teachers may also report less involvement (El Nokali, Bachman, \& Votruba-Drzal, 2010) or less participation in school-based activities compared to parent reports (DePlanty, Coulter-Kern, \& Duchane, 2007).

Though it is not clear the extent to which teacher perceptions of family involvement include assumptions about behavior outside of the school walls, it has been demonstrated that teachers' knowledge of family involvement outside of school may be very limited. Baker, Kessler-Sklar, Piotrkowski, and Parker (1999) reported that over half of teachers surveyed about their knowledge of family involvement indicated that they did not know if parents read to their child, use school resources, discuss school with their child, or attend school-based workshops. Interestingly, only $5 \%$ of teachers responding to the survey indicated that they did not know about parents' overall interest in school. Thus, a study focused on the effects of school-based involvement may be useful for filling gaps in understanding how specific types of parent involvement relate to students' educational outcomes. 
DePlanty, Coulter-Kern, and Duchane (2007) identified five components of parent involvement based on parent and teacher ratings of the importance of particular behaviors for student achievement and found them to include school involvement, time management, school attendance, parent structure, and supportive home environment. The extent to which all of these activities fall under the same construct of parent involvement is not clear, however. For example, parent attendance at school-based meetings and activities has been found to be only weakly correlated with managing children's time in the home (Lee \& Bowen, 2006). This further supports that an analysis of school-based involvement measures separate from measures of home-based involvement may be useful for highlighting the behaviors in which parents may engage at the school that are most useful for ensuring early student achievement.

\section{School-Based Involvement and Cultural Capital}

What is probably the most frequently-cited work on parent involvement categorizes it into six levels: parenting, communicating, volunteering, learning at home, decision making, and collaborating with the community (Epstein, 1995), some of which are more readily translatable to school-based activities than others. Using the parenting level of involvement as an example, families are described as responsible for "maintaining healthy child development across grades (Epstein, 1992, p. 11), with schools playing a supportive role in this, possibly by providing education or other types of assistance. However, the majority of related activities are carried out in the home.

Three of Epstein's types of parent involvement are most clearly related to schoolbased activities. Communicating involves "the notices, phone calls, visits, report cards, and conferences that most schools provide" (Epstein, 1992, p. 11). Volunteering is described as not only the presence of family members in the classroom but also 
attendance at school events. Finally, decision-making includes serving in "participatory roles in the PTA/PTO, Advisory Councils, Chapter 1 programs, school site management team, or other committees or school groups" (p. 12).

Parents can thus engage in a variety of school-based activities that would be considered indicators of involvement, but different types of activities require different forms of knowledge and tools for participation. The next section attempts to classify three types of school-based involvement, each with different requirements or potential obstacles to participation that reflect forms of cultural capital: communication with teachers, participation in school-based organizations, and participation in open events at the school.

Communication with teachers. This type of involvement includes oral and written communication between parents and teachers, as well as volunteering in the classroom. In all such instances, parents are required to understand appropriate communication styles and expected behaviors, and access to valued forms of cultural capital may play a role in both the ways that parents interact with teachers and the ways in which their level of involvement is perceived. Arab parents, for example, were found to prefer face-to-face and phone-based interactions to other forms of communication by teachers and to defer to teachers' requests out of a high value for politeness rather than expressing disagreement with expectations with which they did not intend to comply (Moosa, Karabenick, \& Adams, 2001). Hispanic parents also have been found to defer to teachers more often and to report feeling less comfortable with teachers and schools than did other groups (Ritter, Mont-Reynaud, \& Dornbusch, 1993) and have been found to report communicating less with teachers than other racial/ethnic groups (Wong \& Hughes, 2006). 
Parents may differ in their tools for successfully interacting with teachers and schools once they make the decision to interact with school officials on behalf of their child. Parents may differ in their communication style and this has implications for the effectiveness of their interactions. Working class and poor families may feel they lack the vocabulary needed to effectively communicate with teachers and school staff about their child's school experience (Lareau, 2011) and may be more likely to behave in a confrontational manner and to express anger with school staff (Lareau \& Calarco, 2012).

Participation in school-based groups. Involvement at the school provides parents an opportunity to interact not only with teachers and other school staff but also to meet with other parents and develop social networks that can be used as resources for providing educational supports. Parents with access to different forms of cultural capital, however, may differ in the extent to which they are able to build connections with other parents and leverage those connections to enhance ability to support their child's educational experiences. For example, middle class parents were found to more frequently draw on contacts with other parents to gain information and pool resources to intervene on behalf of their child's educational experiences than were parents from working class backgrounds (Horvat, Weininger, \& Lareau, 2003).

The types of involvement engaged in by families may also be affected by the behaviors, or perceived attitudes of, other parents and school staff. For example, highly involved families who regularly participate in parent-teacher organizations or other decision-making bodies within a school may, even unintentionally, behave in ways that send the message to less involved parents that they do not fit in (McGrath \& Kuriloff, 1999). Parent participation in parent-teacher organizations and other school-based organizations may be also shaped by parents' beliefs of how highly valued their 
participation is among school staff (Comer, 1986), and parents' beliefs about the value of their contributions may be influenced by the tools they have at hand for interacting with these organizations

Participation in open events at the school. Some school-based activities that fall under the umbrella of involvement do not necessarily require direct interaction between family members and school staff. For activities such as open-houses, sporting events, or fairs, nothing more than attendance may be required. For some groups, however, awareness of such activities may depend on culturally-based tools such as language skills or access to the mechanisms of communication. Failure to provide newsletters or other announcements in languages other than English may leave non-English speaking parents unaware or confused about opportunities for involvement (Smith, Stern, \& Shatrova, 2008).

Requirements outside of specific understandings or tools may also shape parents' ability to be involved in activities at the school. Flexibility in work schedules, for example, has been noted for its importance for meeting the needs of families (Hill, Hawkins, Ferris, \& Weitzman, 2001), but without it, parents who are employed might be limited to only those involvement opportunities that are offered outside of their scheduled work hours (Weiss et al., 2003). Parent involvement is thus shaped by other microsystems, namely the workplace, in which family members are situated.

\section{The Role of Parent Involvement in Achievement Outcomes}

Research focused on family involvement in education has generally found involvement to relate positively to student achievement outcomes. A commonly cited meta-analysis found consistently positive effects of parental involvement on academic achievement across a variety of measures of both involvement and achievement (Fan \& 
Chen, 2001). Although average effects across studies may indicate that parent involvement is beneficial for student outcomes, other research has noted differences in the impacts of school performance by different types of parent involvement (Izzo, Weissberg, Kasprow, \& Fendrich, 1999).

Early parent involvement has been found to be a significant predictor of middle school achievement through its effects on kindergarten achievement (Froiland, Peterson, \& Davison, 2013). Parent involvement has similarly been shown to be positively associated with both kindergarten and eighth grade reading achievement and with lower rates of grade retention, after controlling for age at school entry, National School Lunch Program eligibility, parent's completion of high school, and gender (Miedel \& Reynolds, 1999). Furthermore, it has been found to be a significant predictor of grades and teacher ratings of academic performance in reading and mathematics at the elementary level (Lee \& Bowen, 2006). However, other research has found involvement at school to have no significant association with eighth grade achievement after controlling for prior achievement (Trivette \& Anderson, 1995). Appropriate or effective parent involvement may thus vary across grade levels. For example, the monitoring of assignments and homework may be a more important form of involvement for middle school aged children than for younger students (Barge \& Loges, 2003). What is not clear in the existing literature is the relationship between school-based parent involvement at the outset of K-12 schooling and its relationship with early achievement.

Parent involvement at the school may positively relate to student achievement through a variety of mechanisms. Communication between families and school staff may create a foundation for coordinating activities at home and school that support educational success. If parents are informed of the happenings in school and if teachers 
are informed of happenings at home, then both will likely be better equipped to support one another (Baker, Kessler-Sklar, Piotrkowski, \& Parker, 1999). Similarly, communicating with teachers and school staff may increase parent's understanding of the skills and abilities being addressed in the class or whether their child is experiencing problems, and parents' interventions or supports can be adjusted accordingly (Baker \& Stevenson, 1986). Family involvement in education may also relate to achievement through its effects on both students' perceptions of their own cognitive competence and the quality of student-teacher relationships (Topor, Keane, Shelton, \& Calkins, 2010).

Parent involvement could also be counter-productive if increased involvement creates tension between parent and teacher or if parents demonstrate one set of behaviors while at the school but behave in a contradictory fashion when at home. Lareau (2011), for example, describes a working class parent who defers to teachers and school staff during meetings about her children but who asserts her disagreement with the teacher when she is home and only in the presence of here children. This might send a confusing message to children about the value of education. McGrath and Kuriloff (1999) discuss potential problems associated with increased parent involvement, particularly parents' effectiveness in dealing with school staff and parent involvement leading to too much focus on a small number of students. Certain forms of parent involvement can actually have negative impacts when they occur with greater frequency. Teachers noted that parents' criticism of the school, whether directly to teachers or in the home, can have negative consequences for students' attitudes toward school (Barge \& Loges, 2003).

Quantitative studies tend to report positive effects of parent involvement, though some studies present conflicting results. Often, regardless of effects, these studies are built around relatively small, homogenous samples or are focused on single school 
districts or cities (e.g., Barnard, 2004; Oyserman, Brickman, \& Rhodes, 2007; Rogers, Theule, Ryan, Adams, \& Keating, 2009). Qualitative studies on family involvement in schools have highlighted that all activities might not be accessible to all parents and may relate to achievement in different ways, depending on how equipped parents and other family members are to engage in particular activities. The present study seeks to build on some of this qualitative work, which asserts that there may be sociocultural differences in the engagement in, and subsequent impact of, parent involvement in school. Specifically, this study will explore the measurement of parent involvement across multiple subgroups and then document the relations between involvement and early achievement. This will include testing the potential moderating effects of certain family and school characteristics on this relationship.

\section{The Importance the School Context}

Parent's school involvement is carried out in the context of school policies and practices that may shape opportunities for involvement. These policies and practices represent one contribution of the school to the family-school mesosystem, while also reflecting the forms of family cultural capital that are valued by schools.

Schools may offer programs specifically targeting family involvement, such as shared reading programs, emphasized partnership programs, checking homework programs, parent-teacher communication programs, head start programs, and ESL teaching programs (Jeynes, 2012). Such programs identify the family contributions that are valuable for improving educational outcomes and seek to build families' capacity for engaging in these activities. Particular types of schools, such as charter schools, may have policies in place which require parents to enter into contracts in which they agree to engage in a specified number of hours of service at the school or may be structured such 
that parents assume a larger role in governance and decision making (Smith and Wohlstetter, 2009).

Parent engagement in activities such as volunteerism and membership in parentteacher organizations have also been found to be more frequent in private schools than in public schools (Feuerstein, 2000). Other research has suggested that teachers vary in the amount of effort that they expend in reaching out to parents and that this may impact levels of involvement (Patrikakou and Weissberg, 2000). This suggests that the population served by a school may relate to expectations around and opportunities for parent involvement. For example, school staff may vary in their definitions of appropriate parent involvement based on their understanding of the populations they serve (Hilado, Kallemeyn, Leow, Lundy, \& Isreal, 2011), which could have implications for the types of involvement in which parents are able to engage.

The interaction between family and school is characterized not only by the characteristics and behaviors of the family but by those of the school as well. Therefore, it stands to reason that the type of school may have an additional moderating effect on the relationship between parent involvement and early achievement among the various subgroups. The final analytical step in this study was to document the extent to which school type had such a moderating effect.

\section{Developing a Model for Understanding the Relationship between Families' School-}

\section{Based Involvement and Student Achievement}

Integrating components of early ecological systems theory with cultural capital theory provides a framework within which to explore the interactions between families and schools and the factors that characterize them and how these interactions might shape individual outcomes. The present study focused on one of the many ways that families 
and schools may interact: parent involvement at the school. Because of its exploratory nature, this study does not posit specific research questions but rather seeks to augment existing research on parent involvement and early student achievement by addressing the following research goals:

- Identify the components of school-based parent involvement;

- Examine whether the different components of school-based parent involvement coincide with different forms of cultural capital as implied by prior research;

- Determine if the measurement of school-based parent involvement components is consistent across multiple sociocultural subgroups to allow for quantitative comparisons between groups; and

- Ascertain any moderating effects of sociocultural background characteristics and type of school attended.

Many studies combine the multiple facets of parent involvement in ways that make understanding the unique contribution of involvement at the school difficult to parse out. This study adds to the literature on parent involvement by focusing specifically on the activities that are most visible to school staff, and thereby may be most amenable to intervention. This study further adds to the literature by exploring involvement activities through the lens of cultural capital and recognizing that particular activities reflect cultural requirements that may not fit well with the cultural tools individuals or families have accumulated throughout differing sets of lived experiences. Specifically, this study modeled school-based parent involvement as a multi-faceted construct in an attempt to capture these influences of cultural capital and to verify that this approach to measurement was appropriate for various sociocultural groups. Next, this study focuses on parent involvement at the outset of students' K-12 educational experience. 
Understanding the influence of parent involvement in the early years of schooling can inform educators 'efforts to establish patterns of involvement that will carry on throughout a child's educational experience. Finally, this study adds to the literature on parent involvement by looking at the relations between school-based parent involvement and early achievement using a nationally representative sample while exploring the potential moderating effects of sociocultural background characteristics and the type of school attended. The next chapter details the methods employed. 


\section{CHAPTER 3}

\section{METHODS}

\section{Description of Dataset}

This study used the restricted base-year data for the 2010:11 Kindergarten cohort from the Early Childhood Longitudinal Survey- Kindergarten (ECLS-K). The ECLS-K is one of three longitudinal studies conducted by the National Center for Educational Statistics (NCES) and is focused on the educational experiences of children in grades K-8 (NCES, 2013). To date, only the data for the kindergarten cohort has been made available to researchers and only in a restricted access format. This present analyses focused on parent involvement at the kindergarten level only.

\section{Description of Sample}

One benefit of using data available from the ECLS-K is that it reflects a nationally representative sample of students attending both public and private schools (NCES, 2013). Representativeness is achieved through a weighting process in which individual responses are multiplied by a sampling weight that adjusts for differences in selection probabilities (i.e., simple random sampling is not used) and for potential biases associated with non-response. For the present analyses, the sampling weight W2PO was applied as student assessment data from both fall and spring were used in conjunction with base year parent and teacher data (NCES, 2013). The distributions of the outcomes and 
moderating variables in the unweighted sample $\left(n=18,170^{2}\right)$ are presented along with the descriptions of the variables below.

\section{Description of Variables}

Measures of parent involvement. Parent involvement is the characteristic of the family-school mesosytem of interest in the present study. Fifteen indicators of parent involvement were used in this study. A major assumption of this study is that these various activities reflect different forms of cultural capital requirements that roughly correspond to direct interactions with teachers, participation in school-based groups, and participation in open events at the school, as previously discussed.

Teacher measures of involvement. Teacher perceptions of parent involvement are measured by NCES via several questionnaire items. The forms of school-based involvement that were included among teacher measures included parent attendance at regularly-scheduled conferences at the school, parent attendance at informal meetings initiated by the teacher to discuss the child's progress, and parent volunteering to help in the classroom or school. Each item was dichotomously measured using a 'Yes' or 'No' response. 'Yes' values were recoded as 1 and 'No' values were recoded as 0 for the analyses.

Parent measures of involvement. The parent survey component of the ECLS-K contains several items in which respondents were asked to indicate whether or not they had attended or participated in several activities at the school. These included: open house/back-to-school night, PTA/PTO meetings, parent advisory group/policy council, regularly scheduled parent-teacher conference, play/sports event/science fair, classroom volunteering, school committee, or fundraiser. Each item was dichotomously measured

\footnotetext{
${ }^{2}$ Sample size has been rounded due to use of restricted dataset.
} 
using a 'Yes' or 'No' response. 'Yes' values were recoded as 1 and 'No' values were recoded as 0 for the analyses.

Achievement outcome measures. Achievement outcomes were the individuallevel characteristic of interest in this study. The analytical approach used recognizes that individual achievement is embedded within and influenced more encompassing social systems and does so by analyzing the relations between achievement and parent involvement activities across multiple sociocultural subgroups and school settings.

Early reading skills have been found to relate to the development of children's overall academic self-concept (Chapman, Tunmer, \& Prochnow, 2000). As such, it is important to understand factors that relate to early reading achievement. This study measured student reading achievement in two different ways, using scores from the spring administration of both measures. Different measures of student achievement may reflect different aspects of the underlying achievement construct (Dickinson \& Adelson, 2013), and examining student achievement via multiple measures takes this into consideration.

First, student scores on direct cognitive assessments of reading were used. At the kindergarten level, these assessments include items designed to measure basic English reading skills, including basic skills such as print familiarity, letter recognition, and beginning and ending sounds, and recognition of common words (NCES, 2013). Student scale scores on these assessments are calculated within an IRT framework, allowing them to be comparable across administrations. The mean IRT reading score of the unweighted sample was 49.26 , with a range of 5.9 to 80.4 and a standard deviation of 11.94).

Second, teacher ratings of student achievement in language and literacy on the Academic Rating Scale (ARS) were used. Though there is some amount of overlap in the 
content domains measured by the direct cognitive assessments and the ARS, the latter is designed to capture learning processes as well as learning products (NCES, 2013). The mean teacher literacy rating of the unweighted sample was 3.19, with a range of 1 to 5 and a standard deviation of 0.97).

Background characteristics. Student/family background characteristics were used to identify groups for testing measurement invariance in the factor model. Each group was selected based on the review of literature which indicated that these characteristics of the individual or the family microsystem may shape access to cultural capital. The following section provides more details about these variables and how they were recoded for analysis.

Race/ethnicity. Access to cultural capital is frequently analyzed across racial and ethnic groups (e.g., Trueba, 2002; Wells, 2008). Child's racial/ethnic categorization is a nominal level variable including the following values: white/non-Hispanic, black or African American/non-Hispanic, Hispanic, Asian, native Hawaiian/Pacific Islander, American Indian/Alaskan native, and more than one race/non-Hispanic. The ECLS-K captures information on a child's race/ethnicity on multiple surveys and creates a composite variable by cross-referencing these multiple sources. This composite race/ethnicity variable was recoded into multiple dummy variable that categorized students into the following groups: white, black, Hispanic, Asian, and other (with white as the reference group). Because of the amount of missing data associated with parent background variables, student-level data for race were used to create racial groupings and was assumed to be associated with the racial and ethnic characteristics of the family. Directions for future research differentiating between child and family racial/ethnic identity will be discusses in the concluding section. The distribution of race/ethnicity 
categories in the unweighted sample was $47 \%$ white, $13.3 \%$ black, $25 \%$ Hispanic, $8.6 \%$ Asian, and $6 \%$ other race/ethnicity.

Socioeconomic status. Socioeconomic status (SES) is a frequently used construct that is intended to capture a combination social factors that embody an individual's or family's access to wealth, status, and prestige, and by extension access to cultural capital. Although the ECLS-K contains a composite variable that combines the available data on parents' income, education, and occupational prestige, it may be preferable to model the specific components of SES in order to capture the different mechanisms through which each component relates to the other variables of interest (Dickinson \& Adelson, in press). The approach in the present study draws on Lareau's work on class-based differences in parent involvement in which class membership is largely defined by parents' education and occupational prestige (Lareau, 2011).

Parents' education level. Parents' own educational experiences may provide them access to the tools of cultural capital that are valued in educational settings (Reay, 2004). The highest level of education completed by either parent is an ordinal level variable including the following values: $8^{\text {th }}$ grade or below, $9^{\text {th }}-12^{\text {th }}$ grade, high school diploma/equivalent, vocational/technical program, some college, bachelor's degree, graduate/professional school/no degree, master's degree, and doctorate/professional degree. Research on the effects of parent education levels on educational outcomes typically collapses the number of categories to distinguish between high school completion, some postsecondary experience, and completion of a postsecondary degree (e.g., Choy, 2001). Because the present study was particularly interested in parent involvement during early elementary, it was posited that not earning a high school diploma might lead differences in parents' attitudes and behaviors related to K-12 
education compared to those who earned a diploma. The parent education variable was thus recoded into the following groups: less than high school, high school diploma, undergraduate-level postsecondary experience, and bachelor's degree or higher, with the less than high school diploma subgroup. The distribution of parent education categories in the unweighted sample was $9 \%$ with less than a high school diploma, $20.4 \%$ with a high school diploma, $31.3 \%$ with some postsecondary experience, and $38.8 \%$ with a college degree or beyond.

Parents' occupational prestige. The relative prestige of parents' occupations may provide them access to cultural capital that enables them to more effectively communicate with school personnel or to participate in valued roles at the school (Lareau, 1987). Parent occupational information is presented in two ways in the ECLS-K data set. Parents' occupations are coded at the nominal level with a label describing the type of occupation held (e.g., mechanics \& repairs, natural scientists \& mathematicians) and are given an occupational prestige index based on results from the 1989 General Social Survey (NCES, 2004). Because the ECLS-K dataset does not provide a categorical measure of occupational prestige that reflects the relative prestige of classes of occupations, a preliminary exploration of these two variables was conducted. First, the range of occupational prestige index scores within each occupational label was tabulated. The full distribution of occupational prestige values was then compared to the occupational labels and their associated prestige ranges. This comparison indicated that several occupations were always associated with an occupational prestige index in the upper quartile of the distribution. For several other labels, the range of associated prestige scores fell mostly within the middle $50 \%$ of the full range of prestige index scores. Only one occupational label ('Handler, Equip, Cleaner, Helpers, Labor') was associated with 
occupational index scores that were always in the lowest quartile. Based on this exploration, it was determined that occupational prestige scores would be organized into three groups representing the bottom quartile, the interquartile range, and the upper quartile of the occupational index distribution. The highest occupational prestige index available for mother and/or father was used to determine the parent occupational prestige grouping variable. The distribution of parent occupation categories in the unweighted sample was $26.5 \%$ in the lower prestige group, $47.7 \%$ in the middle prestige group, and $25.8 \%$ in the higher prestige group.

Primary Language Usage. Language is both a cultural component and a fundamental tool for interacting with others (Jiang, 2000; Vygotsky, 1978). Therefore, it stands to reason that access to the language of the larger culture will shape families' opportunities for involvement. The ECLS-K contains an indicator of whether or not English is the language used in a child's home. This variable was recoded so that a value of 1 indicated that a language other than English was used in the home, while a value of 0 indicated that English was used in the home. The distribution of primary language categories in the unweighted sample was $81.7 \%$ primary English speakers and $18.7 \%$ primary non-English speakers.

School type. School microsystems may vary in both their expectations and opportunities for parent involvement (Hill \& Taylor, 2004), and these shape influence the family-school mesosytem. The final research goal is to determine whether or not the type of school has an additional moderating effect on the relationship between involvement and achievement beyond any possible moderating effect of subgroup membership. A school type variable was created by combining the school type indicator (i.e., public or private) with the charter school indicator (i.e., charter or non-charter). This yielded three 
school types: public non-charter, public charter, and private non-charter (there were no private charter schools in the dataset). The distribution of school types in the unweighted sample was $84.6 \%$ public non-charter, $2.7 \%$ public charter, and $12.7 \%$ private noncharter. Because of the very small percentage of public charter school, school type was further recoded into public non-charter schools (school type $=0$ ) and public charter/private schools (school type $=1$ ).

\section{Description of Analyses}

Factor analysis. The goal of factor analysis is to analyze the patterns of correlations among items to determine if a large number of items can be reduced down to a smaller number of factors. The factors produced are a linear combination of the observed responses (Tabachnick \& Fidell, 2001), and patterns of responses are assumed to reflect latent processes that lead individuals to respond to particular items in particular ways (Mislevy, 1986). The present study utilized two separate but complimentary approaches to factor analysis. Exploratory factor analysis (EFA) was first conducted on a subsample of the data to determine the patterns of correlations among items. Next, confirmatory factor analysis (CFA) was used within the context to determine if these same patterns of correlations could be observed among the full sample.

Exploratory factor analysis. EFA is useful when there is no a priori supposition about the number of factors underlying a set of items (Hurley et al., 1997). Though no prior studies positing cultural capital-based components of school-based involvement specifically were found, the review of literature on family cultural capital in the context of school involvement suggested that it is reasonable to suspect that some underlying latent processes could lead respondents to endorse participating in particular types of involvement. 
As the larger goals of this study included documenting whether or not the measurement of school-based parent involvement and its relations to achievement are invariant across subgroups, it was important to use only a portion of the sample to conduct the EFA so that the resulting factor structure could be tested using the entire sample. This was done by drawing a random sample of cases for the EFA analysis. A total of 500 cases were selected at random from the full sample. This yielded substantially more than the preferred 10:1 ratio of subjects to items (Costello \& Osbourne, 2005).

The EFA for this study was conducted using SPSS 20.0. The extraction method used for this EFA was principal axis factoring, a method that takes into account measurement error, unlike the other commonly used factor extraction method, principal components analysis (PCA). Schmitt (2011) pointed out that PCA and EFA have “different goals resulting in different outcomes" (p. 307) and cited prior research that indicated PCA may result in inflated amounts of variance being accounted for by the components.

The method of factor rotation employed was Direct Oblimin rotation, an oblique rotation which allows for factor intercorrelations (Tabachnick \& Fidell, 2001), which was considered most appropriate given that prior research has indicated correlations among different types of parent involvement (Grolnick \& Slowiaczek, 1994). Browne (2001) also asserted that "oblique rotation is probably more appropriate in most practical situations" (p.114).

Measures of sampling adequacy (MSA's) were analyzed to confirm the appropriateness of conducting exploratory factor analysis. Barlett's test of Sphericity tests the null hypothesis that the correlation matrix is an identity matrix. The results 
indicated that the null hypothesis should be rejected (Chi-square $=453.94 ; p<.001)$, suggesting that the correlation matrix derived from the data was appropriate for exploratory factor analysis (Dziuban \& Shirkey, 1974). The Kaiser-Meyer-Olkin Measure of Sampling Adequacy (KMO) was .72, meeting the criteria of appropriateness for conducting EFA (Dziuban \& Shirkey, 1974).

Factors were selected for extraction using a combination of the Kaiser-Guttman rule, examination of the scree plot, and parallel analysis (PA) with PCA analysis. Based on the Kaiser

Guttman-rule, in which factors with eigenvalues greater than 1.0 are retained, four factors were indicated. Preacher and MacCallum (2003) summarize the many limitations associated with using Kaiser-Guttman as a stand-alone criterion for factor selection. Closer inspection of the eigenvalues found that those of the fourth factors exceeded a value of 1.0 by less than 0.1 and that this factor accounted for less than $5 \%$ of variance. Examination of the scree plot (see Figure 3) found a "marked drop" (Preacher \& MacCallum, 2003, p. 34) between the first and second and second and third eigenvalues and a flattening of the curve between the third and fourth eigenvalues, supporting the retention of three factors. Finally, the PA with PCA analysis was conducted. Within this approach, eigenvalues greater than the corresponding mean random eigenvalue (Dinno, 2009) are retained. For the fourth factor, the raw data eigenvalues were lower than the associated mean values, offering further support for the three factor solution. 


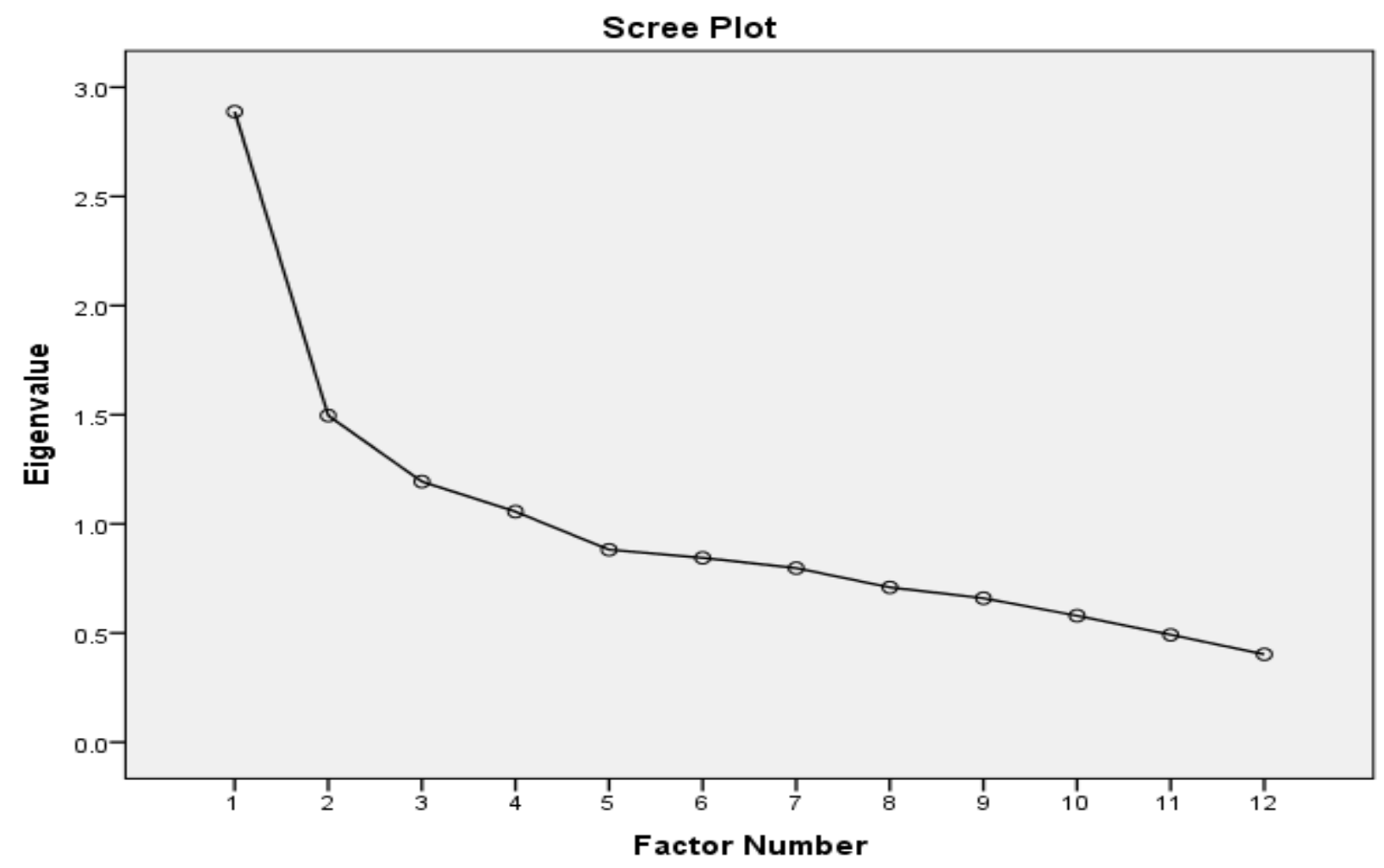

Figure 3. Scree plot depicting number of factors extracted.

Table 1 presents the factor loadings for the three extracted factors. Indicators were selected if their loading was greater than .3 on only one factor (Costello \& Osbourne, 2005). This yielded five indicators of factor one (participating in open events at the school), two indicators of factor two (communicating with teachers), and three indicators of factor three (participating in school-based groups). This represents the factor structure that was tested for the full sample via CFA.

Table 1

Pattern Matrix of Factor Loadings for Selected Indicators

Factor

$\begin{array}{llll}\text { Parent Involvement Indicator } & 1 & 2 & 3\end{array}$ 
Parent Involvement Indicator

Volunteered at school

Attended sporting event

Attended school event

Participated in fundraising

Attended back to school night

Attended parent-teacher conferences

Parent came in for informal meeting

Attended parent advisory group

Served on a school committee
1

.785

.372

.345

.327

.311
$2 \quad 3$ 
capabilities for accommodating the complex sampling design used for the ECLS-K. Specifically, the Complex analysis type available in Mplus allows for use of the school ID variable as a cluster ID to account for students nested within schools while also allowing for the application of sampling weights (W2PO) provided by NCES. Weighted least squares with mean and variance adjustment (WLSMV) estimation was used given the dichotomous measurement of the variables included in the CFA model.

Prior to running the analyses, several checks were made to ensure the appropriateness of CFA given the characteristics of the sample data. First, sample size was taken into consideration. Though there is mixed guidance on the sample size requirements of CFA, the ECLS-K is a large-scale database that easily meets the preferred criterion of samples sizes greater than 200 described by DiStefano and Hess (2005). Missing data issues were also addressed, as approaches such as listwise deletion of cases with missing values could reduce sample sizes considerably. An added benefit of using Mplus software is that it makes use of all available data rather than deleting cases with missing values by employing maximum likelihood estimation techniques (Muthén \& Muthén, 1998-2012). However, data were first evaluated to determine if any items were missing large amounts of data or if patterns of missingness were associated with the identified subgroups. The percentage of missing responses across the indicators used in this study ranged from $14.7 \%$ to $32 \%$. This reflects a typical, if not high, rate of response for survey-based research (Baruch \& Holtom, 2008). More importantly, the patterns of missingness indicated that there were no systematic differences in the amount of missing data for the included subgroups. The implications of missing data for the present study and directions for future research will be addressed in Chapter 5. Finally, model identification was considered. Identification refers to whether or not model parameters 
are estimable (Bollen \& Bauldry, 2010) and can be compromised when the number of items measuring a factor is small (Bollen, 1989). To minimize the possibility of identification problems during the CFA, only those factors with appropriate factor loadings for at least two items should be included in the confirmatory model. All identified factors had at least two such indicators. Also, for each factor, the item with the largest EFA factor loading was selected to serve as the marker variable for that factor in the CFA, and its loading was fixed at 1 (Byrne, 2004).

Based on the factor structure indicated by the EFA, an Mplus command file was created in which items were grouped together to reflect their common factor, with marker variables fixed at 1 as previously described. This model was run to determine if the EFAimplied factor structure could be confirmed among the full sample. The initial CFA model was then evaluated using several indicators of model fit.

Model fit refers to the extent to which any discrepancies between the variancecovariance matrices, one implied by the model and the other derived from the observed data, are attributable to sampling error only (Kline, 2011). Chi-square values are a commonly used measure and can be interpreted as a statistical test; however, they are sample size-dependent and often indicate model fit that is incongruous with other measures (Anderson \& Gerbing, 1984). Like Chi-square, the Root Mean Square Error of Approximation (RMSEA) is an absolute fit index that indicates the amount of discrepancy between the model and observed data, but it also takes into account model complexity. The Comparative Fit Index (CFI) and Tucker Lewis index (TLI) are incremental fit indices that reflect the relative improvement in model fit of the tested model over a model that hypothesizes no relationships among the variables and is not contingent upon sample size. Commonly applied rules of thumb suggest that good model 
fit is indicated by CFI values above .95 , TLI values greater than .90 (Kenny, 2014), and by an RMSEA value less than .06 (Hu \& Bentler, 1999).

In cases where initial model fit statistics fail to meet established benchmarks, modification indices can be requested in Mplus. These provide an indication of how model fit statistics might be improved by the addition or removal of particular parameters. Modification indicators were evaluated and applied only if the initial model fit was unacceptable and if there was sound conceptual reason for making specified changes to the model.

Multiple groups SEM with latent means. A primary question of interest in the present study is if parent involvement, as a reflection of cultural capital, may be measured similarly for different sociocultural groups with access to different forms of cultural capital and if parent involvement relates to early student achievement in similar ways. This question necessitated a multiple groups SEM with latent means modeled, positing relationships between observed items and latent constructs as well as between latent constructs and observed outcomes. CFA techniques were used to test for measurement invariance between groups, testing for equivalence between groups on the means of the latent factors, and finally testing equivalence of the relations between the parent involvement factors and the achievement outcomes.

Measurement model. CFA approaches are frequently employed to provide evidence of the construct validity of assessments and other measures of psychological constructs (DiStefano \& Hess, 2005). A great deal of literature on CFA recognizes the importance of establishing the validity of constructs among multiple groups of respondents for verifying that observed scores are not a reflection of construct-irrelevant variance such as what might be attributed to membership in a particular subgroup (French 
\& Finch, 2006). In other words, if group membership is associated with factors other than the construct of interest that influence response patterns, then scores derived from the instrument would not be comparable across groups.

To explore measurement invariance across the subgroups of interest in the present study, a series of multiple groups CFA models were run. This process involved defining the groups of interest by the grouping variables described previously and then adding a series of constraints to the models. The first two sets of constraints are considered the most important for establishing measurement invariance, or the degree to which equivalent measures of a common construct would be produced from an instrument applied under different conditions (Meade \& Bauer, 2007). In this case, the different conditions were defined by subgroup membership. The first stage of the multiple group models involved constraining only the pattern of factor loadings across subgroups to be equal. This step provides an indication of whether or not the same items loaded on the same factors for all groups (i.e., configural invariance). This established the baseline multiple group model, the fit of which was evaluated based on the chi-square, CFI, and RMSEA values separately for each group.

Next, the factor loadings themselves were constrained to be equal, thus testing a model in which the degree to which the underlying factors related to each item was equivalent across groups. Invariance of factor loadings establishes weak invariance (Wu, Li, \& Zumbo, 2007).This model was then compared to the baseline model using the chisquare difference test. This tests the null hypothesis that the designated parameters are invariant across groups. A statistically significant difference in chi-square values between the models being compared would indicate that this assumption of invariance should be rejected; a non-significant difference in chi-square would indicate that the model with 
parameters set to be equal is the preferred model. Although rules of thumb for comparing differences between models on other model fit statistics have been discussed (see Cheung \& Rensvold, 2002, and Chen, 2007), the present study followed the recommendations of Vandenberg and Lance (2000) and used the chi-square difference test as the primary means of evaluating model differences.

If weak invariance among all factors could not be established, then a series of tests were run to determine if there was partial invariance across groups. A series of models were run in which invariance of each factor and each indicator were tested separately (Byrne, Shavelson, \& Muthen, 1989). The next set of constraints were then added to test for strict invariance ( $\mathrm{Wu}, \mathrm{Li}, \&$ Zumbo, 2007) of any individual factors for which weak invariance could be established. Strict invariance is established by holding the residual variances of the factor indicators to be equal across groups. If measurement invariance beyond configural invariance could not be established, then the parent involvement factors and their relations to achievement outcomes would need to be evaluated within each subgroup, without making comparisons across subgroups.

The final constraint added to the measurement model was a test of invariance of factor means for any factors for which at least partial measurement invariance was established. Equivalence across groups on factor means would signify that the latent constructs were comparable enough across groups that it would be appropriate to make cross-group comparisons of average values on the constructs. Comparison of latent means has been described as a powerful tool for testing hypotheses about the influences that sociocultural factors might have on latent constructs (Little, 1997). Non-equivalence across subgroups would therefore present an interesting finding on its own. 
Invariance in latent means, along with information from the preceding invariance tests would indicate that the school-based parent involvement factors were equivalent for the identified groups and that the relations between involvement and achievement held for the full sample, regardless of membership in the identified subgroups. However, if invariance could not be established at a particular level of testing, then the prior model was used as the final model and run separately for each subgroup and interpreted accordingly.

Structural model. The posited model contained a structural component in which paths from the involvement factors lead to the achievement outcome, indicating a relation between involvement and achievement. To each best-fitting measurement model, achievement outcomes were added and regressed on the three parent involvement factors. The fit indices of these models provided a baseline to which a final constraint was added. Paths between factors for which at least partial measurement invariance had been established were constrained to be equal across groups. This provided an indication of whether or not the relation between involvement factors and achievement were the same for the identified groups. Table 2 summarizes the series of multiple groups SEM models run.

Table 2

Multiple Groups SEM Analyses Predicting each Achievement Type from Parent Involvement

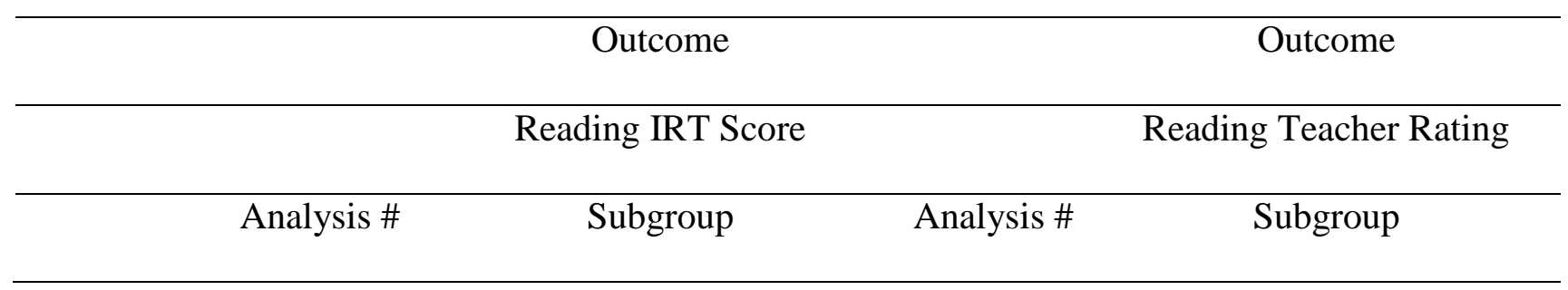




\begin{tabular}{|c|c|c|c|c|c|}
\hline \multirow{4}{*}{ 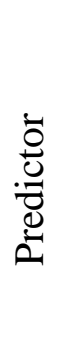 } & $\breve{\Xi}$ & 1 & Race/ethnicity & 2 & Race/ethnicity \\
\hline & $\stackrel{0}{2}$ & 3 & Parent education & 4 & Parent education \\
\hline & $\gtrsim$ & 5 & Parent occupational prestige & 6 & Parent occupational prestige \\
\hline & ص̈ & 7 & Primary Language & 8 & Primary Language \\
\hline
\end{tabular}

One final step was to account for the potentially moderating effects of the type of school attended on the relation between involvement and achievement. To do so, the final subgroup-specific models regressing student reading achievement on the involvement factors were rerun separately for students from public and non-public schools. This approach demonstrates whether there are patterns of difference in the involvementachievement relationships among the subgroups across the school types but does not allow for quantification of these moderation effects or analysis of their statistical significance. The implications of this approach and directions for future research will be discussed in Chapter 5.

\section{Using Multiple Groups SEM to Understand the Relationship between Parent Involvement and Achievement}

Accounting for cross-cultural differences in the measurement of constructs is an important step for testing the validity of assertions about the relations between variables in the larger population (Little, 1997). This study sought to establish a factor structure underlying multiple indicators of parent involvement at school that reflected different forms of cultural capital requirements. As forms of cultural capital to which families have access are shaped by broader social and cultural factors, it was important to determine if these cultural capital-infused parent involvement factors were measured similarly across groups identified by multiple sociocultural characteristics and if subgroup membership 
moderated the relationships between involvement and achievement. These analyses thus served as a basis for further understanding the role that school-based parent involvement may play in early achievement outcomes across multiple subgroups, while also accounting for the potential moderating effects of school type. Results from the analyses are presented in the next chapter. 


\section{CHAPTER 4}

\section{RESULTS}

This chapter presents the results obtained from the methods described in the previous chapter. First, the procedure of testing the fit of the factor structure identified by the EFA to the full sample is discussed. The remainder of the results are organized around the eight analyses listed in Table 2 and include discussions of the tests for measurement invariance across subgroups, the relations between the parent involvement factors and achievement across subgroups, and the potential for the additional moderating effect of school type. Because measurement invariance had to be tested prior to adding covariates to the model, the eight analyses have been collapsed into four sections, with each achievement outcome presented as a separate subsection within.

\section{Confirmatory Factor Analysis Using the Full Sample}

The factor structure implied by the EFA was first run using the full sample as described in the Methods chapter. This initial model resulted in a Heywood case (Kline, 2011), due to a negative error variance associated with one of the factor indicators ('Served on a school committee'). The modification indices suggested a possible crossloading, suggesting that the variance of the problematic indicator might be accounted for by more than one of the posited factors (participating in open school events and communicating with teachers). Next, a modified model including this crossloading was run and yielded adequate model fit (chi-square $=611.15, p<.001 ;$ RMSEA $=.03$; $\mathrm{CFI}=.96 ; \mathrm{TLI}=.94)$. An alternate model in which this indicator was removed was also 
run and yielded good model fit (chi-square $=191.45, p<.001 ; \mathrm{RMSEA}=.02 ; \mathrm{CFI}=.98$; TLI= .98). Kline (2011) recommends adding crossloadings only if they are clearly justified by theory. Given the exploratory nature of the present study, the decision was made to remove the problematic item. The final CFA that was used in the remainder of the study included five indicators for factor 1 (participating in open school events), and two indicators each for factors 2 (communicating with teachers) and 3 (participating in school-based organizations). Figure 4 depicts the final CFA model.

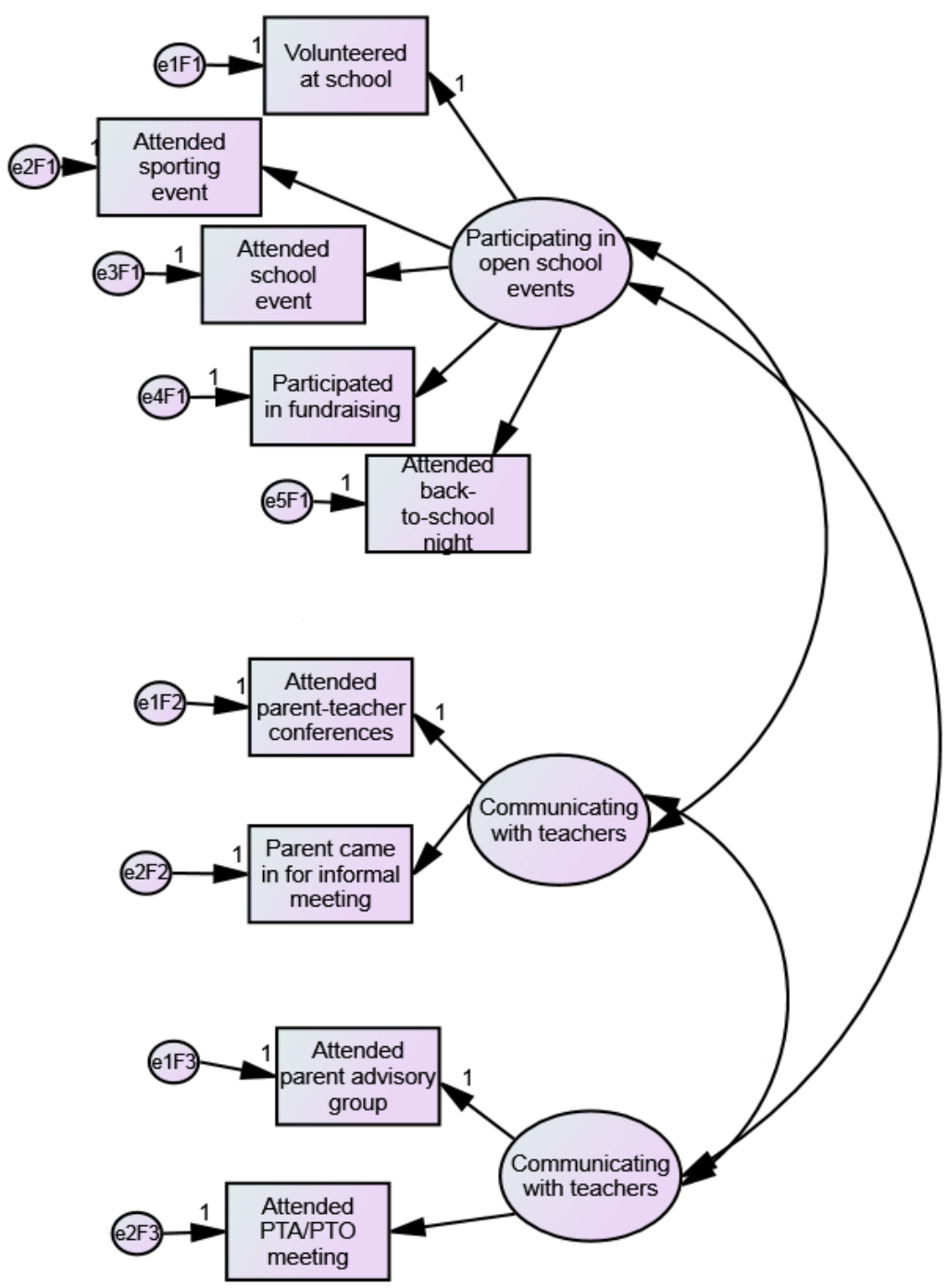

Figure 4. Final model of school-based parent involvement factors. 


\section{Analyses 1 and 2: Racial/Ethnic Subgroups}

Testing for measurement invariance. The first step in this process involved running the model separately for each group to obtain model fit statistics for each group separately. As expected with the very large sample sizes used in this study, chi-square statistics tended to be significant, indicating poor model fit. The two smaller racial/ethnic groups however, had non-significant chi-square values, indicating good fit. For all racial/ethnic groups, RMSEA, CFI, and TLI indicated good model fit (see Table 3).

Next, all racial/ethnic groups were included in a single model with parameters freely varying between the groups. This provided a baseline model with which to compare equality constraints across the groups. This model established configural invariance, in which the underlying factor structure was common across groups, but all parameters were allowed to vary freely across groups. Model fit statistics indicated good model fit $($ chi-square $=361.62, p<.001 ; \mathrm{RMSEA}=.02 ; \mathrm{CFI}=.98 ; \mathrm{TLI}=.96)$.

Next, the constraints were added to the model to test invariance of factor loadings across the racial/ethnic groups. The chi-square difference test was statistically significant $(p<.001)$, indicating that that assumption of invariance of factor loadings should be rejected. Tests for partial invariance as described in the Methods chapter were run, all indicating that invariance of factor loadings for any individual factor or item could not be established. This suggests that though the same items tend to be explained by common factors across all racial/ethnic groups, the variability in the observed scores explained by these factors was different enough to indicate that the underlying factors were not the same for each group. Therefore, cross-group comparisons of the factors and their relations to other variables would not be appropriate. The relations between the parent involvement factors and achievement were thus modeled separately for each group. 
Table 3

Tests of Measurement Invariance across Racial/Ethnic Subgroups

\begin{tabular}{|c|c|c|c|c|c|c|c|}
\hline Subgroup & df & Chi-square & & RMSEA & CFI & TLI & \\
\hline White & 20 & 96.33 & & .02 & .98 & 98 & \\
\hline Black & 20 & 60.70 & & .03 & .99 & .98 & \\
\hline Hispanic & 20 & 90.85 & & .03 & .98 & .96 & \\
\hline Asian & 20 & $25.27(p=.39)$ & & .01 & 1.00 & 1.00 & \\
\hline Other & 20 & $34.28(p=.08)$ & & .02 & .98 & .97 & \\
\hline Model & & & $\begin{array}{l}\text { Chi-square } \\
\text { difference }\end{array}$ & & & & Preferred Model \\
\hline Configural & 120 & 361.62 & & .02 & 98 & .96 & \\
\hline Weak & 140 & 446.11 & 93.20 & .03 & .97 & .96 & Configural \\
\hline \multicolumn{8}{|l|}{ Partial } \\
\hline $\mathrm{F} 1$ & 150 & 991.06 & 578.57 & .04 & .92 & .90 & Configural \\
\hline $\mathrm{F} 2$ & 140 & 679.14 & 299.04 & .03 & .95 & .93 & Configural \\
\hline F3 & 140 & 699.76 & 302.92 & .04 & .95 & .93 & Configural \\
\hline F1 Item 1 & 140 & 698.90 & 312.16 & .04 & .95 & .93 & Configural \\
\hline F1 Item 2 & 140 & 704.98 & 321.28 & .04 & .95 & .93 & Configural \\
\hline F1 Item 3 & 136 & 724.82 & 349.18 & .04 & .94 & .93 & Configural \\
\hline F1 Item 3 & 136 & 826.61 & 407.12 & .04 & 93 & 91 & Configural \\
\hline
\end{tabular}

Note. Degrees of freedom have been rounded due to use of restricted data set. Chi-square and chi-square difference tests are statistically significant $(p<.001)$ unless otherwise noted. F1, F2, and F3 refer to Factors 1 (participating in open school events), 2 (communicating with teachers), and 3 (participating in school-based organizations). In rows testing partial invariance, only the listed factor or item was held invariant across groups, while other factor loadings freely varied. 
The relationship between parent involvement and achievement. The next set of analyses were conducted using two different measure of achievement. First, the relationship between parent involvement factors and reading IRT scores is discussed, followed by the relationship between parent involvement factors and teacher ratings of literacy skills. Because measurement invariance was not established, results are presented separately for each racial/ethnic subgroup.

Parent involvement and reading IRT scores. The upper portion of Table 4 summarizes the results of the model in which the three parent involvement factors were posited as having a direct relationship with reading IRT scores among white students. Unstandardized coefficients can be interpreted as the expected change in reading IRT score for every unit increase in the factor. Of the three factors, only the participating in open school events factor had a statistically significant relationship. For every one unit increase in participating in open school events, reading IRT scores among white students would be expected to increase 2.74 points.

The bottom portion of Table 4 illustrates tests the potential moderating effect of school type. When school type is taken into account, participating in open school events has a statistically significant, positive relationship with reading IRT scores for white students in public schools only.

Table 4

Unstandardized Regression Results Predicting Reading IRT Scores among White

\section{Students}

\begin{tabular}{lcccc}
\hline & Parent involvement factor & Unstandardized coefficient & Standard error & $p$ \\
\hline Across & Open events & 2.74 & 0.51 & $<.001$
\end{tabular}




\begin{tabular}{llccc} 
schools & Teacher communication & 0.32 & 0.24 & .18 \\
& School-based organizations & -0.64 & 0.46 & .16 \\
\hline Public & Open events & 3.40 & 0.67 & $<.001$ \\
& Teacher communication & 0.24 & 0.24 & .31 \\
& School-based organizations & -1.24 & 0.62 & .05 \\
\multirow{2}{*}{ Non- } & Open events & 1.06 & 0.80 & .19 \\
Public & Teacher communication & -0.34 & 0.93 & .71 \\
& School-based organizations & 0.70 & 1.00 & .48 \\
\end{tabular}

Table 5 presents results for the same analyses among the black subgroup only. The upper portion of the table indicates that only the participating in open school events has a statistically significant relationship with reading IRT scores among black students, such that a one-unit increase in participating in open school events would yield an expected increase of 5.22 points in reading IRT score. When school type was taken into account, there was still a positive, statistically significant relationship between participating in open school events and reading IRT scores among black students in public schools. The model estimated for black students in non-public schools was empirically underidentified, indicating that model parameters could not be reliably estimated with this sample (Kenny, 1979).

Table 5

Unstandardized Regression Results Predicting Reading IRT Scores among Black Students 


\begin{tabular}{llccc}
\hline Across & Open events & 5.22 & 1.44 & $<.001$ \\
schools & Teacher communication & 0.06 & 0.19 & .74 \\
& School-based organizations & -1.57 & 1.34 & .24 \\
& Open events & 3.07 & 1.33 & .02 \\
\multirow{2}{*}{ Public } & Teacher communication & 0.15 & 0.35 & .67 \\
& School-based organizations & 0.82 & 0.81 & .31 \\
& Open events & & & \\
Non- & Teacher communication & & Not identified & \\
public & School-based organizations & & & \\
& & & & \\
\hline
\end{tabular}

Table 6 presents results for the same analyses among the Hispanic subgroup only. The top portion of the table indicates that the participating in open school events and participating in school-based organizations factors have statistically significant relationships with reading IRT scores among Hispanic students. For every unit increase in participating in open school events, reading IRT scores among Hispanic students can be expected, on average, to increase 12.27 points. Conversely, a one-unit increase in participating in school-based organizations is associated with an average loss of 13.23 score points. When school type is taken into account, there are statistically significant relationships among Hispanic students in public schools only.

Table 6

Unstandardized Regression Results Predicting Reading IRT Scores among Hispanic Students

Parent involvement factor $\quad$ Unstandardized coefficient $\quad$ Standard error $\quad p$ 


\begin{tabular}{|c|c|c|c|c|}
\hline Across & Open events & 12.27 & 2.06 & $<.001$ \\
\hline \multirow[t]{3}{*}{ schools } & Teacher communication & -0.86 & 0.58 & .14 \\
\hline & School-based organizations & -.13 .23 & 2.49 & $<.001$ \\
\hline & Open events & 10.91 & 2.13 & $<.001$ \\
\hline \multirow[t]{2}{*}{ Public } & Teacher communication & -0.29 & 0.49 & .55 \\
\hline & School-based organizations & -12.41 & 2.82 & $<.001$ \\
\hline \multirow{3}{*}{$\begin{array}{l}\text { Non- } \\
\text { public }\end{array}$} & Open events & 14.23 & 16.06 & .38 \\
\hline & Teacher communication & 0.42 & 1.32 & .75 \\
\hline & School-based organizations & -11.92 & 15.14 & .43 \\
\hline
\end{tabular}

Table 7 presents results for the same analyses among the Asian subgroup only. None of the parent involvement factors has a statistically significant relationship with reading IRT scores among Asian students, and this pattern continued when school type was taken into account. This suggests that increases in the parent involvement factors are not associated with changes in IRT reading scores among Asian students, regardless of school type.

Table 7

Unstandardized Regression Results Predicting Reading IRT Scores among Asian Students

\begin{tabular}{llccc}
\hline & & Unstandardized coefficient & Standard error & $p$ \\
\hline Across & Open events & 1.33 & 2.47 & .59 \\
\multirow{2}{*}{ schools } & Teacher communication & 4.97 & 3.64 & .17 \\
& School-based organizations & -2.59 & 1.64 & .11 \\
\hline
\end{tabular}




\begin{tabular}{llccc}
\hline \multirow{3}{*}{ Public } & Open events & 2.74 & 2.77 & .32 \\
& Teacher communication & 4.71 & 4.28 & .27 \\
& School-based organizations & -2.36 & 1.81 & .19 \\
& Open events & -3.46 & 5.67 & .54 \\
Non-public & Teacher communication & 10.93 & 7.66 & .15 \\
& School-based organizations & 6.19 & 8.14 & .45 \\
\hline
\end{tabular}

Table 8 presents results for the same analyses among other racial/ethnic subgroups only. The top portion of the table indicates that only the communicating with teachers factor has a statistically significant relationship with reading IRT scores among other racial ethnic subgroups. A unit increase in communicating with teachers is associated with an average increase of 4.42 points in reading IRT score.

When school type is taken into account, there is a statistically significant positive relationship between the communicating with teachers factor and reading IRT scores among other racial/ethnic subgroups in public schools. The model estimated for students in other racial/ethnic subgroups in non-public schools yielded a Heywood case and was thus uninterpretable.

Table 8

Unstandardized Regression Results Predicting Reading IRT Scores among Students of Other Racial/Ethnic Backgrounds

\begin{tabular}{llccc}
\hline & Parent involvement factor & Unstandardized coefficient & Standard error & $p$ \\
\hline Across & Open events & -0.41 & 1.35 & .76 \\
\multirow{2}{*}{ schools } & Teacher communication & 4.42 & 1.76 & .01 \\
& School-based organizations & -0.19 & 1.83 & .92 \\
\hline
\end{tabular}




\begin{tabular}{lllll}
\hline & Open events & -1.13 & 1.61 & .48 \\
Public & Teacher communication & 4.23 & 1.77 & .02 \\
& School-based organizations & -0.65 & 2.36 & .78 \\
Non- & Open events & & & \\
public & Teacher communication & & Heywood case & \\
& School-based organizations & & \\
\hline
\end{tabular}

Parent involvement and teacher literacy ratings. The upper portion of Table 9 summarizes the results of the model in which the three parent involvement factors were posited as having a direct effect on teacher literacy ratings among white students.

Participating in open school events and communicating with teachers factors have statistically significant relationships with teacher literacy rating. For every unit increase in participating in open school events, teacher literacy ratings among white students are expected to increase an average of 0.20 points. For every unit increase in communicating with teachers, teacher literacy ratings among white students are expected to increase an average of 0.07 points.

When school type is taken into account, there are statistically significant positive relationships with the participating on open school events and communicating with teachers factors among white students in public schools only. There are no statistically significant relationships between the parent involvement factors and teacher literacy ratings among white students in non-public schools.

Table 9

Unstandardized Regression Results Predicting Teacher Literacy Ratings among White Students 


\begin{tabular}{lllcc}
\hline & Parent involvement factor & Unstandardized coefficient & Standard error & $p$ \\
\hline Across & Open events & 0.20 & 0.05 & $<.001$ \\
schools & Teacher communication & 0.07 & 0.03 & .01 \\
& School-based organizations & -0.08 & 0.05 & .08 \\
\hline Public & Open events & 0.22 & 0.06 & $<.001$ \\
& Teacher communication & 0.07 & 0.03 & .02 \\
& School-based organizations & -0.11 & 0.06 & .06 \\
Non- & Open events & -0.07 & 0.07 & .39 \\
Public & Teacher communication & 0.04 & 0.06 & .49 \\
& School-based organizations & 0.05 & 0.08 & .58 \\
& & & & \\
\hline
\end{tabular}

The upper portion of Table 10 summarizes the results of the model in which the three parent involvement factors were posited as having a direct relationship with teacher literacy ratings among black students. Only participating in open school events has a statistically significant positive effect on teacher literacy ratings among black students.

When school type is taken into account, there is a positive, statistically significant relationship between the participating in open school events factor and teacher literacy ratings among black students in public schools. The model estimated for black students in non-public schools yielded a Heywood case and was thus uninterpretable.

Table 10

Unstandardized Regression Results Predicting Teacher Literacy Ratings among Black Students

Parent involvement factor $\quad$ Unstandardized coefficient $\quad$ Standard error $\quad p$ 


\begin{tabular}{lllll}
\hline Across & Open events & 0.23 & 0.10 & .02 \\
schools & Teacher communication & 0.02 & 0.03 & .41 \\
& School-based organizations & 0.03 & 0.08 & .76 \\
\hline Public & Open events & 0.22 & 0.11 & .04 \\
& Teacher communication & 0.03 & 0.03 & .34 \\
& School-based organizations & 0.04 & 0.08 & .62 \\
Non- & Open events & & & \\
Public & Teacher communication & & Heywood case & \\
& School-based organizations & & & \\
& & & & \\
\hline
\end{tabular}

The upper portion of Table 11 summarizes the results of the model in which the three parent involvement factors were posited as having a direct effect on teacher literacy ratings among Hispanic students. Only the participating in open school events factor had a statistically significant, positive relationship with teacher literacy ratings among Hispanic students.

When school type was taken into account, there was a statistically significant positive relationship between participation in open school events and teacher literacy ratings among Hispanic students in public schools. There was also a statistically significant negative relationship between participation in school-based organizations and teacher literacy ratings among Hispanic students in public schools. There were no statistically significant relationships between any of the parent involvement factors and teacher literacy ratings among Hispanic students in non-public schools.

Table 11 
Unstandardized Regression Results Predicting Teacher Literacy Ratings among Hispanic

\section{Students}

\begin{tabular}{|c|c|c|c|c|}
\hline & Parent involvement factor & Unstandardized coefficient & Standard error & $p$ \\
\hline Across & Open events & 0.34 & 0.06 & $<.001$ \\
\hline \multirow[t]{2}{*}{ schools } & Teacher communication & 0.02 & 0.02 & .35 \\
\hline & School-based organizations & -0.05 & 0.04 & .16 \\
\hline \multirow[t]{3}{*}{ Public } & Open events & 0.34 & 0.06 & $<.001$ \\
\hline & Teacher communication & 0.02 & 0.03 & .48 \\
\hline & School-based organizations & -0.20 & 0.07 & .01 \\
\hline Non- & Open events & -0.07 & 0.08 & .39 \\
\hline \multirow[t]{2}{*}{ Public } & Teacher communication & 0.04 & 0.06 & .49 \\
\hline & School-based organizations & 0.05 & 0.08 & .58 \\
\hline
\end{tabular}

The upper portion of Table 12 summarizes the results of the model in which the three parent involvement factors were posited as having a direct effect on teacher literacy ratings among Asian students. None of the parent involvement factors have a statistically significant relationship with teacher literacy ratings among Asian students, and this pattern continued when school type was taken into account. This suggests that increases in the parent involvement factors are not associated with changes in teacher literacy ratings among Asian students, regardless of school type.

Table 12

Unstandardized Regression Results Predicting Teacher Literacy Ratings among Asian Students 


\begin{tabular}{lllcc}
\hline & Parent involvement factor & Unstandardized coefficient & Standard error & $p$ \\
\hline Across & Open events & 0.07 & 0.09 & .39 \\
schools & Teacher communication & 0.17 & 0.11 & .12 \\
& School-based organizations & 0.01 & 0.08 & .91 \\
\hline Public & Open events & 0.08 & 0.08 & .33 \\
& Teacher communication & 0.16 & 0.12 & .17 \\
& School-based organizations & 0.003 & 0.07 & .96 \\
Non- & Open events & -0.01 & 0.32 & .86 \\
Public & Teacher communication & 0.42 & 0.34 & .22 \\
& School-based organizations & 0.38 & 0.27 & .16 \\
\hline
\end{tabular}

Table 13 presents results for the same analyses among other racial/ethnic subgroups only. Only participating in open school events has a statistically significant, positive relationship with teacher literacy ratings among students from other racial/ethnic subgroups. When school type is taken into account, there are no significant associations between any of the factors and teacher literacy ratings among public school students from other racial/ethnic backgrounds. Results for non-public school students could not be interpreted due to the presence of a Heywood case.

Table 13

Unstandardized Regression Results Predicting Teacher Literacy Ratings among Students of Other Racial/Ethnic Backgrounds

\begin{tabular}{lcccc}
\hline & Parent involvement factor & Unstandardized coefficient & Standard error & $p$ \\
\hline Across & Open events & 0.18 & 0.09 & .04
\end{tabular}




\begin{tabular}{lllll} 
schools & Teacher communication & 0.06 & 0.06 & .34 \\
& School-based organizations & -0.11 & 0.14 & .42 \\
\hline Public & Open events & 0.16 & 0.09 & .09 \\
& Teacher communication & 0.05 & 0.06 & .45 \\
& School-based organizations & -0.10 & 0.18 & .57 \\
Non- & Open events & & & \\
Public & Teacher communication & \multicolumn{3}{c}{ Heywood case } \\
& School-based organizations & \multicolumn{3}{c}{}
\end{tabular}

\section{Analyses 3 and 4: Parent Education Subgroups}

Testing for measurement invariance. Table 14 presents the results from the tests of measurement invariance among parent education subgroups. The baseline model established configural invariance across the subgroups, but invariance of all factor loadings was not supported by the chi-square difference test (chi-square $=42.47, p<.001$ ). Tests for partial invariance indicated that the communicating with teachers factor loadings were invariant across subgroups, as well as four of the five indicators of the participating in open school events factor (including the marker variable). Because the majority of the participating in school events factor's indicators were established as invariant, it was considered acceptable to treat the factor as invariant (Vandenberg \& Lance, 2000). The final measurement model included these parameter constraints when testing the relationships between the parent involvement factors and reading achievement outcomes.

Table 14 Tests of Measurement Invariance across Parent Education Subgroups 


\begin{tabular}{|c|c|c|c|c|c|c|c|}
\hline Subgroup & $\mathrm{df}$ & Chi-square & & RMSEA & CFI & TLI & \\
\hline$<$ High school diploma & 20 & 67.73 & & .04 & .96 & .94 & \\
\hline High school diploma & 20 & 72.28 & & .03 & .98 & .98 & \\
\hline Postsecondary experience & 0 & 72.50 & & .02 & .98 & .97 & \\
\hline College degree or beyond & 20 & 79.61 & & .02 & .98 & .97 & \\
\hline Model & & & $\begin{array}{l}\text { Chi-square } \\
\text { difference }\end{array}$ & & & & $\begin{array}{c}\text { Preferred } \\
\text { Model }\end{array}$ \\
\hline Configural & 100 & 300.73 & & .02 & .98 & .97 & \\
\hline Weak & 110 & 338.08 & 42.47 & .02 & .98 & .97 & Configural \\
\hline Partial & & & & & & & \\
\hline $\mathrm{F} 1$ & 110 & 322.28 & $26.97(p=.01)$ & .02 & .98 & .97 & Configural \\
\hline $\mathrm{F} 2$ & 100 & 306.55 & $6.04(p=.11)$ & .02 & .98 & .97 & Partial \\
\hline F3 & 100 & 314.49 & $\begin{array}{c}15.73 \\
(p=.001)\end{array}$ & .02 & .98 & .97 & Configural \\
\hline F1 Item 1 & 100 & 301.11 & $2.59(p=.46)$ & .02 & .98 & .97 & Partial \\
\hline F1 Item 2 & 100 & 301.01 & $2.06(p=.56)$ & .02 & .98 & .97 & Partial \\
\hline F1 Item 3 & 100 & 307.19 & $7.96(p=.05)$ & .02 & .98 & .97 & Partial \\
\hline F1 Item 4 & 100 & 315.09 & $\begin{array}{c}14.58 \\
(p<.001)\end{array}$ & .02 & .98 & .97 & Configural \\
\hline
\end{tabular}

Note. Degrees of freedom have been rounded due to use of restricted data set. Chi-square and chi-square difference tests are statistically significant $(p<.001)$. In rows testing partial invariance, only the listed factor or item was held invariant across groups, while other factor loadings freely varied.

Because group differences in the parent involvement factors was of interest in this study, invariance of the means of the factors for which measurement invariance was 
established were tested. Invariance of means was only established for the communicating with teachers factor only (chi-square difference $=3.74 p=.15$ ), indicating that parent education subgroups had the same mean value for that factor. Subgroup means for the participating in open school events were estimated for all groups, with the less than high school diploma subgroup used to set the scale by holding their factor mean at 0 . Table 15 shows that mean scores on the participating in open school events factor increased as the level of parent education increased.

Table 15

Comparing Participating in Open School Events Factor Means among Parent Education Subgroups

\begin{tabular}{lc}
\hline Subgroup & Participating in open school events \\
\hline < High school diploma & 0.00 \\
High school diploma & 0.36 \\
Postsecondary experience & 0.85 \\
College degree or beyond & 1.59 \\
\hline
\end{tabular}

The relationship between parent involvement and achievement. The next set of analyses were conducted using two different measure of achievement. First, the relationship between parent involvement factors and reading IRT scores is discussed, followed by the relationship between parent involvement factors and teacher ratings of literacy skills.

Parent involvement and reading IRT scores. A test of invariance of paths between the factors for which measurement invariance had been established indicated that it was not appropriate to constrain the relations between these parent involvement 
factors and the achievement outcome to be equal (Participating in open school events factor: chi-square difference $=490.27, p<.001$; Communicating with teachers factor: chisquare difference $=604.87, p<.001)$. Table 16 compares the relations between the parent involvement factors for which measurement variance was established. Participating in open school events has a statistically significant, positive relationship among all the parent education subgroups. Using unstandardized coefficients allows for the magnitude of these relations to be compared. Increases in participation in open school events were associated with the highest increases in reading IRT scores among the group with less than a high school diploma. For every unit increase in parent participation in open school events, reading IRT score among students whose highest level of parent education is less than a high school diploma would be expected to increase by an average of 18.26 points.

The communicating with teachers factor had statistically significant relations with both the groups with high diploma and some postsecondary experience. These effects differed in both magnitude and direction. For the high school diploma subgroup, unit increases in communicating with teachers were associated with an average decrease of 0.89 score points. For the postsecondary experience subgroup, unit increases in communicating with teachers were associated with an average increase of 0.43 score points.

Table 16

Comparing Unstandardized Regression Results Predicting Reading IRT Scores among Parent Education Subgroups

\begin{tabular}{cccl}
\hline Parent & Subgroup & Unstandardized coefficient & Standard error
\end{tabular}




\begin{tabular}{|c|c|c|c|c|}
\hline factor & & & & \\
\hline & $<$ High school diploma & 18.26 & 7.61 & .02 \\
\hline Open school & High school diploma & 11.16 & 2.79 & $<.001$ \\
\hline \multirow[t]{3}{*}{ events } & Postsecondary experience & 1.82 & 0.55 & .001 \\
\hline & College degree or beyond & 1.76 & 0.51 & .001 \\
\hline & $<$ high school diploma & -1.25 & 0.86 & .14 \\
\hline Teacher & High school diploma & -0.89 & 0.42 & .03 \\
\hline \multirow[t]{2}{*}{ communication } & Postsecondary experience & 0.43 & 0.20 & .03 \\
\hline & College degree or beyond & 0.47 & 0.27 & .08 \\
\hline \multicolumn{5}{|l|}{ School-based } \\
\hline organizations & & Not comparable & & \\
\hline
\end{tabular}

Table 17 presents results when school type was taken into account. Only results for students in public schools were interpretable due to a Heywood case when the model was run using non-public school students only. Table 17 shows that in public schools, participation in open school events had a positive and statistically significant relationship with reading IRT scores only among students whose parents had a high school diploma or less. In contrast, communicating with teachers had a positive and statistically significant relationship with reading IRT scores only among public school students whose parents had at least some postsecondary experience.

Table 17

Comparing Unstandardized Regression Results Predicting Reading IRT Scores among Parent Education Subgroups: Comparable Factors by School Type 


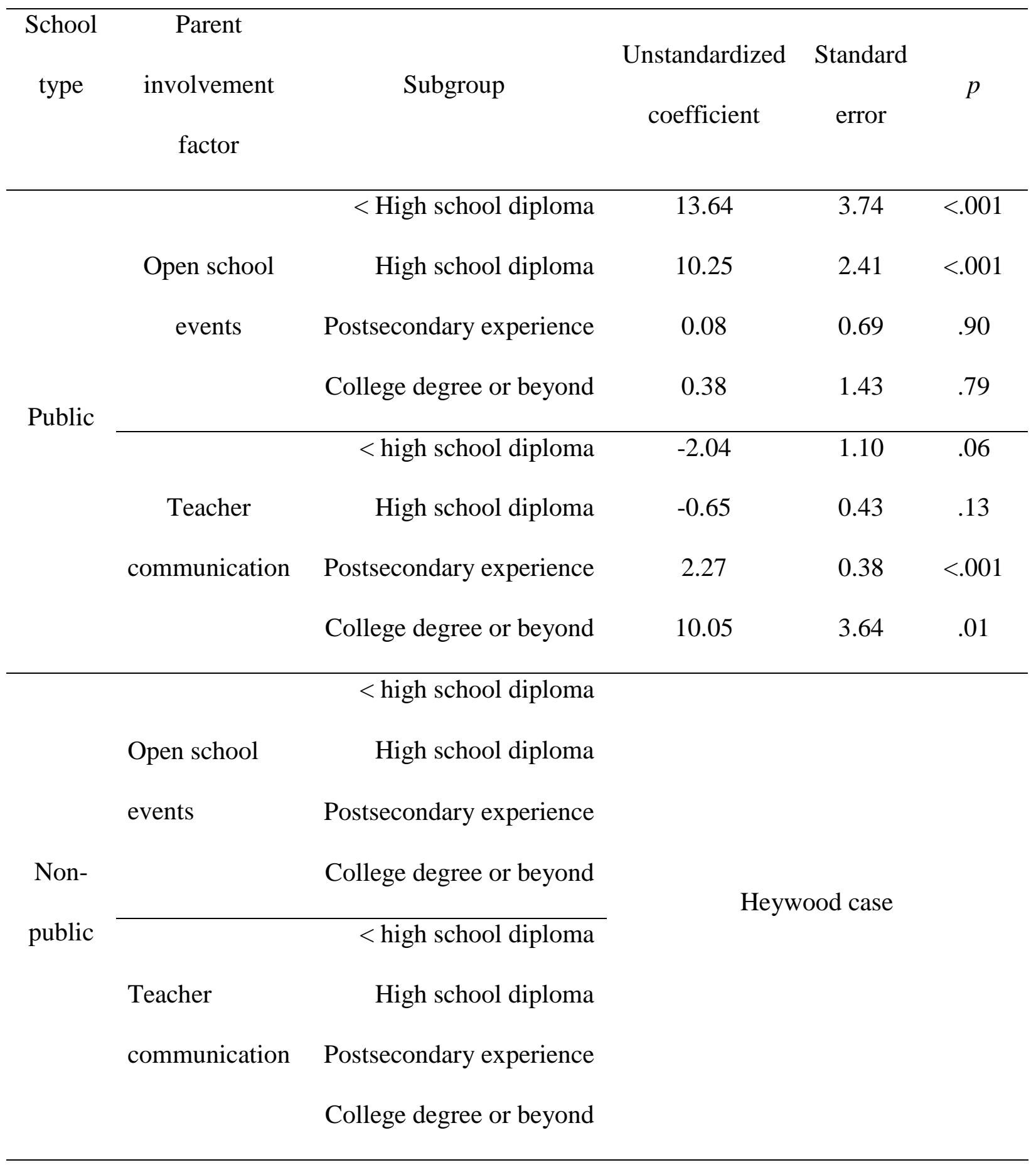

Table18 presents the relation between the participating in school-based organizations and reading IRT scores separately for each parent education subgroup. Table 18 shows that participating in school-based organizations has a statistically significant, negative relationship with reading IRT scores for the subgroups with a high 
school diploma or less but no statistically significant relationship was observed among the postsecondary experience and college degree or beyond subgroups. When school type was taken into account, a statistically significant, negative relationship between participating in school-based organizations and reading IRT scores was observed among students in public schools for all groups except for the group with some parent postsecondary experience. Results were not interpretable for non-public schools due to a Heywood case.

Table 18

Unstandardized Regression Results Predicting Reading IRT Scores for Participating in School-Based Organizations by Parent Education Subgroup and by School Type

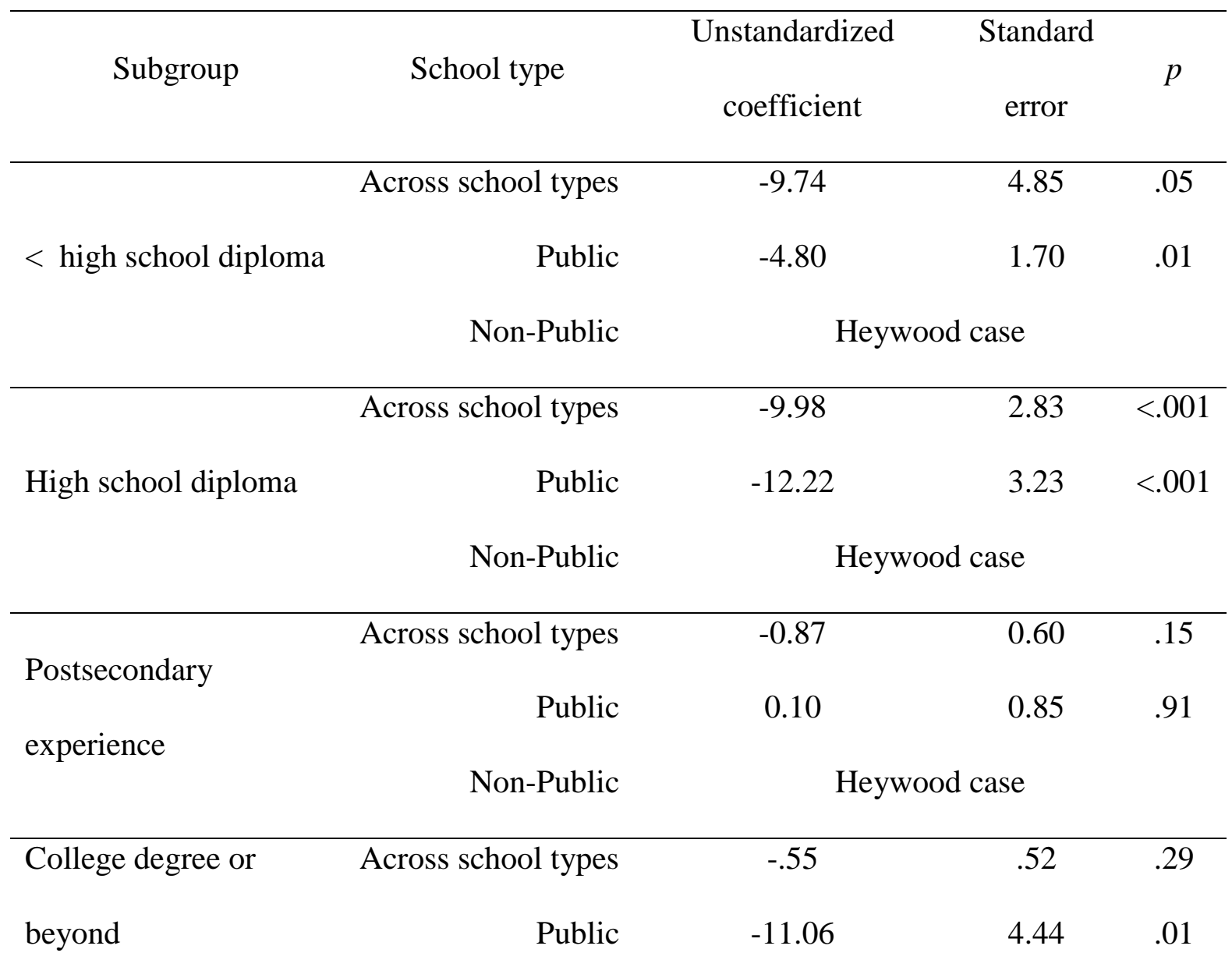

Note. Coefficients are not comparable between the parent education subgroups. 
Parent involvement and teacher literacy ratings. A test of invariance of paths between the factors for which measurement invariance had been established yielded a Heywood case, so these relationships were estimated for each group. Table 19 compares the regression results for the two comparable factors. Participating in open school events has a statistically significant, positive relationship with teacher literacy ratings among all but the college degree or beyond subgroup. The relationship is strongest among the less than high school diploma group, with a unit increase in participating in open school events associated with a 0.44 -unit increase in teacher literacy rating. Communicating with teachers has a small, positive, statistically significant relationship with teacher ratings among the postsecondary experience and college degree or beyond subgroups only.

Table 19

Comparing Unstandardized Regression Results Predicting Reading Teacher Ratings among Parent Education Subgroups

Parent

involvement $\quad$ Subgroup $\quad$ Unstandardized coefficient $\quad$ Standard error $p$ factor

\begin{tabular}{crccc}
\hline \multirow{3}{*}{ Open school } & < High school diploma & 0.44 & 0.15 & .003 \\
\multirow{2}{*}{ events } & High school diploma & 0.21 & 0.06 & $<.001$ \\
& Postsecondary experience & 0.12 & 0.05 & .01 \\
& College degree or beyond & 0.07 & 0.04 & .09 \\
\hline
\end{tabular}




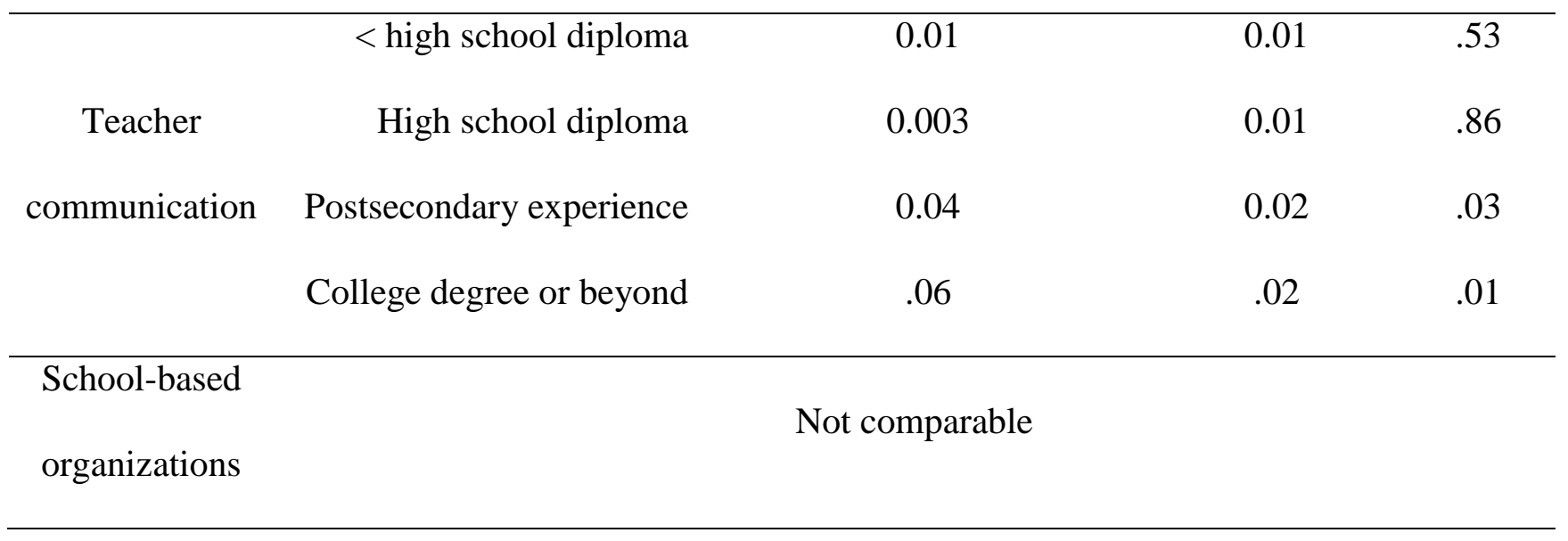

Table 20 explores the potential for moderating effects of school type on the relations between the participating in open school events and communicating with teachers factors and teacher literacy ratings across the education subgroups. Results for public school students were not interpretable due to a Heywood case. Among students in non-public schools, there were no statistically significant relationships between the participating in open school events and communicating with teachers factors and teacher literacy ratings for any of the parent education subgroups.

Table 20

Comparing Unstandardized Regression Results Predicting Teacher Literacy Ratings among Parent Education Subgroups: Comparable Factors by School Type

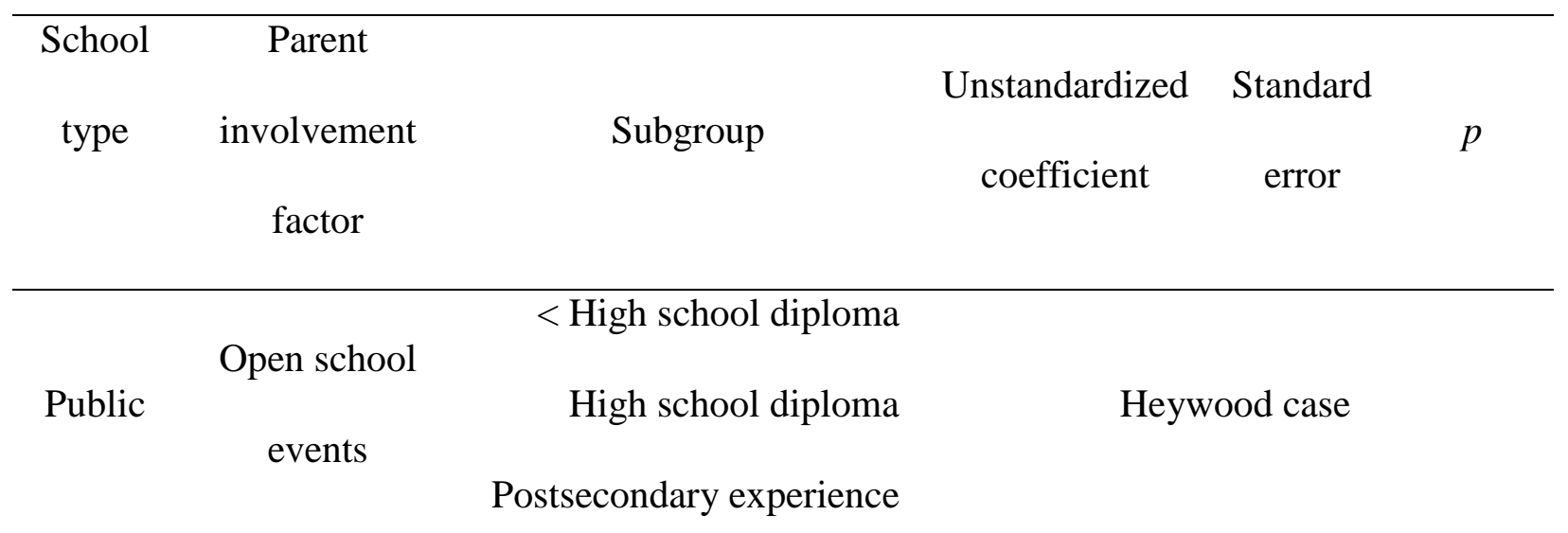




\begin{tabular}{|c|c|c|c|c|c|}
\hline $\begin{array}{l}\text { School } \\
\text { type }\end{array}$ & $\begin{array}{c}\text { Parent } \\
\text { involvement } \\
\text { factor }\end{array}$ & Subgroup & $\begin{array}{c}\text { Unstandardized } \\
\text { coefficient }\end{array}$ & $\begin{array}{l}\text { Standard } \\
\text { error }\end{array}$ & $p$ \\
\hline & $\begin{array}{c}\text { Teacher } \\
\text { communication }\end{array}$ & $\begin{array}{r}\text { College degree or beyond } \\
\text { high school diploma } \\
\text { High school diploma } \\
\text { Postsecondary experience } \\
\text { College degree or beyond }\end{array}$ & & & \\
\hline Non- & $\begin{array}{l}\text { Open school } \\
\text { events }\end{array}$ & $\begin{array}{r}<\text { high school diploma } \\
\text { High school diploma } \\
\text { Postsecondary experience } \\
\text { College degree or beyond }\end{array}$ & $\begin{array}{l}0.98 \\
0.20 \\
0.18 \\
-0.13\end{array}$ & $\begin{array}{l}0.54 \\
0.18 \\
0.13 \\
0.09\end{array}$ & $\begin{array}{l}.07 \\
.27\end{array}$ \\
\hline public & $\begin{array}{l}\text { Teacher } \\
\text { communication }\end{array}$ & $\begin{array}{r}<\text { high school diploma } \\
\text { High school diploma } \\
\text { Postsecondary experience } \\
\text { College degree or beyond }\end{array}$ & $\begin{array}{l}-0.02 \\
-0.06 \\
0.06 \\
0.03\end{array}$ & $\begin{array}{l}0.09 \\
0.07 \\
0.06 \\
0.04\end{array}$ & $\begin{array}{l}.39 \\
.36\end{array}$ \\
\hline
\end{tabular}

Table 21 summarizes analyses of the relationships between the school-based organizations factor and teacher literacy ratings across both school types, and by school type. There were no significant relationships observed between participation in schoolbased organizations and teacher literacy ratings for any of the parent education subgroups before school was taken into account. Although results were not interpretable for public school students, among non-public school students the same pattern of non-significant relationships emerged. 
Table 21

Unstandardized Regression Results Predicting Teacher Literacy Ratings for the Participating in School-Based Organizations by Parent Education Subgroup and by School Type

\begin{tabular}{|c|c|c|c|c|}
\hline Subgroup & School type & Unstandardized coefficient & S.E. & $p$ \\
\hline \multirow{3}{*}{$<$ high school diploma } & Across school types & -0.14 & 0.10 & .18 \\
\hline & Public & \multicolumn{3}{|l|}{ Heywood case } \\
\hline & Non-Public & -0.15 & 0.64 & .82 \\
\hline \multirow{3}{*}{ High school diploma } & Across school types & -0.08 & 0.05 & .11 \\
\hline & Public & \multicolumn{3}{|l|}{ Heywood case } \\
\hline & Non-Public & -0.05 & 0.13 & .67 \\
\hline \multirow{3}{*}{ Postsecondary experience } & Across school types & -0.03 & 0.05 & .63 \\
\hline & Public & \multicolumn{3}{|l|}{ Heywood case } \\
\hline & Non-Public & -0.02 & 0.06 & .79 \\
\hline \multirow{3}{*}{ College degree or beyond } & Across school types & -0.02 & 0.04 & .62 \\
\hline & Public & \multicolumn{3}{|l|}{ Heywood case } \\
\hline & Non-Public & -0.31 & 0.41 & .45 \\
\hline
\end{tabular}

Note. Coefficients are not comparable between the parent education subgroups.

\section{Analyses 5 and 6: Parent Occupation Subgroups}

Testing for measurement invariance. Table 22 presents the results from the tests of measurement invariance among parent occupation subgroups. The CFA model run separately for each subgroup indicated very good model fit, as did the combined model establishing configural invariance. When factor loadings were constrained to be equal across groups, the chi-square difference test was not statistically significant (chi- 
square $=20.64, p=.06$ ), indicating that the null hypothesis of invariance should not be rejected. Next, strict invariance was tested by constraining the residual variance of the indicators to be equal across groups. Again, the non-significant chi-square $(16.35, p=.18)$ indicated that the strict invariance model was the preferred model. This was the final model to which achievement outcomes were added.

Table 22

Tests of Measurement Invariance across Parent Occupation Subgroups

\begin{tabular}{|c|c|c|c|c|c|c|c|}
\hline Subgroup & $\mathrm{df}$ & Chi-square & & RMSEA & CFI & TLI & \\
\hline Low occupational prestige & 20 & 63.93 & & .02 & .98 & .98 & \\
\hline $\begin{array}{l}\text { Medium occupational } \\
\text { prestige }\end{array}$ & 20 & 92.06 & & .02 & .98 & .97 & \\
\hline High occupational prestige & 20 & $\begin{array}{l}44.81 \\
(p=.01)\end{array}$ & & .02 & .98 & .97 & \\
\hline Model & & & $\begin{array}{l}\text { Chi-square } \\
\text { difference }\end{array}$ & & & & $\begin{array}{c}\text { Preferred } \\
\text { Model }\end{array}$ \\
\hline Configural & 70 & 199.46 & & .02 & .98 & .97 & \\
\hline Weak & 80 & 217.26 & $\begin{array}{l}20.64 \\
(p=.06)\end{array}$ & .02 & .98 & .98 & Weak \\
\hline Strict & 100 & 226.63 & $\begin{array}{c}16.35 \\
(p=.18)\end{array}$ & .02 & .98 & .98 & Strict \\
\hline
\end{tabular}

Note. Degrees of freedom have been rounded due to use of restricted data set. Chi-square and chi-square difference tests are statistically significant $(p<.001)$. In rows testing partial invariance, only the listed factor or item was held invariant across groups, while other factor loadings freely varied. 
Establishing strict measurement invariance allowed for the means of the three parent involvement factors to be compared. First, a test of equality of factor means was conducted, and was rejected (chi-square $=101.18 . p<.001)$. Factor means were then estimated using the low occupational prestige group to set the scale. Table 23 shows that the means of all factors tended to be larger for groups with more occupational prestige. The magnitude of difference between the medium and high occupational prestige groups was very small for the communicating with teachers factor.

Table 23

Comparing Factor Means among Parent Occupation Subgroups

\begin{tabular}{lccc}
\hline \multicolumn{1}{c}{ Subgroup } & $\begin{array}{c}\text { Open school } \\
\text { events }\end{array}$ & $\begin{array}{c}\text { Teacher } \\
\text { communication }\end{array}$ & organizations \\
\hline Low occupational prestige & 0.00 & 0.00 & 0.00 \\
Medium occupational prestige & 0.48 & 0.89 & 0.04 \\
High occupational prestige & 0.88 & 0.90 & 0.12 \\
\hline
\end{tabular}

The relationship between parent involvement and achievement. The next set of analyses was conducted using two different measure of achievement. First, the relationship between parent involvement factors and reading IRT scores is discussed, followed by the relationship between parent involvement factors and teacher ratings of literacy skills.

Parent involvement and reading IRT scores. A test of invariance of paths indicated that it was not appropriate to constrain the relations between the parent involvement factors and the achievement outcome to be equal (chi-square $=18.76, p=.01)$. Table 24 compares the unstandardized regression coefficients across the three parent 
occupational prestige subgroups. For all three groups, participating in open school events has a statistically significant, positive relationship with reading IRT scores. The magnitude of the relationship is largest among the low occupational prestige group; a unit increase in participating in open school events is associated with a 4.03 point increase in reading IRT score.

There is no statistically significant relationship between the communicating with teachers factor and reading IRT scores for any of the parent occupational prestige subgroups. Participating in school-based organizations has statistically significant, negative relationships with reading IRT scores among the low and medium occupational prestige groups. Again, the magnitude of the effect is greatest among the low occupational prestige subgroup.

Table 24

Comparison of Unstandardized Regression Results Predicting Reading IRT Scores among Parent Occupation Subgroups

\begin{tabular}{lccc}
\hline $\begin{array}{c}\text { Parent involvement } \\
\text { factor/subgroup }\end{array}$ & Unstandardized coefficient & Standard error & $p$ \\
\hline Open school events & & & \\
Low occupational prestige & 4.03 & 0.54 & $<.001$ \\
Medium occupational prestige & 3.09 & 0.59 & $<.001$ \\
High occupational prestige & 2.26 & 0.77 & .003 \\
Teacher communication & & & .62 \\
Low occupational prestige & 0.07 & 0.14 & .45
\end{tabular}




\begin{tabular}{cccc}
\hline $\begin{array}{l}\text { Parent involvement } \\
\text { factor/subgroup }\end{array}$ & Unstandardized coefficient & Standard error & $p$ \\
\hline High occupational prestige & 0.12 & 0.22 & .59 \\
School-based organizations & & & \\
Low occupational prestige & -2.38 & 0.64 & .001 \\
Medium occupational prestige & -1.51 & 0.53 & .004 \\
High occupational prestige & -0.28 & 0.77 & .71 \\
\hline
\end{tabular}

Table 25 shows the results of school type being taken into account. Participation in open school events has a statistically significant, positive association with reading IRT scores among public school students with parents at all levels of occupational prestige, but only among non-public school students with parents at the lowest level of occupational prestige. Communication with teachers was not statistically significantly associated with reading IRT scores for any occupational prestige subgroup for both types of schools. Statistically significant, negative associations were observed between participation in school-based organizations and reading IRT scores only among public school students from the low and medium occupational subgroups.

Table 25

Comparison of Unstandardized Regression Results Predicting Reading IRT Scores among Parent Occupation Subgroups by School Type

\begin{tabular}{ccccccc}
\hline Parent & Unstandardized & Standard & & Unstandardized & Standard & \\
involvement & coefficient & error & & coefficient & error & $p$ \\
factor/subgroup & & & & & \\
\hline
\end{tabular}


Open school events

Public school

Non-public school

Low prestige

3.53

0.56

$<.001$

5.09

2.18

.02

Medium prestige

3.15

$0.62<.001$

0.26

1.95

.89

High prestige

2.52

1.02

.01

0.52

1.80

.77

Teacher communication

Public school

Non-public school

\begin{tabular}{|c|c|c|c|c|c|c|}
\hline \multirow{2}{*}{ Low prestige } & \\
\hline & 0.15 & 0.25 & .55 & -0.06 & 0.41 & .88 \\
\hline Medium prestige & 0.21 & 0.24 & .40 & 0.40 & 2.30 & .86 \\
\hline High prestige & 0.64 & 0.54 & .24 & -0.16 & .99 & .87 \\
\hline \multicolumn{7}{|c|}{ School-based organizations } \\
\hline & \multicolumn{3}{|c|}{ Public school } & \multicolumn{3}{|c|}{ Non-public school } \\
\hline Low prestige & -1.69 & 0.68 & .01 & -4.13 & 2.46 & .09 \\
\hline Medium prestige & -1.37 & 0.61 & .02 & 0.12 & 1.24 & .92 \\
\hline High prestige & -0.81 & 0.93 & .39 & 1.24 & 2.02 & .54 \\
\hline
\end{tabular}

Parent involvement and teacher literacy ratings. A test of invariance of paths between the factors for which measurement invariance had been established indicated that it was appropriate to constrain the relations between the parent involvement factors and the achievement outcome to be equal across the parent occupational prestige subgroups (chi-square difference $=2.54, p=.86$ ). In other words, parent occupational prestige did not moderate the relationships between the parent involvement factors and teacher literacy ratings. 
Table 26 depicts statistically significant relationships between all three parent involvement factors and teacher literacy ratings. These relationships were positive for participating in open school events and communicating with teachers, and negative for participating in school-based organizations. Increases in factors participating in open school events and communicating with teachers are associated with increases in teacher literacy ratings, while increases in participating in school-based organizations are associated with decreases in teacher literacy ratings.

Table 26

Unstandardized Regression Results Predicting Teacher Literacy Ratings among Parent Occupation Subgroups

\begin{tabular}{lccc}
\hline \multicolumn{1}{c}{ Parent involvement factor } & Unstandardized coefficient & Standard error & $p$ \\
\hline Open events & .17 & .03 & $<.001$ \\
Teacher communication & .03 & .01 & .02 \\
School-based organizations & -.07 & .03 & .03 \\
\hline
\end{tabular}

Table 27 presents the results of school type being added to the model. Although school type had a statistically significant effect for medium and high occupational subgroups, it did not moderate the magnitude of the relations between parent involvement factors and teacher literacy ratings.

Table 27

Unstandardized Regression Results Predicting Teacher Literacy Ratings among Parent Occupation Subgroups with School Type Added 


\begin{tabular}{lcccccc}
\hline Parent & Unstandardized & Standard & & Unstandardized & Standard & \\
involvement & coefficient & error & $p$ & coefficient & error & $p$ \\
factor & & & & & & \\
\hline Open events & 0.18 & 0.03 & $<.001$ & 0.01 & 0.07 & .90 \\
Teacher & 0.03 & 0.01 & .04 & 0.01 & 0.17 & .95 \\
communication & & & & & & \\
School-based & -0.06 & 0.04 & .08 & 0.003 & 0.06 & .96 \\
organizations & & & & & & \\
\hline
\end{tabular}

\section{Analyses 7 and 8: Primary Language Subgroups}

Testing for measurement invariance. Table 28 presents the results from the tests of measurement invariance among primary language subgroups. The CFA model run separately for each subgroup indicated good model fit, as did the combined model establishing configural invariance. When factor loadings were constrained to be equal across the language subgroups, the chi-square difference test indicated that the null hypothesis of invariance should be reject (chi-square difference $=37.38, p<.001$ ). Tests of partial invariance indicated that the participating in open school events factor loadings could be constrained to be equal across the primary language subgroups (chi-square difference $=5.81, p=.21)$. These constraints were included in the final model to which achievement outcomes were added.

Table 28

Tests of Measurement Invariance across Primary Language Subgroups

\begin{tabular}{llllll}
\hline Subgroup & df & Chi-square & RMSEA & CFI & TLI
\end{tabular}




\begin{tabular}{|c|c|c|c|c|c|c|c|}
\hline English & 20 & 148.65 & & 0.02 & 0.99 & 0.98 & \\
\hline Non-English & 20 & 90.95 & & 0.03 & 0.96 & 0.94 & \\
\hline \multirow{2}{*}{ Model } & & & Chi-square & & & & Preferred \\
\hline & & & difference & & & & Model \\
\hline Configural & 50 & 232.42 & & .02 & .98 & .98 & \\
\hline Weak & 50 & 268.21 & $37.38(p<.001)$ & .02 & .98 & .97 & \\
\hline \multicolumn{8}{|l|}{ Partial } \\
\hline F1 & 50 & 234.06 & $5.81(p=.21)$ & .02 & .98 & .98 & Partial \\
\hline $\mathrm{F} 2$ & 50 & 261.45 & $39.88(p<.001)$ & .02 & .98 & .97 & Configural \\
\hline F3 & 50 & 264.19 & $2.01(p<.001)$ & .02 & .98 & .97 & Configural \\
\hline
\end{tabular}

Note. Degrees of freedom have been rounded due to use of restricted data set. Chi-square and chi-square difference tests are statistically significant $(p<.001)$. In rows testing partial invariance, only the listed factor or item was held invariant across groups, while other factor loadings freely varied.

Tests of invariance of the participating in open school events factor means indicated that the mean values on that factor of the two language subgroups were not equal. Table 29 presents the estimates of factor means, showing that the non-English subgroup had a lower average score on participating in open school events.

Table 29

Comparing Factor Means among Primary Language Subgroups

\begin{tabular}{lc}
\hline Subgroup & Open school events \\
\hline English & 0.00 \\
Non-English & -0.95 \\
\hline
\end{tabular}


The relationship between parent involvement and achievement. The next set

of analyses was conducted using two different measure of achievement. First, the relationship between parent involvement factors and reading IRT scores is discussed, followed by the relationship between parent involvement factors and teacher ratings of literacy skills.

Parent involvement and reading IRT scores. A test of invariance of paths indicated that it was not appropriate to constrain the relations between the participating in open school events factor and the achievement outcome to be equal (chi-square difference $=520.827, p<.001)$. Table 30 compares the relations between participating in open school events and reading IRT scores for the primary language subgroups. The relationship is statistically significant and positive for both groups, though the relationship is stronger for the non-English subgroup.

Table 30

Comparing Unstandardized Regression Results Predicting Reading IRT Scores among Primary Language Subgroups

\begin{tabular}{crrrr}
\hline $\begin{array}{c}\text { Parent involvement } \\
\text { factor }\end{array}$ & Subgroup & Unstandardized coefficient & Standard error & $p$ \\
& & & & \\
\hline \multirow{2}{*}{ Open events } & English & 3.45 & 0.40 & $<.001$ \\
& Non-English & 4.69 & 1.07 & $<.001$ \\
\hline Teacher & Not comparable & \\
communication & & \\
\hline School-based \\
organizations
\end{tabular}


Table 31 shows the results after school type was taken into account. Statistically significant, positive associations between participation in open school events and reading IRT scores were observed among public school students from all language backgrounds and from students in the primarily English subgroup in non-public schools. There was no significant association between participating in open school events and reading IRT scores for non-public school students in the primarily non-English subgroup.

Table 31

Comparing Unstandardized Regression Results Predicting Reading IRT Scores from Participation in Open School Events among Primary Language Subgroup by School Type Public Non-public

\begin{tabular}{ccccccc}
\hline \multirow{2}{*}{ Subgroup } & $\begin{array}{c}\text { Unstandardized } \\
\text { coefficient }\end{array}$ & Standard & error & $p$ & Unstandardized & Standard \\
& & & & coefficient & error & \\
\hline English & 3.50 & 0.45 & $<.001$ & 3.49 & 1.28 & .01 \\
Non-English & 4.34 & 1.09 & $<.001$ & -1.93 & 2.25 & .39 \\
\hline
\end{tabular}

Table 32 summarizes the results for the remaining two factors and shows that only participating in school-based organizations has a statistically significant, negative relationship with reading IRT scores among both language subgroups when analyzed across school types. When school type is taken into account, a positive statistically significant association is observed between teacher communication and reading IRT scores among non-public school students from primarily English-speaking homes. The negative associations between participation in school-based organizations and reading IRT scores are observed are observed among both language subgroups, but among public school students only. 
Table 32

Unstandardized Regression Results Predicting Reading IRT Scores from Teacher

Communication and School-Based Organizations by Parent Primary Language Subgroup and by School Type

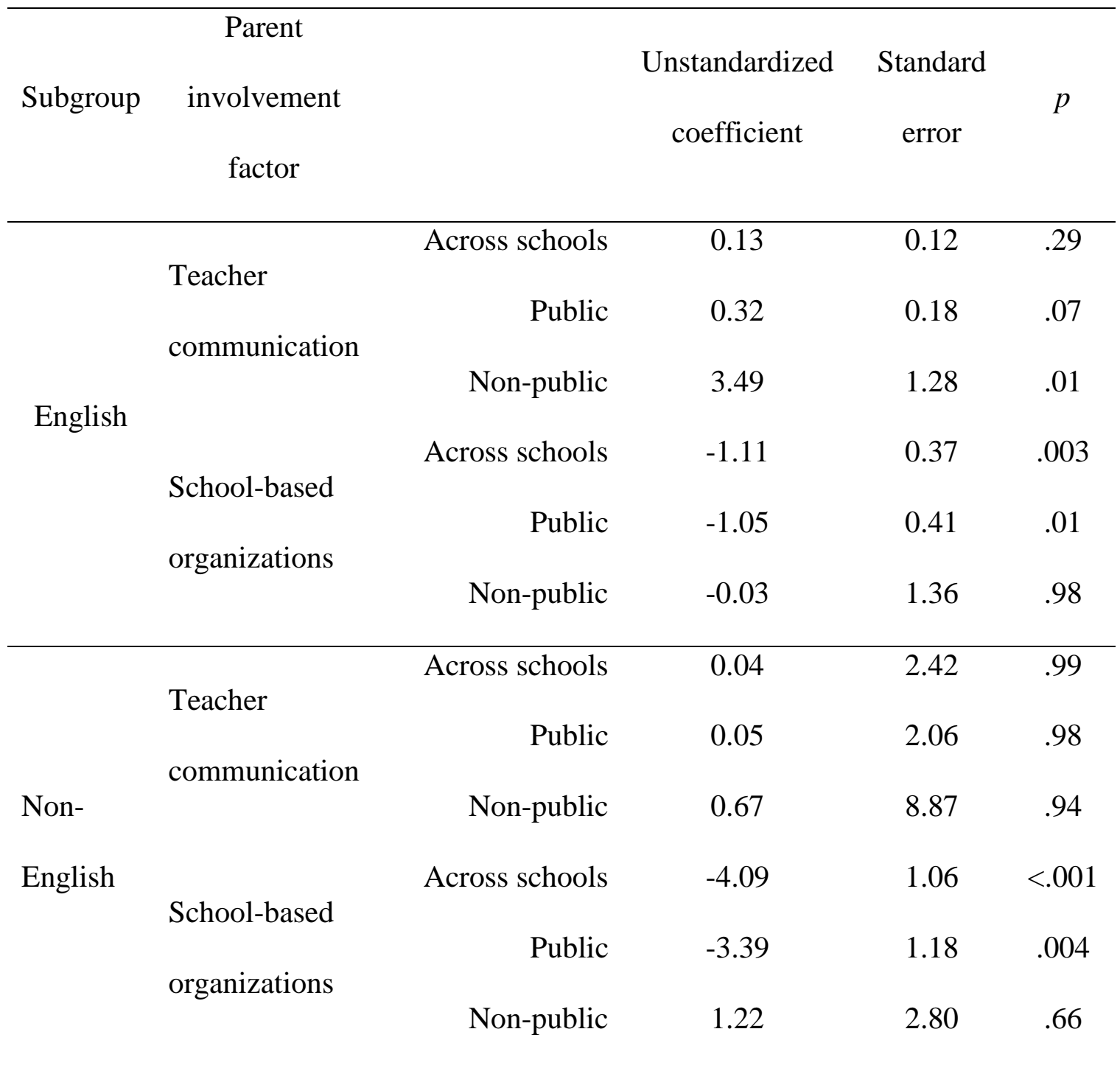

Note. Coefficients are not comparable between the primary language subgroups.

Parent involvement and teacher literacy ratings. A test of invariance of paths

indicated that it was appropriate to constrain the relations between the participating in open school events factor and the achievement outcome to be equal (chi-square difference $=0.33, p=.56$ ). Table 33 depicts the statistically significant, positive 
relationship between participating in open school events and teacher literacy ratings that is equal in magnitude for the two primary language subgroups.

Table 33

Comparing Unstandardized Regression Results Predicting Reading Teacher Ratings among Primary Language Subgroups

\begin{tabular}{|c|c|c|c|c|}
\hline $\begin{array}{c}\text { Parent involvement } \\
\text { factor }\end{array}$ & Subgroup & Unstandardized coefficient & Standard error & $p$ \\
\hline Open events & English & 0.23 & 0.03 & $<.001$ \\
\hline & Non-English & 0.23 & 0.03 & $<.001$ \\
\hline $\begin{array}{c}\text { Teacher } \\
\text { communication }\end{array}$ & & Not comparable & & \\
\hline $\begin{array}{l}\text { School-based } \\
\text { organizations }\end{array}$ & & Not comparable & & \\
\hline
\end{tabular}

Table 34 presents results from the model to which school type was taken into account. A statistically significant relationship between participation in open school events and teacher literacy ratings was only observed among public school students. Table 34

Comparing Unstandardized Regression Results Predicting Teacher Literacy Ratings from Participation in Open School Events among Primary Language Subgroup by School Type 


\begin{tabular}{ccccccc}
\hline & $\begin{array}{c}\text { Unstandardized } \\
\text { coefficient }\end{array}$ & Standard & error & $p$ & Unstandardized & Standard \\
& & & & coefficient & error & \\
\hline English & 0.24 & 0.04 & $<.001$ & .057 & .08 & .47 \\
Non-English & 0.24 & 0.04 & $<.001$ & .057 & .08 & .47 \\
\hline
\end{tabular}

Table 35 summarizes results for the remaining two factors and includes both results for all students across schools and by school type. Among students from homes in which English is the primary language, a statistically significant, positive association between teacher communication and teacher literacy ratings was only observed among public school students. Similarly, among students from homes in which English is the primary language, a statistically significant, negative association between participation in school-based organizations and teacher literacy ratings was only observed among public school students. Among the non-English primary language subgroup, there was a nonsignificant association between participation in school-based organizations and teacher literacy ratings across regardless of school type. There was a statistically significant, positive relationship between participation in school-based organizations and teacher literacy ratings among the non-English subgroup in public schools only.

Table 35

Unstandardized Regression Results Predicting Reading IRT Scores from Teacher Communication and School-Based Organizations by Parent Primary Language Subgroup and by School Type 


\begin{tabular}{|c|c|c|c|c|c|}
\hline \multirow[b]{2}{*}{ Subgroup } & \multirow[b]{2}{*}{$\begin{array}{l}\text { involvement } \\
\text { factor }\end{array}$} & \multirow[b]{2}{*}{ School type } & \multirow[b]{2}{*}{$\begin{array}{c}\text { Unstandardized } \\
\text { coefficient }\end{array}$} & \multirow[b]{2}{*}{$\begin{array}{c}\text { Standard } \\
\text { error }\end{array}$} & \multirow[b]{2}{*}{$p$} \\
\hline & & & & & \\
\hline \multirow{6}{*}{ English } & \multirow{3}{*}{$\begin{array}{l}\text { Teacher } \\
\text { communication }\end{array}$} & Across schools & 0.03 & 0.01 & .03 \\
\hline & & Public & 0.03 & 0.01 & .04 \\
\hline & & Non-public & 0.01 & 0.06 & .84 \\
\hline & \multirow{3}{*}{$\begin{array}{l}\text { School-based } \\
\text { organizations }\end{array}$} & Across schools & -0.08 & 0.03 & .01 \\
\hline & & Public & -0.07 & 0.04 & .04 \\
\hline & & Non-public & -0.01 & 0.06 & .86 \\
\hline \multirow{6}{*}{$\begin{array}{l}\text { Non- } \\
\text { English }\end{array}$} & \multirow{3}{*}{$\begin{array}{l}\text { Teacher } \\
\text { communication }\end{array}$} & Across schools & 0.02 & 0.05 & .69 \\
\hline & & Public & -0.45 & 2.18 & .84 \\
\hline & & Non-public & 0.04 & 0.34 & .91 \\
\hline & \multirow{3}{*}{$\begin{array}{l}\text { School-based } \\
\text { organizations }\end{array}$} & Across schools & -0.13 & 0.06 & .03 \\
\hline & & Public & 0.60 & 0.08 & $<.001$ \\
\hline & & Non-public & -0.04 & 0.18 & .82 \\
\hline
\end{tabular}

Note. Coefficients are not comparable between the primary language subgroups.

The results from this series of analyses will be further summarized in the next chapter of this study. A discussion of key findings and directions for future research will also be presented. 


\section{CHAPTER 5}

\section{DISCUSSION AND DIRECTIONS FOR FUTURE RESEARCH}

This study sought to explore parent involvement and its relationship to early reading achievement, noting that parent involvement activities differ in terms of the both the expectations of schools and the cultural capital tools that parents can access and use when they interact at the school. As these expectations and tools are shaped by larger social and cultural structures in which peoples' lived experiences take place (Bronfenbrenner, 1976), it stands to reason that members of various sociocultural subgroups might differ in both the types of involvement in which they engage and the relations these forms of involvement have with student achievement.

This section summarizes the results from the preceding chapter and demonstrates how these results relate back to the theoretical framework that sought to integrate ecological systems theory with the concept of cultural capital. Overall, the results provide some support for the theoretical framework depicting parent involvement as a component of the family-school context that shapes and is shaped by a child's development, while also being shaped by the larger sociocultural forces that provide families with access to cultural capital and influence school expectations.

These general conclusions will be supported by first discussing the measurement of parent involvement types as a reflection of cultural capital. Next, the relationships between the parent involvement factors and student achievement measures are discussed, including a discussion of the potential moderating effects of school type. And because the 
present study was exploratory in nature, the final section will consider several directions for future research.

\section{Parent Involvement Types and Cultural Capital}

Results from both the exploratory and confirmatory factor analyses supported a three-factor structure that corresponds with three types of parent involvement, each reflecting different forms of cultural capital, both in terms of the expectations of schools and the cultural tools to which parents have access. Volunteering at school, attending sporting events, attending school events, participating in fundraising, and attending back to school night were all parent involvement activities that shared common variance that distinguished them from other parent involvement activities. These activities share in common minimal expectations from schools and do not necessarily require special cultural tools for participation beyond being able to attend and adhering to behavioral norms. Attending parent-teacher conferences and attending informal meetings with teachers also shared common variance and reflect additional sets of expectations and tools related to effective on-on-one communication. Attending parent advisory committee meetings and attending PTA/PTO meetings reflect even more expectations and tools including communicating and coordinating with both school staff and other parents and engaging in parliamentary or other formal procedures.

The three parent involvement factors thus reflect different sets of tools which may be accessible to some groups more than to others. Prior research on parent involvement has noted that families from different sociocultural backgrounds might differ in their access to the cultural capital tools required to meet the schools' expectations regarding appropriate or useful parent involvement (Lareau, 2011). If this were the case, then it 
would be expected that families from different backgrounds would differ in terms of the types of involvement in which they engaged.

Family involvement at the school is one characteristic of the family-school mesosystem. This mesosystem is a prominent component of the larger environment in which a child's educational experience is situated. As such, involvement would be expected to shape, and be shaped by, a child's academic achievement. It would therefore be expected that parent involvement activities would have a relationship with student achievement outcomes. And because families may differ in their access to the cultural capital tools needed to successfully engage in these activities, it is important to document that extent to which different types of involvement may relate to achievement outcomes in different ways.

If such differences are to be quantified, it is important to ensure that parent involvement is measured similarly across the groups between which comparisons are to be made. To that end, multiple group analyses were conducted to establish that the parent involvement factors were not only conceptually similar across the various sociocultural subgroups that were to be compared but also that the factors were also being measured on a comparable scale.

Among the four subgroups included in the present study (i.e., student race/ethnicity, parents' highest level of education, parents' occupational prestige, and primary language usage), configural invariance was established for all three parent involvement factors. Configural invariance meets the minimum requirement for establishing that "different groups employ the same conceptual framework" when responding to a set of measures (Wu, Li, \& Zumbo, 2007, p. 7). This indicated that analyzing parent involvement around the three identified factors was appropriate for all 
subgroups but was not sufficient for making quantitative comparisons between the groups in terms of the extent to which the groups engaged in each type of involvement or in how the involvement factors related to achievement measures.

Table 36 summarizes the results of the additional measurement invariance tests for the four sets of subgroups included in the present study. Cells containing the value of 'incomparable' indicate that it is not appropriate to quantify differences between the parent involvement factors across those subgroups because the factors are essentially being measured on different scales within each group (Wu, Li, \& Zumbo, 2007). Cells containing the value of 'comparable' indicate that the factors were not only conceptually equivalent but that they also were measured on a similar scale, thus allowing for the assessment of group differences in the average amounts of the parent involvement factors and in the magnitude of the relationships between the parent involvement factors and the achievement measures.

Table 36 indicates that none of the factors were measured on a similar scale across the student race/ethnicity subgroups, that the participating in school-based organizations factor was not comparable across the parent education subgroups, and that the communicating with teachers and participating in school-based organizations factors were not comparable across the primary language subgroups. Failure to establish measurement invariance may reflect residual variability in the indicators that is dependent on other influences (Little, 1997). In other words, after controlling for the common variance explained by the underlying factor, variability in the individual indicator scores may reflect group-specific characteristics. For example, students from non-white racial/ethnic groups may more frequently attend schools with fewer resources for providing opportunities for school-based involvement (McNeal, 1999). 
Table 36

Summary of Measurement Invariance Test Results

\begin{tabular}{cccc}
\hline Subgroup & Open events & Teacher communication & School-based organizations \\
\hline Racial/Ethnic & Incomparable & Incomparable & Incomparable \\
Parent Education & Comparable & Comparable & Incomparable \\
Parent Occupation & Comparable & Comparable & Comparable \\
Primary Language & Comparable & Incomparable & Incomparable \\
\hline
\end{tabular}

Table 37 summarizes the comparisons of groups within the subgroup types for the factors for which measurement invariance was established. It is not appropriate to compare these values across the different subgroup types (i.e., do not compare education subgroup means to occupational subgroup means). The reference subgroup in each model has a value of 0 , as one of the factor means must be fixed at zero for model identification purposes. If a different reference group was used, estimates would be slightly different, but the pattern of differences would be the same.

Table 37

Summary of Comparisons of Factor Means

\begin{tabular}{lccc}
\hline \multicolumn{1}{c}{ Subgroup } & Open events & Teacher communication & School-based organizations \\
\hline < High school diploma & 0.00 & & \\
High school diploma & 0.36 & Equal & Incomparable \\
Postsecondary experience & 0.85 & & \\
College degree or beyond & 1.59 & 0.00 & 0.00
\end{tabular}


prestige

$$
0.48 \quad 0.89
$$

$\begin{array}{llll}\text { High occupational prestige } & 0.88 & 0.90 & 0.12\end{array}$

\begin{tabular}{ll}
\hline English & 0.00
\end{tabular}

Non-English $-0.95$

Incomparable Incomparable

Note. Comparisons should only be made within each subgroup type and should not be made across factors.

Table 38 shows that the less than high school diploma group has the lowest average amount of participation in open-school events and that average values on this factor increase as the highest level of parent education increases. The four parent education subgroups do not differ in their mean values of communicating with teachers. This suggests that on average, families in which parents have higher levels of education tend to participate more in open school events, while all parent subgroups participate in similar amounts of communication with teachers. Attending open school events may not require particular the cultural tools related to communication and coordination that are posited to be required of the other parent involvement factors, but it does require that family members have time away from work and home responsibilities, and to understand what events are open to them and what participation in these events will entail. Parents with higher levels of education may feel more comfortable participating in school-based events given their own experiences in educational environments (Hill \& Taylor, 2004). The equality of means on the teacher communication factor indicates that on average all families communicate with teachers in equal amounts, regardless of parents' level of education. This runs counter to literature that suggests that parents with higher levels of education are more comfortable communicating with teachers (Kohl, Lengua, \& 
McMahon, 2000). Similarities in average amounts of communication among the parent educations subgroups do not, however, provide an indication of the quality or effectiveness of this communication.

Among the parent occupational prestige subgroups, all groups differed in their mean values for all three factors. For all factors, higher levels of occupational prestige are associated with higher mean values. However, the means of the medium and high occupational prestige groups are very similar on the teacher communication factor. This suggests that parents with higher levels of occupational prestige may have access to tools that allow them to participate more frequently in school events, meetings or other forms of communication with teachers, (e.g., emails, phone calls), and other school-based organizations. This may include more flexible work schedules, more access to multiple means of communication, and more familiarity communicating in an organizational context (Halsey, 2005; Kohl, Lengua, \& McMahon, 2000).

Among the primary language subgroups, only the open school events factor was comparable. Families who primarily speak English have higher average levels of participation in open school events. This may reflect English-speaking families access to language requirements needed to both be aware of and participate in such events (Lee, 2005).

\section{Parent Involvement Factors and Early Reading Achievement}

This study posited that parent involvement at school is a component of a child's family-school mesosytem that shapes a child's development, including their academic performance. The correlational results also illustrate how the family-school mesosystem is itself shaped by the child (Bronfenbrenner, 1976). Families from different sociocultural backgrounds may differ not only in the frequency with which they participate in different 
types of parent involvement activities but also in the factors that may trigger increases in their involvement and the ways that their involvement enhances or undermines academic achievement. The next portion of this study thus focused on the relations between parent involvement and early student reading achievement.

Table 38 summarizes the associations between the three parent involvement factors and the two measures of kindergarten reading achievement. It is important to note that the research design does not allow for the interpretation of causal relationships. Parent involvement indicators and achievement measures were obtained in the same general time frame (spring of the kindergarten school year), so neither variable can be interpreted as "causing" the other. Although parent involvement may have benefits for students' academic performance, it is also possible that student performance serves as an impetus for increased involvement. Multiple possible interpretations of the observed associations will therefore be discussed.

Table 38

Summary of Associations between Parent Involvement Factors and Measures of Reading

Achievement

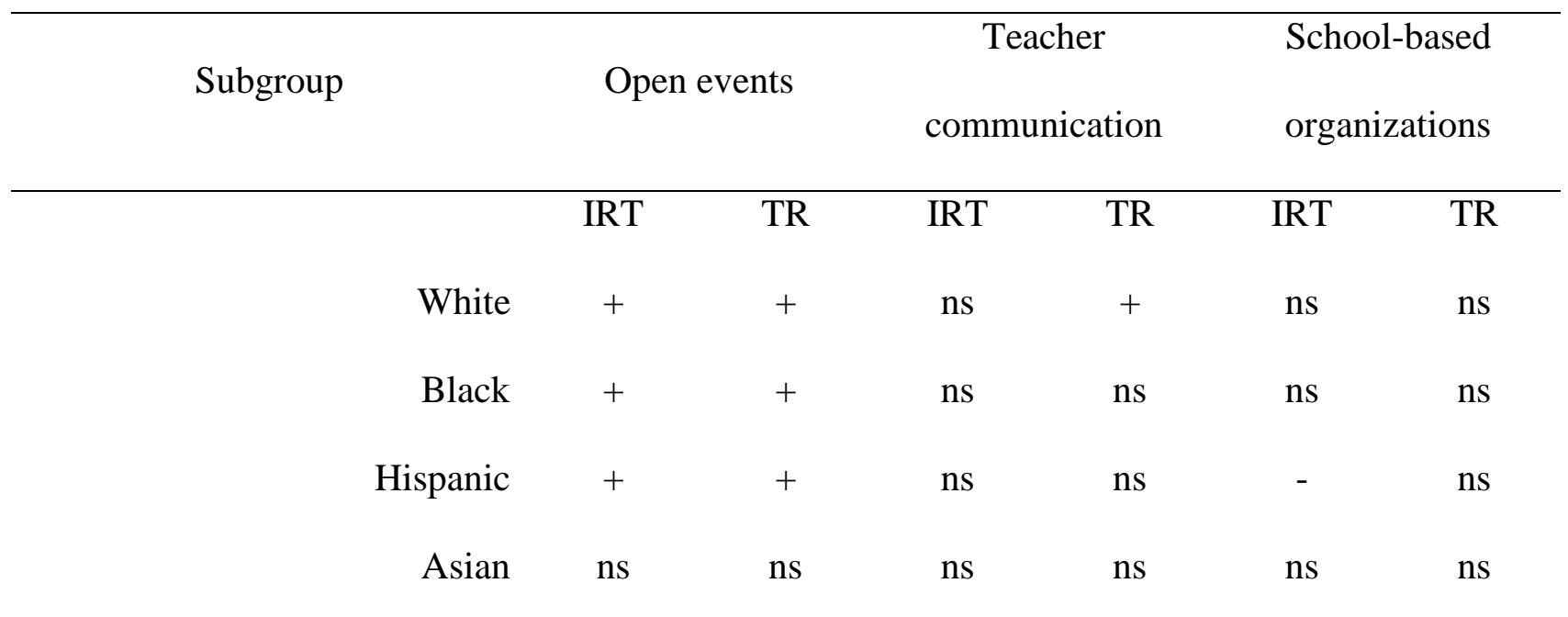




\begin{tabular}{|c|c|c|c|c|c|c|}
\hline Subgroup & \multicolumn{2}{|c|}{ Open events } & \multicolumn{2}{|c|}{ Teacher } & Scl & \\
\hline Other & $\mathrm{ns}$ & + & + & ns & ns & ns \\
\hline No high school diploma & + & + & $\mathrm{ns}$ & $\mathrm{ns}$ & - & $\mathrm{ns}$ \\
\hline High school diploma & + & + & - & $\mathrm{ns}$ & - & ns \\
\hline Some postsecondary & + & + & + & + & ns & ns \\
\hline College degree + & + & ns & $\mathrm{ns}$ & + & ns & ns \\
\hline Low occupational prestige & + & + & $\mathrm{ns}$ & + & - & - \\
\hline Medium occupational prestige & + & + & ns & + & - & - \\
\hline High occupational prestige & + & + & ns & + & ns & - \\
\hline English primary language & + & + & ns & + & - & - \\
\hline Non-English primary language & + & + & $\mathrm{ns}$ & $\mathrm{ns}$ & - & - \\
\hline
\end{tabular}

Note. IRT $=$ reading IRT score. $\mathrm{TR}=$ teacher literacy rating. $+=$ positive association. - = negative association. $\mathrm{ns}=$ no significant association.

Looking down the columns of Table 46 provides an indication of the pattern of relations between the parent involvement factors and achievement outcomes across the included subgroups. Where a statistically significant relationship was observed, the 'attend open school events' factor has a positive relationship with student achievement, regardless of how it is measured. This could be indicative of higher levels of parent involvement helping to boost student performance by creating stronger connections between school and family (Haynes \& Ben-Avie, 1996), or could simply reflect a pattern of parents being more involved when their child is doing well in school. If the latter is the case, then schools might consider making extra efforts to encourage participation among families whose students are struggling. It is possible that the family of a low performing 
child might feel uncomfortable at the school because they perceive that their child isn't meeting expectations. Schools could address such concerns by ensuring families that they are all part of the school community, and that every child is supported.

The 'communicate with teachers' factor tends to have either no association with achievement measures, or to have a positive association, but with one exception. These positive associations indicate that higher amounts of communication with teachers tend to be associated with higher levels of kindergarten reading achievement. Among the subgroup of parents with a high school diploma as the highest education level, there is a negative association between the 'communicate with teachers' factor. This could be evidence of parents with only a high school education being more likely to communicate with teachers when their child is not performing well. On the other hand, it might indicate that these parents lack tools to effectively communicate with teachers, leading to a schism between home and school that contributes to low levels of student performance (Howland, Anderson, Smiley, \& Abbott, 2006).

The 'participate in school-based groups' factor tends to have either no association with the achievement measures, or to have a negative association. These negative associations indicate that higher amounts of participation in school-based groups tend to be associated with lower levels of kindergarten reading achievement. This may be a reflection of parents participating in these groups in response to their concerns over their child's performance. If a child is struggling with reading for example, parents may feel the need to join these groups in an effort to improve the school. On the other hand, increased involvement in school-based groups might be associated with lower reading achievement when parents have antagonistic or other types of negative interactions with school staff (Comer \& Haynes, 1991). 
Table 39 summarizes the comparisons between subgroups in terms of the magnitude of the relationships between parent involvement and early reading achievement. Participating in open school events has stronger positive relationships with reading IRT scores among the subgroups with lower levels of parent education, lower levels of occupational prestige or that primarily speak a language other than English. This suggests that participation in open school events may produce greater benefits for students from families with these backgrounds. On the other hand, having a high achieving student might enhance parents' sense of efficacy and lead them to engage in more school involvement (Hoover-Dempsey \& Sandler, 1997). When teacher literacy ratings were the achievement outcome, there still appeared to be some extra benefit associated with more participation in open school events for students from families with low levels of education.

As discussed above, communicating with teachers had a negative relationship with reading IRT scores among the high school diploma subgroup but a positive relationship among the group with some postsecondary education. Parents with some postsecondary education may communicate more with teachers when their child is performing well (Hoover-Dempsey \& Sandler, 1997), or may be more successful at communicating with teachers such that their child's performance benefits (Lareau, 2000). Communicating with teachers has a positive relationship with teacher literacy ratings that is similar in magnitude for families whose parents have either postsecondary experience or a college degree. The relationship between communicating with teachers and teacher literacy ratings is not moderated by parent occupational prestige, as subgroups at all levels experience the same positive relationship between this involvement factor and teacher literacy ratings. Communicating with teachers may in part be a reflection of 
parents' sense of efficacy in communicating on behalf of their child, and prior research suggests that such efficacy is not significantly related to employment status (HooverDempsey, Bassler, \& Brissie, 1992).

Participating in school-based groups had a stronger negative relationship with reading IRT scores among families with low levels of parent occupational prestige compared to those families with occupational prestige in the middle range. It is possible that families with lower level of occupational prestige participate more in school-based groups when their child is particularly low achieving, or that parents from families with lower levels of occupational prestige are involved in school-based groups in a way that has more negative outcomes on their child's educational experience. Prior research has found that parents from lower SES backgrounds (of which occupational prestige is a key component) may be more engaged in involvement activities when they lack trust in the school and are compelled to intervene on their child's behalf. This may in turn contribute to a school climate that is characterized by conflict (Rosenblatt \& Peled, 2002), which may have negative implications for student achievement outcomes. The relationship between participating in school-based groups and teacher literacy ratings is not moderated by parent occupational prestige, as subgroups at all levels experience the same negative relationship between this involvement factor and teacher literacy ratings.

Table 39

Comparison of the Magnitude of Comparable Unstandardized Factor Loadings

\begin{tabular}{llllll}
\hline Subgroup & Open events & & \multicolumn{2}{c}{ Teacher } & School-based \\
& & communication & organization \\
& & & & \\
\hline
\end{tabular}




\begin{tabular}{rcccccc}
\hline No high school diploma & 18.26 & .44 & $\mathrm{~ns}$ & $\mathrm{~ns}$ & & \\
High school diploma & 11.16 & .21 & -.89 & $\mathrm{~ns}$ & & \\
Some postsecondary & 1.82 & .12 & .43 & .04 & & \\
College degree + & 1.76 & $\mathrm{Ns}$ & $\mathrm{ns}$ & .06 & & \\
\hline Low occupational prestige & 4.03 & .17 & $\mathrm{~ns}$ & .03 & -2.38 & -.07 \\
Medium occupational prestige & 3.09 & .17 & $\mathrm{~ns}$ & .03 & -1.51 & -.07 \\
High occupational prestige & 2.26 & .17 & $\mathrm{~ns}$ & .03 & $\mathrm{~ns}$ & -.07 \\
\hline English primary language & 3.45 & .23 & & & & \\
\hline Non-English primary language & 4.69 & .23 & & & &
\end{tabular}

Note. Comparisons should only be made within each subgroup type and should not be made across factors.

The descriptive evidence obtained in this study suggests that school factors may further moderate the relationships between the parent involvement factors and the reading achievement outcomes. Table 40 summarizes the associations between the parent factors and achievement measures similar to Table 38 but organizes the results by school type. The most noticeable aspect of Table 40 is the larger proportion of non-significant associations among non-public school students compared to public school students. This could be interpreted in two broad ways. First, it is possible that student performance is less likely to influence whether or not parents become involved in school-based activities at non-public schools. This could be a reflection of school policies or requirements for parent involvement at non-public schools (Smith and Wohlstetter, 2009). Secondly, it is possible that parent involvement does not offer particular benefits or disadvantages for student achievement in non-public schools. Charter and other non-public schools may enjoy a level of autonomy that allows them to offer unique educational programs and 
services (Bulkley \& Fisler, 2003), which may in turn compensate for any effects that school-based parent involvement might have on early reading outcomes.

One particularly interesting pattern observed was among students in the nonEnglish primary language subgroup. When data were analyzed across school types, there was a negative association between participation in school-based organizations and teacher literacy ratings. However, when the focus was on public school students only, a positive association between participation in school-based organizations and teacher literacy ratings was observed. Although a body of research offering an explanation for this observed pattern has not been established, it is possible that parents of public school students who do not primarily speak English are more likely to join these groups if their child is high achieving, or may reflect that public schools are more likely to reach out to parents of high-achieving students for participation in these groups. It is also possible that public school students from homes in which English is not the primary language get a particular boost in early reading achievement from their parent's involvement in schoolbased decision making bodies as a result of the strengthened connection between home and school that has been discussed in relation to the more general student population (Haynes, 1996).

Table 40

Summary of Associations between Parent Involvement Factors and Measures of Reading Achievement by School Type

$$
\text { Public Non-public }
$$

\begin{tabular}{|c|c|c|c|c|c|c|}
\hline Subgroup & $\mathrm{F} 1$ & $\mathrm{~F} 2$ & F3 & $\mathrm{F} 1$ & $\mathrm{~F} 2$ & F3 \\
\hline
\end{tabular}




\begin{tabular}{|c|c|c|c|c|c|c|c|c|c|c|c|c|}
\hline \multirow[b]{2}{*}{ Subgroup } & \multicolumn{6}{|c|}{ Public } & \multicolumn{6}{|c|}{ Non-public } \\
\hline & \multicolumn{2}{|c|}{ F1 } & \multicolumn{2}{|c|}{$\mathrm{F} 2$} & \multicolumn{2}{|c|}{ F3 } & \multicolumn{2}{|c|}{ F1 } & \multicolumn{2}{|c|}{$\mathrm{F} 2$} & \multicolumn{2}{|c|}{ F3 } \\
\hline White & + & + & ns & + & ns & ns & ns & $\mathrm{ns}$ & $\mathrm{ns}$ & ns & ns & ns \\
\hline Black & + & + & ns & ns & ns & ns & -- & -- & -- & -- & -- & -- \\
\hline Hispanic & + & + & ns & ns & - & - & ns & $\mathrm{ns}$ & $\mathrm{ns}$ & ns & $\mathrm{ns}$ & ns \\
\hline Asian & ns & ns & ns & ns & ns & ns & ns & ns & ns & ns & ns & ns \\
\hline Other & ns & ns & + & $\mathrm{ns}$ & ns & ns & -- & -- & -- & -- & -- & -- \\
\hline No HS diploma & + & -- & $\mathrm{ns}$ & -- & - & -- & -- & $\mathrm{ns}$ & -- & $\mathrm{ns}$ & -- & ns \\
\hline HS diploma & + & -- & ns & -- & - & -- & -- & $\mathrm{ns}$ & -- & ns & -- & ns \\
\hline Some postsecondary & ns & -- & + & -- & ns & -- & -- & $\mathrm{ns}$ & -- & ns & -- & ns \\
\hline College degree + & ns & -- & + & -- & - & -- & -- & ns & -- & ns & -- & ns \\
\hline Low prestige & + & + & ns & + & - & ns & + & ns & $\mathrm{ns}$ & ns & ns & ns \\
\hline Medium prestige & + & + & $\mathrm{ns}$ & + & - & $\mathrm{ns}$ & $\mathrm{ns}$ & $\mathrm{ns}$ & $\mathrm{ns}$ & $\mathrm{ns}$ & ns & ns \\
\hline High prestige & + & + & $\mathrm{ns}$ & + & $\mathrm{ns}$ & ns & $\mathrm{ns}$ & $\mathrm{ns}$ & $\mathrm{ns}$ & $\mathrm{ns}$ & $\mathrm{ns}$ & ns \\
\hline English & + & + & ns & + & - & - & + & ns & + & ns & ns & ns \\
\hline Non-English & + & + & ns & ns & - & + & ns & ns & ns & ns & ns & ns \\
\hline
\end{tabular}

Note. $\mathrm{IRT}=$ reading IRT score $. \mathrm{TR}=$ teacher literacy rating. $+=$ positive association. $-=$ negative association. $\mathrm{ns}=$ no significant association. $--=$ not interpretable. $\mathrm{F} 1=$ Participating in open school events. F2= Communicating with teachers. F3= Participating in school-based organizations.

The present study used an existing data source to explore the measurement of school-based parent involvement. Results indicate that future research in this vein is worth pursuing. The available parent involvement indicators were found to reflect underlying factors that corresponded with types of involvement identified in the parent involvement literature, and that corresponded to differences in the cultural capital tools 
that may be required for engagement in these activities. There was also indication that sociocultural groups differ in the degree to which they participate in particular types of school-based parent involvement activities. Correlational results also suggest that families from different sociocultural backgrounds may differ in their reasons for engaging in school-based involvement activities, or in how these activities might impact student achievement outcomes. Finally, results suggest that school characteristics broadly defined may play a role in the associations between parent involvement and student achievement.

Taken together, these results provide empirical support for the theoretical framework integrating cultural capital and ecological systems theory. Characteristics of families and schools relate to the types of school-based involvement in which families engage, and in how these activities relate to their child's educational outcomes. Future research in this area will be focus on strengthening and extending these initial findings by applying this framework to additional data sources, using more sophisticated analytical tools, and identifying new measures that will provide a more nuanced understanding of the interplay between family and school characteristics in the context of parent involvement.

\section{Directions for Future Research}

Future research into the relationships between school-based parent involvement and student achievement could be taken in several directions based on this exploratory study. These will be discussed in three broad categories: subsequent releases of ECLS-K datasets, independent data collections, and additional analytical approaches.

Subsequent releases of ECLS-K datasets. The present study utilized the latest release of the ECLS-K dataset that contained information about kindergarten students 
only. As additional years of data are made available to researchers, new options will become available for documenting the relationships between parent involvement and student achievement.

The present study could be replicated using a higher grade level, as prior research has indicated that parent involvement may relate to student achievement differently at different grade levels (Barge \& Loges, 2003). Additional years of data would also allow for a person-centered analysis (Bauer \& Shanahan, 2007) in which parent involvement and achievement measures are collected at multiple time points, allowing for an analysis of how variability in parent involvement over time relates to changes in students' individual achievement outcomes. Multiple years of data would also allow for the study of reciprocal effects between parent involvement and student achievement outcomes. The cross-sectional nature of the present study did not allow for clear determinations of whether high or low levels of achievement led to greater amounts of parent involvement, or if particular types of parent involvement yielded benefits or disadvantages for student achievement.

Additionally, the ECLS-K collects data from adult household members other than parents. Although the present study looked school-based involvement in a broad sense, future studies might identify students' for whom non-parental family members primarily participate in school-based activities and document if and how the relations between family involvement and achievement differ for these students.

Independent data collections. The above described approaches could also be carried out using independently collected data. Although using an existing data source such as the ECLS-K provides numerous benefits associated with a well-organized, large, nationally representative body of data, it does limit the researcher to available variables. 
Collecting new data would therefore provide the researcher with more control over the type of information collected about parent involvement activities, and potentially moderating student, family, and school level covariates.

New data collections should include the same indicators of parent involvement measured among different sources, which may include students, teachers, and school administrators. Doing so would allow the researcher to cross-validate parent reports of involvement activities. New data collections should also include an adequate sampling of a variety of school types, and should collect more nuanced data about school policies and practices related to parent involvement. Finally, a new data collection should focus on the key variables needed for understanding parent involvement, and in doing so may reduce the likelihood of missing data on the variables of interest.

The present study did not attempt to measure cultural capital directly, but rather inferred it from shared variance among parent involvement indicators that was supported by the literature as requiring different cultural capital tools. Data collections focused solely on parent involvement would allow for more nuanced measures that could better identify the cultural capital requirements of particular parent involvement activities. Respondents could be asked more specifically about the behaviors in which they engaged and did not engage, and their reasons for engaging or not engaging in these activities. Other questions might seek to ascertain the amount of involvement in particular activities such as how often they called their child's teacher, their reasons for contacting the teacher, the quality of their communications with the teacher, how frequently they attended PTA meetings, if they held an office in a parent organization, or if they regularly sought to change school policies. Direct questions about perceptions of parents' tools and abilities for involvement in school-based activities could also be posed. 
Finally, the present study relied upon available student-level racial/ethnicity variables to explore the relations between parent involvement and achievement among students from different racial/ethnic backgrounds. Though it is likely that student racial/ethnic identity is highly correlated with that of parents and other family members, collecting data on parent race/ethnicity specifically would allow for further exploration of how parent characteristics influence school-based involvement.

Additional analytical approaches. The present study modeled linear relationships between parent involvement and achievement. Future research could consider the possibility of curvilinear effects to model the possibility that at particularly high levels, the magnitude and/or direction of the relationship between parent involvement and achievement might change. Research on the notion of "helicopter parenting" for example, has noted that overinvolvement among parents may have detrimental effects on children's well-being (LeMoyne \& Buchanan, 2011).

This study utilized maximum likelihood estimation, a modern approach to handling missing data that is preferential to more traditional approaches (e.g., listwise deletion) that are more likely to produce inaccurate standard errors and biased parameter estimates (Putka \& Williams, 2011). Future studies, more focused on testing hypotheses generated from this exploratory study, should include multiple imputation methods to quantify the potential impact of missing item-level data.

Finally, the present study provided descriptive evidence of the moderating effects of school type on the relationships between school-based parent involvement activities and early reading achievement. Future studies should extend these analyses by modeling latent interactions between the parent involvement factors and school characteristics. Such an approach would allow for the quantification of the moderating effects that school 
characteristics have on the relationships between parent involvement and achievement, as well as for the testing of their statistical significance. Based on the present study, further exploring the moderating effects of school type on the relationship between parent involvement and achievement among students from primarily non-English speaking families is of particular interest. 


\section{REFERENCES}

Alexander, K. L., Entwisle, D. R., \& Thompson, M. S. (1987). School performance, status relations, and the structure of sentiment: Bringing the teacher back in. American Sociological Review, 52, 665-682.

Anderson, J. C., \& Gerbing, D. W. (1984). The effect of sampling error on convergence, improper solutions, and goodness-of-fit indices for maximum likelihood confirmatory factor analysis . Psychametrika, 49, 155-173.

Baker, D., \& Stevenson, D. (1986). Mothers' strategies for high school achievement: Managing the transition to high school. Sociology of Education, 59, 156-167.

Baker, A. J. L., Kessler-Sklar, Piotrkowski, C. S., \& Parker, F. L. (1999). Kindergarten and first-grade teachers' reported knowledge of parents' involvement in their children's education. The Elementary School Journal, 99, 367-380.

Barge, J., \& Loges, W. E. (2003). Parent, student, and teacher perceptions of parental involvement. Journal of Applied Communication Research, 31, 140-163.

Barnard, W. M. (2004). Parental involvement in elementary school and educational attainment. Child and Youth Services Review, 26, 39-62.

Baruch, Y., \& Holtom, B. C. (2008). Survey response rate levels and trends in organizational research. Human Relations, 61, 1139- 1160.

Bauer, D.J., \& Shanahan, M.J. (2007). Modeling complex interactions: person-centered and variable-centered approaches. In T.D. Little, J.A. Bovaird \& N.A. Card (Eds.) 
Modeling Contextual Effects in Longitudinal Studies (pp. 255-284). Mahwah, NJ:

Lawrence Earlbaum Associates.

Bollen, K. A., \& Bauldry, S. (2010). Model identification and computer algebra. Sociological Methods \& Research, 39, 127-156.

Bollen, K. A. (1989). Structural Equations with Latent Variables. New York: John Wiley $\&$ Sons.

Bourdieu, P. (1986) The forms of capital. In J. Richardson (Ed.) Handbook of Theory and Research for the Sociology of Education (pp. 241-258). New York: Greenwood.

Bowles, S. \& Gintis, H. (1975). The problem with human capital theory: A Marxian critique. American Economic Review, 65 (2), 74-82.

Bronfenbrenner, U. (1976). The experimental ecology of education. Teachers College Record, 45, 1-5.

Bronfenbrenner, U. (1986). Ecology of the family as a context for human development: Research perspectives. Developmental Psychology, 22, 723-742

Brooks, N., Bruno, E., \&Burns, T. (1997). Reinforcing students' motivation through parent interaction. (Master's thesis). Retrieved from Education Resources Information Center (No. ED411074).

Browne, M. W., (2001). An overview of analytic rotation in exploratory factor analysis. Multivariate Behavioral Research, 36, 111-150.

Buchanan, A. E, Hansen, P. J., \& Quilling, M. R. (1969). Effects of increased homeschool contact on performance and attitudes in mathematics. Madison: Wisconsin Research and Development Center for Cognitive Learning.

Bulkley, K., \& Fisler, J. (2003). A decade of charter schools: From theory to practice. Educational Policy, 17, 317-342. 
Byrne, B. M. (2004). Testing for multigroup invariance using AMOS Graphics: A road less traveled. Structural Equation Modeling, 11, 272-300.

Byrne, B. M., Shavelson, R. J., \& Muthén, B. (1989). Testing for the equivalence of factor covariance and mean structures: The issue of partial measurement invariance. Psychological Bulletin, 105, 456-466.

Chapman, J. W., Tunmer, W. E., \& Prochnow, J. E. (2000). Early reading-related skills and performance, reading self-concept, and the development of academic selfconcept: A longitudinal study. Journal of Educational Psychology, 92, 703-708.

Chen, F. F. (2007). Sensitivity of goodness of fit indexes to lack of measurement invariance. Structural Equation Modeling, 14, 464-504.

Cheung, G.W., \& Rensvold, R.B. (2002). Evaluating goodness-of fit indexes for testing measurement invariance. Structural Equation Modeling, 9, 233-255.

Choy, S. P. (2001). Students whose parents did not go to college: Postsecondary access, persistence, and attainment (NCES 2001-126). Washington, DC: U.S. Retrieved from http://nces.ed.gov/pubs2001/2001126.pdf.

Comer, J., \& Haynes, N. (1991). Parent involvement in schools: An ecological approach. Elementary School Journal, 91, 271-277.

Comer, J. (1986). Parent participation in schools. Phi Delta Kappan, 67, 226-442.

Costello, A. B., \& Osborne, J. W. (2005). Best practices in exploratory factor analysis: Four recommendations for getting the most from your analysis. Practical Assessment, Research \& Evaluation, 10 (7), 1-9.

Darling, N. (2007). Ecological systems theory: The person in the center of the circles. Research in Human Development, 4, 203-217. 
DePlanty, J., Coulter-Kern, R., \& Duchane, K. A. (2007). Perceptions of parent involvement in academic achievement. The Journal of Educational Research, 100, 361-368.

Dickinson, E. R., \& Adelson, J. L. (2013, April). Using structural equation modeling to explore similarities and differences among measures of student achievement. Presented at the 2013 American Educational Research Association Annual Meeting and Exhibition, San Francisco, CA.

Dickinson, E. R. \& Adelson, J. L. (2014). Exploring the Limitations of Measures of Students' Socioeconomic Status (SES). Practical Assessment, Research \& Evaluation, 19(1). Available online: http://pareonline.net/getvn.asp?v=19\&n=1.

DiMaggio, P. (1982). Cultural capital and school success: the impact of status culture participation on the grades of U.S. high school students. American Sociological Review 47, 189201.

Dinno, A. (2009). Exploring the sensitivity of Horn's parallel analysis to the distributional form of random data. Multivariate Behavioral Research, 44, 362388.

DiStefano, C., \& Hess, B. (2005). Using confirmatory factor analysis for construct validation: An empirical review. Journal of Psychoeducational Assessment, 23, 225-241.

Dodici, B. J., Draper, D. C., \& Peterson, C. A. (2003). Early parent child interactions and early literacy development. Topics in Early Childhood Special Education, 23, 124-136. 
Doucet, F. (2011). Parent involvement as ritualized practice. Anthropology and Education Quarterly, 42, 404-421.

Dziuban, C. D. \& Shirkey, E. C. (1974). When is a correlation matrix appropriate for factor analysis? Some decision rules. Psychological Bulletin, 81, 358-361.

Ehrlich, I. \& Murphy, K. M. (2007). Why does human capital need a journal? Journal of Human Capital, 1, 1-7.

El Nokali, N.E., Bachman, H. J., \& Votruba-Drzal, E. (2010). Parent involvement and children's academic and social development in elementary school. Child Development, 81, 988 - 1005.

Epstein, J. (1987). Toward a theory of family-school connections: Teacher practices and parent involvement. In K. Kurrelmann, F. Kaufmann, \& F. Lasel (Eds.), Social intervention: Potential and constraints. New York: De Gruyter.

Epstein, J. (1992). School and family partnerships. In M. Atkin (Ed.), Encyclopedia of educational research, (6th edition). New York: MacMillan.

Epstein, J. L. (1995). School/family/community partnerships. Phi Delta Kappan, 76, 701712.

Fan, X., \& Chen, M. (2001). Parental involvement and students' academic achievement: A meta-analysis. Educational Psychology Review, 13, 1-22.

Farkas, G. (1996). Human Capital or Cultural Capital? Ethnicity and Poverty Groups in an Urban School District. New York: Aldine de Gruyter.

Feuerstein, A. (2000). School characteristics and parent involvement: Influences on participation in children's schools. The Journal of Educational Research, 94, 2940. 
French, B. F., \& Finch, W.H. (2006). Confirmatory factor analytic procedures for the determination of measurement invariance. Structural Equation Modeling, 13, $378-402$

Froiland, J. M., Peterson, A., \& Davison, M. L. (2013). The long-term effects of early parent involvement and parent expectation in the USA. School Psychology International, 34, 33-50.

Gilmore, J. (1985). Improving the attendance of primary children by involving parents in their education. Practicum Report. Fort Lauderdale, FL: Nova University

Gottfredson, D. C., \& DiPietro, S. M. (2010). School size, social capital, and student victimization. Sociology of Education, 84 (1), 69-89.

Grolnick, W. S. \& Slowiaczek, M. L. (1994). Parents' involvement in children's schooling: A multidimensional conceptualization and motivational model. Child Development, 64, 237-252.

Halsey, P. A. (2005). Parent involvement in junior high schools: A failure to communicate. American Secondary Education, 34, 57-69.

Hampton, F.M, Mumford, D.A., \& Bold, L. (1998). Parent involvement in inner-city schools: The Project FAST extended family approach to success. Urban Education, 33, 410-427.

Haynes, N.M., \& Ben-Avie, M. (1996). Parents as full partners in education. In A. Booth and J.F. Dunn (Eds.), Family-school links: How do they affect educational outcomes? (pp. 45-55). Mahwah, NJ: Lawrence Erlbaum Associates.

Hilado, A., Kallemeyn, L., Leow, C., Lundy, M., \& Israel, M. (2011). Supporting child welfare and parent involvement in preschool programs. Early Childhood Education Journal, 39, 343-353. 
Hill, N. E., \& Taylor, L. C. (2004). Parental school involvement and children's academic achievement. Pragmatics and issues. Current Directions in Psychological Science, $13(4), 161-164$.

Hill, E. J., Hawkins, A. J., Ferris, M., \& Weitzman, M. (2001). Finding an extra day a week: The positive influence of perceived job flexibility on work and family life balance. Family Relations, 50, 49-58.

Hoover-Dempsey, K. V., Bassler, O. C., \& Brissie, J. S. (1992). Explorations in parentschool relations. Journal of Educational Research, 85, 287-294.

Hoover-Dempsey, K. V., \& Sandler, H. M. (1997). Why do parents become involved in their child's education? Review of Educational Research, 67, 3-42.

Horvat, E. M., Weininger, E. B. \& Lareau, A. (2003). From social ties to social capital: Class differences in the relations between schools and parent networks. American Educational Research Journal, 40, 319-351.

Howland, A., Anderson, J. A., Smiley, A. D., \& Abbott, D. J. (2006). School liaisons: Bridging the gap between home and school. The School Community Journal, 16, 47-68.

Hu, L. t., \& Bentler, P. M. (1999). Cutoff criteria for fit indexes in covariance structure analysis: Conventional criteria versus new alternatives. Structural Equation Modeling: A Multidisciplinary Journal, 6, 1-55.

Hurley, A. E., Scandura, T. A., Schriesheim, C. A., Brannick, M. T., Seers, A., Vandenberg, R. J., et.al. (1997). Exploratory and confirmatory factor analysis: Guidelines, issues, and alternatives. Journal of Organizational Behavior, 18, 667683. 
Izzo, C., Weissberg, R., Kasprow, W., \& Fendrich, M. (1999). A longitudinal assessment of teacher perceptions of parent involvement in children's education and school performance. American Journal of Community Psychology, 27, 817-839.

Jaeger, M. M. (2011). Does cultural capital really affect academic achievement? New evidence from combined sibling and panel data. Sociology of Education, 84, 281298.

Jeynes, W. (2012). A meta-analysis of the efficacy of different types of parental involvement programs for urban students. Urban Education, 47, 706-742.

Jiang, N. (2000). Lexical development and representation in a second language. Applied Linguistics, 21, 47-77.

Kenny, D. A. (1979). Correlation and causation. New York: John Wiley

Kenny, D. A. (2014, October 6). Measuring model fit. Retrieved from http://davidakenny.net/cm/fit.htm.

Kline, R. B. (2011). Principles and practice of structural equation modeling (3rd ed.). New York: The Guilford Press.

Kohl, G. O., Lengua, L. J., \& McMahon, R. J. (2000). Parent involvement in school conceptualizing multiple dimensions and their relations with family and demographic risk factors. Journal of School Psychology, 38, 501-523.

Lareau, A., \& Calarco, J. M. (2012). Class, cultural capital, and institutions: The case of families and schools. In Fiske, S. T., \& Markus, H. (eds.), Facing Social Class: Social Psychology of Social Class (chapter 4). New York: Russell Sage.

Lareau, A. (2011). Unequal Childhoods: Class, Race, and Family Life, 2nd Edition. A Decade Later. Berkeley: University of California. 
Lareau, A. (2000). Home Advantage: Social Class and Parental Intervention in Elementary Education (2nd ed.). Lanham, MD: Rowan and Littlefield.

Lareau, A. (1987). Social class differences in family-school relationships: The importance of cultural capital. Sociology of Education, 60, 70-74.

Lauglo, J. (2000). Social capital trumping class and cultural capital? Engagement with school among immigrant youth. In S. Baron, J. Field, \& T. Schuller (eds.), Social Capital: Critical Perspectives (pp. 142-168). Oxford University Press: Oxford.

Lawson, M. A. (2003). School-family relations in context: Parent and teacher perceptions of parent involvement. Urban Education, 38 (1), 77-133

Lee, J-S., \& Bowen, N. K. (2006). Parent involvement, cultural capital, and the achievement gap among elementary school children. American Educational Research Journal, 43, 193-218.

Lee, S. (2005). Selective parent participation: Structural and cultural factors that influence school participation among Korean parents. Equity \& Excellence in Education, 38, 299-308.

LeMoyne, T. \& Buchanan, T. (2011). Does "hovering" matter? Helicopter parenting and its effect on well-being. Sociological Spectrum, 31, 399-417.

Lin, N. (2001). Social capital: A Theory of Social Structure and Action. New York: Cambridge University Press.

Little, T. D. (1997). Mean and covariance structures (MACS) analyses of cross-cultural data: Practical and theoretical issues. Multivariate Behavioral Research, 32, 5376. 
McGrath, D. J., \& Kuriloff, P. J. (1999). "They're going to tear the doors off this place": Upper-middle-class parent school involvement and the educational opportunities of other people's children. Educational Policy, 13, 603-629.

McNamee, S. J., \& Miller, Jr., R. K. (2004). The Meritocracy Myth. Lanham, MD: Rowan and Littlefield.

McNeal, R. B. (1999). Parental involvement as social capital: Differential effectiveness on science achievement, truancy, and dropping out. Social Forces, 78, 117-144.

Meade, A. W., \& Bauer, D. J. (2007). Power and precision in confirmatory factor analytic tests of measurement invariance. Structural Equation Modeling, 14, 611-635.

Miedel, W. T., \& Reynolds, A. J. (1999). Parent involvement in early intervention for disadvantaged children: Does it matter? Journal of School Psychology, 37, 379402.

Milfont, T. L., \& Fischer, R. (2010). Testing measurement invariance across groups: Applications in cross-cultural research. International Journal of Psychological Research (Special Issue on Current Issues in Exploratory and Confirmatory Data Analysis), 3, 112-131.

Mislevy, R. J. (1986). Recent developments in the factor analysis of categorical variables. Journal of Educational and Behavioral Statistics, 11, 3-31.

Moosa, S., Karabenick, S. \& Adams, L. (2001). Teacher perceptions of Arab parent involvement in elementary schools. The School Community Journal, 11, 1-23.

Muthén, L. K., \&Muthén, B. O. (1998-2012). Mplus Users Guide (7th ed.). Los Angeles, CA: Muthén \& Muthén.

Oyserman, D., Brickman, D., \& Rhodes, M. (2007). Racial-ethnic identity in adolescence: Content and consequences for African American and Latino youth. 
In. A. Fuligni (Ed.) Social Categories, Identities and Educational Participation (pp. 91-114). NY: Russell-Sage.

Patrikakou, E. N. \& Weissberg, R. P. (2000). Parents' perceptions of teacher outreach and parent involvement in children's education. Journal of Prevention \& Intervention in the Community, 20, 103-119.

Preacher, K.J. \& R.C. MacCallum, (2003). Repairing Tom Swift's electric factor analysis machine. Understanding Statistics, 2, 13-43.

Putka, D. J. \& Williams, L. J. (2011, April). A practitioner's guide to the galaxy...of statistical methods: Primer on developments from the last two decades and a look ahead. Presented at the 2011 Annual Society for Industrial and Organizational Psychology Conference, Chicago, IL.

Putnam, R. D. (1995). Bowling alone: America's declining social capital. Journal of Democracy, 6, 64-78.

Reay, D. (2004). Education and cultural capital: the implications of changing trends in education policies. Cultural Trends, 13, 73-86.

Ritter, P.L., Mont-Reynaud, R. \& Dornbusch, S.M. (1993). Minority parents and their youth: Concern, encouragement and support for school achievement. In N.F. Chavkin (Ed). Families and Schools in a Pluralistic Society (pp. 107-119). Albany, NY: State University of New York Press.

Rogers, M. A., Theule, J., Ryan, B. A., Adams, G. R., \& Keating, L. (2009). Parental involvement and children's school achievement: Evidence for mediating processes. Canadian Journal of School Psychology, 24, 34-57.

Rosenblatt, Z., \& Peled, D. (2002). School ethical climate and parental involvement. Journal of Educational Administration, 40, 349-367. 
Rubtsova, A., \& Dowd, T. J. (2004). Cultural capital as a multi-level concept: The case of an advertising Aagency." Research in the Sociology of Organizations, 22, 117 146.

Schmitt, T. A. (2011). Current methodological considerations in exploratory and confirmatory factor analysis. Journal of Psychoeducational Assessment, 29, 304321.

Schmitt, S. A., Simpson, A. M., \& Friend, M. (2011). A longitudinal assessment of the home literacy environment and early language. Infant and Child Development, 20, 409-431.

Smith, J., \& Wohlstetter, P. (2009). Parent involvement in urban charter schools: A new paradigm or the status quo? Nashville, TN: National Center on School Choice Vanderbilt University. Retrieved from http://www.eric.ed.gov/PDFS/ED509552.pdf.

Smith, J., Stern, K., \& Shatrova, Z. (2008). Factors inhibiting Hispanic parents' school involvement. Rural Educator, 29 (2), 8-13.

Tabachnick, B. G. \& Fidell, L. S. (2001). Using Multivariate Analysis. Boston: Allyn and Bacon.

Todd, P. E. \& Wolpin, K. I. (2003). On The specification and estimation of the production function for cognitive achievement. The Economic Journal, 113, F3F33.

Todd, P. E. \& Wolpin, K. I. (2007). The production of cognitive achievement in children: Home, school, and racial test score gaps. Journal of Human Capital, 1, 91-136. 
Tondeur, J., Sinnaeve, I., van Houtte, M., \& van Braak, J. (2010). ICT as cultural capital: The relationship between socioeconomic status and the computer-use profile of young people. New Media \& Society, 13(1), 151-168.

Topor, D. R., Keane, S. P., Shelton, T. L., \& Calkins, S. D. (2010). Parental involvement and student academic performance: A multiple mediational analysis. Journal of Prevention and Intervention in the Community, 38, 183-197.

Trivette, P., \& Anderson, E. (1995). The effects of four components of parental involvement on eighth-grade student achievement. School Psychology Review, 24, 299-318.

Tudge, J. R. H., Mokrova, I., Hatfield, B. E., \& Karnik, R. B. (2009). Uses and misuses of Bronfenbrenner's bioecological theory of human development. Journal of Family Theory and Review, 1,198-210.

Trueba, H. (2002). From failure to success: The roles of culture and cultural conflict in the academic achievement of Chicano students. In R. Valencia (Ed.), Chicano School Failure and Success: Past, Present and Future (pp. 151- 164). London: Routledge Farmer.

U.S. Department of Education. Institute of Education Sciences, National Center for Education Statistics. (2004). ECLS-K base year public-use data files and electronic codebook. Retrieved from: http://nces.ed.gov/pubsearch/pubsinfo.asp?pubid=2001029rev.

U.S. Department of Education. Institute of Education Sciences, National Center for Education Statistics. (2013). Improving the measurement of socioeconomic status for the National Assessment of Educational Progress: A theoretical foundation. 
Retrieved from:

http://nces.ed.gov/nationsreportcard/researchcenter/socioeconomic_factors.aspx.

Vandenberg, R. J., \& Lance, C. E. (2000). A review and synthesis of the measurement invariance literature: Suggestions, practices, and recommendations for organizational research. Organizational Research Methods, 3, 4-70.

Vygotsky, L. S. (1978). Mind in Society: The Development of Higher Psychological Processes. Cambridge, MA: Harvard University Press.

Wallenborn, M. (2010). Vocational education and training and human capital development: Current practice and future options. European Journal of Education, 45, 181-198.

Weiss, H. B., Mayer, E., Kreider, H., Vaughn, M., Dearing, E., Hencke, R., et. al. (2003). Making it work: Low-income mothers' involvement in their children's education. American Educational Research Journal, 40, 879-901.

Wells, R. (2008). Social and cultural capital, race and ethnicity, and college student retention. Journal of College Student Retention: Research, Theory and Practice, $10,103-128$.

Winters, J. V. (2011). Human capital and population growth in nonmetropolitan U.S. counties: The importance of college student migration. Economic Development Quarterly, 25, 353-365.

Wong, S. W., \& Hughes, J. N. (2006). Ethnicity and language contributions to dimensions of parent involvement. School Psychology Review, 35, 645-662.

Wu, A. D., Li, Z. \& Zumbo, B. D. (2007). Decoding the meaning of factor invariance and updating the practice of multi - group confirmatory factor analysis. Practical Assessment, Research and Evaluation, 12(3), 1-26. 


\section{CURRICULUM VITA}

NAME: $\quad$ Emily R. Dickinson

ADDRESS: 1452 Indiana Ave.

Louisville, KY 40213

DOB: $\quad$ Louisville, KY - November 7, 1974

EDUCATION

\& TRAINING: $\quad$ B.A., Sociology

University of Louisville

1992-2000

M.A., Sociology

University of Louisville

2000-01

Ph.D., Education Counseling \& Personnel Services

University of Louisville

2010-14

\section{PROFESSIONAL EXPERIENCE:}

Senior Scientist. Validity Investigations in Education and the Workplace Program, Human Resources Research Organization. 2014 to present.

Research Scientist. Validity Investigations in Education and the Workplace Program, Human Resources Research Organization. 20052010; 2012 to 2014.

Graduate Assistant. Educational Psychology, Measurement, and Evaluation Program, Educational and Counseling Psychology Department, College of Education and Human Development, University of Louisville. 2011 to 2012.

Graduate Assistant. National Research Center for Career and Technical Education, University of Louisville. 2010 to 2011.

Adjunct Faculty. Department of Sociology. University of Louisville. 2001 
to $2002 ; 2009$ to 2011.

Research Associate. Center for Learning Evaluation and Assessment Research Program, Human Resources Research Organization. 2002 to 2005.

Graduate Intern. Office of Accountability, Research and Planning, Jefferson County Public Schools. 2001.

\section{UNIVERSITY COURSES TAUGHT:}

University of Louisville, Educational and Counseling Psychology, Counseling, and College Student Personnel (ECPY) Courses

Structural Equation Modeling (TA)

Hierarchical Linear Modeling (TA)

Measurement and Evaluation (TA)

University of Louisville, Sociology Courses

Intro to Sociology

Intro to Social Statistics

Intro to Research Methods

Sociology of Education (TA)

\section{PUBLICATIONS:}

Peer Reviewed Journals

Dickinson, E. R. \& Adelson, J. L. (2014). Exploring the Limitations of Measures of Students' Socioeconomic Status (SES). Practical Assessment, Research \& Evaluation, 19(1). Available online: http://pareonline.net/getvn.asp? $\mathrm{v}=19 \& \mathrm{n}=1$.

Dickinson, E. R., Adelson J. L., \& Owen, J. (2012). Gender balance, representativeness, and statistical power in sexuality research using undergraduate student samples. [Guest editorial.] Archives of Sexual Behavior, 41, 325.

Selected Technical Reports

Dickinson, E. R., \& Thacker, A. A. (2014). The accuracy of students' novice, apprentice, proficient, and distinguished classifications for the 2013 Kentucky endof-course tests (2014 No. 024). Alexandria, VA: Human Resources Research Organization.

Dickinson, E. R., \& Thacker, A. A. (2014). Third-party checking of 2014 scaling and equating for the Pennsylvania system of school assessment (2014 No. 039). Alexandria, VA: Human Resources Research Organization. 
Dickinson, E. R., \&Thacker, A. A. (2014). Third party checking of 2013 scaling and equating for the North Dakota state assessment (2014 No. 018). Alexandria, VA: Human Resources Research Organization.

Dickinson, E. R., Becker, D. E., \& Thacker, A. A. (2014). Independent validation of analysis of scoring errors for the Miller Analogies Test (2014 No. 006). Alexandria, VA: Human Resources Research Organization.

Thacker, A. A., Dickinson, E. R., Levinson, H., Becker, D. E., Sinclair, A. L., Deatz, R. C., \& Nemeth, Y. M. (2014). Independent review of item development processes and alignment verification for the New York State Testing Program (NYSTP) (2014 No. 007). Alexandria, VA: Human Resources Research Organization.

Thacker, A. A., Dickinson, E. R., Wise, L. L., \& Becker, D. E. (2014). PARCC studies to examine comparability of scores across states, assessment forms, scoring methods and other relevant variables memorandum (2014 No. 005). Alexandria, VA: Human Resources Research Organization.

Becker, D. E., Dickinson, E. R., \& Thacker, A. A. (2013). Washington's Statewide Improvement Initiative: Final Cumulative Evaluation Report (2013 No. 089). Alexandria, VA: Human Resources Research Organization.

Dickinson, E. R., \& Becker, D. E. (2013). 2012-13 End-of-year evaluation report: School improvement grant (SIG) initiative (2013 No. 072). Alexandria, VA: Human Resources Research Organization. Alexandria, VA: Human Resources Research Organization.

Thacker, A. A., \& Dickinson, E. R. (2013). Independent review of Oklahoma's 2013 scaling and equating procedures (2013 No. 063). Alexandria, VA: Human Resources Research Organization. Alexandria, VA: Human Resources Research Organization.

Dickinson, E. R., Levinson, H., \& Thacker, A. A. (2013). Exploring patterns in school achievement from KCCT to K-PREP: The role of school-level socioeconomic status. (2013 No. 036). Alexandria, VA: Human Resources Research Organization.

Dickinson, E. R., Levinson, H., Thacker, A. A., \& Hoffman, R. G. (2013).The accuracy of students' novice, apprentice, proficient, and distinguished classifications for the 2012 Kentucky performance rating for educational progress (K-PREP) tests (2013 No. 037). Alexandria, VA: Human Resources Research Organization.

Dickinson, E. R., \& Thacker, A. A. (2013). Third-party checking of 2013 scaling and equating for the Pennsylvania System of School Assessment (2013 No. 039). Alexandria, VA: Human Resources Research Organization. 
Adelson, J. L., Lau, T., \& Dickinson, E. R. (January, 2013). Fall 2012 pre-post evaluation of Girls on the Run Louisville: Body image satisfaction, self-esteem, and attitudes toward physical activity. Report for Girls on the Run Louisville.

Dickinson, E. R., Latino, E. R., \& Adelson, J. L. (July, 2012). A pre-post evaluation of Girls on the Run Louisville: Body Image Satisfaction, Self-Esteem, and Attitudes toward Physical Activity. Report for Girls on the Run Louisville

Adelson, J. L., Latino, E. R., \& Dickinson, E. R. (January, 2012). A pre-post evaluation of Girls on the Run Louisville: Body Image Satisfaction, Self-Esteem, and Attitudes toward Physical Activity. Report for Girls on the Run Louisville.

Adelson, J. L., \& Dickinson, E. R. (August, 2011). Literacy patterns across Kentucky. Report submitted to the Collaborative Center for Literacy Development.

Dickinson, E.R., Taylor, L.R., Thacker, A.A. (2009). Kentucky's alternate assessment portfolio-revised (KAAP-R) year 2 scoring materials and processes: Review and recommendations (FR-09-49). Alexandria, VA: Human Resources Research Organization.

Dickinson, E.R., \& Hoffman, R.G. (2009). Evaluation of The College Board Florida Partnership for Minority and Underrepresented Students: Summary of results from the online principal survey (FR-09-47). Alexandria, VA: Human Resources Research Organization.

Dickinson, E.R., \& Thacker, A.A. (2009). Relations among Kentucky's core content test ACT scores and students' self-reported high school grades (FR-0932). Alexandria, VA: Human Resources Research Organization.

Dickinson, E.R., \& Hoffman, R.G. (2009). Evaluation of The College Board Florida Partnership for Minority and Underrepresented Students: Interim report (FR-09-29). Alexandria, VA: Human Resources Research Organization.

Thacker, A. \& Dickinson, E. R. (2008). Third party checking of equating for the 2008 on-demand writing Kentucky core content test (FR-08-134). Alexandria, VA: Human Resources Research Organization.

Dickinson, E.R., Taylor, L.R., \& Thacker, A.A. (2008). Kentucky's alternate assessment portfolio-revised (KAAP-R): Findings and recommendations from scoring site visits (FR-08-121). Alexandria, VA: Human Resources Research Organization.

Dickinson, E.R., Taylor, L.R., Thacker, A.A., Koger, L.E., \& Deatz, R.C. (2008). Independent alignment review of the mathematics test for English language (FR 08-105). Alexandria, VA: Human Resources Research Organization. 
Taylor, L.R., Dickinson, E.R., Campbell, H.L., Thacker, A.A., Koger, L.E., Deatz, R.C., \& Hooper, A., (2008). Independent alignment review of the Minnesota test of academic skills: Mathematics (FR 08-103). Alexandria, VA: Human Resources Research Organization.

Dickinson, E., \& Thacker, A. (2008). Item content, difficulty and depth of knowledge mapping by form and item type for the 2008 Kentucky core content tests (FR-08-79). Alexandria, VA: Human Resources Research Organization.

Thacker, A.A., \& Dickinson, E.R. (2008). An investigation of Illinois state assessment system high school scoring patterns (FR-08-22). Alexandria, VA: Human Resources Research Organization.

Dickinson, E. R., \& Hoffman, R.G. (2008). Interim report: Review of South Carolina's report card processes and programming (DFR-08-06). Alexandria, VA: Human Resources Research Organization.

Hoffman, R.G., \& Dickinson, E.R. (2006). The Accuracy of School Classifications for the 2006 Accountability Cycle of the Kentucky Commonwealth Accountability Testing System (FR-06-84). Alexandria, VA: Human Resources Research Organization.

Hoffman, R.G., \& Dickinson, E. R. (2006). The Accuracy of Students' Novice, Apprentice, Proficient, and Distinguished Classifications for the 2006 Kentucky Core Content Tests and Augmented Norm-Referenced Tests (FR-06-81). Alexandria, VA: Human Resources Research Organization.

Dickinson, E. R., Taylor, L., Koger, M., Moody, R., Deatz, R., \& Koger, L. (2006). Alignment of long term trend and main NAEP (FR-06-24). Alexandria, VA: Human Resources Research Organization.

Hoffman, R.G., \& Dickinson, E.R. (2005). Idaho Standards Achievement Test: Item mapping for the 2004 Idaho Standards Achievement Test (FR-05-04). Alexandria, VA: Human Resources Research Organization.

Thacker, A.A., Dickinson, E.R., \& Koger, M.E. (2004). Relationships Among the Pennsylvania System of School Assessment (PSSA) and Other Commonly Administered Assessments (FR-04-33). Alexandria, VA: Human Resources Research Organization.

\section{CONFERENCE PRESENTATIONS}

Dickinson, E. R., \& Adelson, J. L. (2014, April). Exploring the measurement of student socioeconomic status (SES) using a nationally representative dataset. To be presented at the 2014 American Educational Research Association Annual Meeting and Exhibition, Philadelphia, PA. 
Adelson, J. L., Dickinson, E.R., \& Cunningham, B. C. (2014, April). A multigrade, multiyear statewide examination of reading achievement. Paper presented at the 2014 American Educational Research Association Annual Meeting and Exhibition, Philadelphia, PA.

Adelson, J. L., Dickinson, E.R., \& Cunningham, B. C. (2014, April). The mathematicsreading achievement relationship: Patterns found in a multigrade, multiyear statewide examination. Paper presented at the 2014 American Educational Research Association Annual Meeting and Exhibition, Philadelphia, PA.

Aliaga, O. A., Kotamajru, P., Stone, J. R., and Dickinson, E. R. (2014, April). Engaging students in high school: A survival analysis of the impact of career and technical education. To be presented at the 2014 American Educational Research Association Annual Meeting and Exhibition, Philadelphia, PA.

Dickinson, E. R., \& Adelson, J. L. (2013, April). Using structural equation modeling to explore similarities and differences among measures of student achievement. Presented at the 2013 American Educational Research Association Annual Meeting and Exhibition, San Francisco, CA.

Adelson, J. L., Dickinson, E. R., Watkins, J., \& Levinson, H. (2013, April). Structural Equation Modeling: Introduction and applications. Invited symposium presented at the Educational and Counseling Psychology, Counseling, and College Student Personnel Department Fun Friday Lecture Series, University of Louisville, Louisville, KY.

Kotamajru, P., Aliaga, O. A., \& Dickinson, E. R. (2011, April). The college and career readiness of US high school graduates: Moving from concept to measurement. Presented at the 2011 American Educational Research Association Annual Meeting and Exhibition, New Orleans, LA.

Adelson, J. L., \& Dickinson, E. R. (2011, October). Literacy patterns across Kentucky. Paper presented in CCLD's Research Agenda: Study Findings and Implications for the Field. Symposium conducted at the 2011 Annual Conference of the Kentucky Reading Association, Lexington, KY.

Kotamajru, P., \& Dickinson, E. R. (2011, April). Getting timing and sequencing of math and science course-taking right: A possible answer to the college and career readiness of high school graduates concentrating on career and technical education (CTE). Presented at the 2011 American Educational Research Association Annual Meeting and Exhibition, New Orleans, LA.

\section{SERVICE AND LEADERSHIP:}

National Level

Senior Representative, American Educational Research Association, Division D, Graduate Student Committee. Current 
Junior Representative, American Educational Research Association, Division D, Graduate Student Committee. 2012 to 2013

Committee Member, American Educational Research Association, Division D, Graduate Student Committee. 2011 to 2012

Proposal reviewer, American Educational Research Association Annual Meeting and Exhibition, Division H, 2012 to 2013

Ad-hoc reviewer, Journal of Advanced Academics

Ad-hoc reviewer, Gifted Child Quarterly

Ad-hoc reviewer, Journal of Educational Research

University Level

Faculty Search Committee Member, University of Louisville, College of Education and Human Development, Department of Educational and Counseling Psychology, Educational Psychology, Measurement, and Evaluation Program, 2011 to 2012

President, Sociology Graduate Student Association, 1999 to 2001

\section{MEMBERSHIP IN PROFESSIONAL ORGANIZATIONS:}

American Educational Research Association (AERA)

Division D: Measurement and Research Methodology

Division H: Research, Evaluation, \& Assessment in Schools

Division G: Social Context of Education

American Psychological Association (APA)

Division 5: Evaluation, Measurement, and Statistics 